\title{
Does ICT in schools affect residential adoption and adult utilization outside schools?
}

\author{
Pitikorn Tengtrakul and Jon M. Peha
}

\begin{abstract}
Policymakers around the world are considering whether to invest in putting information and communication technology (ICT) in schools, and how. While educational impact is likely to be the primary objective, such investments can also affect residential adoption and adult utilization of ICT in the communities, thereby reducing the digital divide. Using a census survey of Thailand for a time when ICT was available in roughly half of the nation's schools, this study employs logistic regression and propensity score matching (PSM) to show that placing ICT in schools does have significant spill-over effects outside schools. This effect is larger for ICT in primary schools than secondary schools, and larger in schools with both Internet and computers than schools with just computers. The effects are observed in households of all incomes and educational levels. Considering these spill-over effects when allocating resources should lead to greater welfare gains for the amount of resources spent. The study also finds that there is a sizable portion of the adult population that chooses not to use ICT even after adopting this ICT in their households for their children, thereby eliminating any barriers to use related to cost and convenience. For this group, policy-makers should seek ways to decrease other impediments to ICT use, such as increasing ICT literacy through training.
\end{abstract}

\subsection{Introduction}

Policymakers around the world are considering whether to invest in putting information and communications technology (ICT) in schools. While the primary impact of this ICT is likely to be on the education that students get while at school, there may be spill-over effects that are worth considering, where any impact outside the school is considered a spill-over effect. This study measures the spill-over effects of bringing ICT to students in their schools on adoption of ICT in the households of these students, and on utilization of ICT by adults who live with these students. The specific ICT considered consists of computers and Internet access (either dial-up or broadband). Many believe it is important for a society to increase adoption and utilization of Internet and computers because this has benefits such as improving healthcare (Lua, Xiao, Sears, \& Jacko, 2005), facilitating civic engagement (Norris, 2003), and improving education (Tinio, 2003). This paper presents an econometric study of how putting ICT in schools in Thailand (UNESCO, 2007) affected the adoption and use of ICT in the surrounding communities. This study also looks at how adult utilization of ICT is affected by living with students, and indirectly, by living with ICT that was likely brought into the households for those students. 
Past studies conducted in developed countries have found that households with children are more likely to adopt ICT (Holloway \& Valentine, 2003), and adults in these households are more likely to use ICT (Horrigan, 2009). Whether this is the result of or even related to whether those children use ICT at school is unclear. To understand the spill-over effects of ICT in schools, this study first examines the impact of having students who do not use ICT at school in a household. Then the study examines how this impact might change depending on whether students have access to computers or the Internet at school. Thus, these research questions are addressed:

- To what extent does the presence of students in a household have spill-over effects on household adoption of ICT or utilization of ICT by family members of students?

- To what extent does giving students access to ICT at school have spill-over effects on household adoption of ICT or utilization of ICT by family members of students?

Some may assume that a spill-over effect that leads households to adopt ICT will also lead adults in those households to use ICT, and vice versa. By separating these two forms of spill-over effect, this study will show that this is actually not the case. There are many circumstances in which there is a profound effect on household adoption of ICT, but limited or no change in the use of ICT by adults in that household. Moreover, for those identified cases in which greater household adoption does not lead to greater utilization of ICT by adults, neither cost nor convenience is the real barrier.

This study quantifies the spill-over effects of Thailand's SchoolNet project, which deployed ICT in K-12 schools throughout Thailand (UNESCO, 2007). This study analyzes data from a survey of households in Thailand in 2007, with variables associated with each household and its family members related to ICT adoption and utilization, geographic, and demographic information. The survey was conducted at a time when some but not all schools had ICT, allowing the study to compare the impact of schools with no ICT, schools with computers but no Internet access, and schools with computers and Internet access. This paper also explores how these spill-over effects depend on factors such as the educational level of a student, the number of students in a household, household income, and the education level of adults in that household. Results are based on logistic regression and propensity score matching.

Clearly, many factors influence an adult's decision to use ICT somewhere, and to adopt ICT in the household, including demographics, geography, and whether there are children in the household. A spill-over occurs if giving a child access to ICT at school further changes the behavior of adults who live with that child, as shown in 


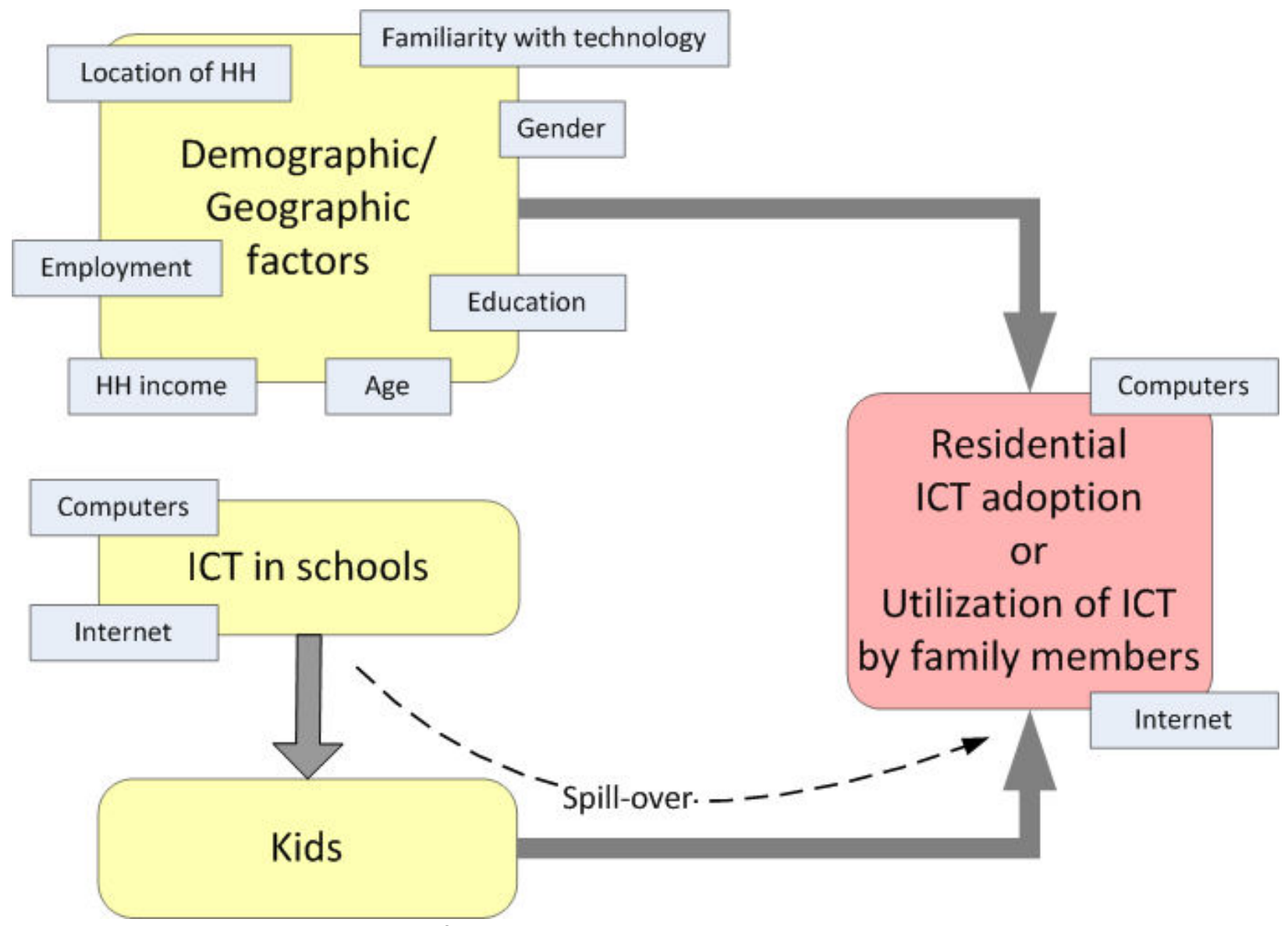

Fig. 1. This may occur in a variety of ways. Once children become ICT users, then parents may adopt ICT in the household for their children's benefit. Moreover, the presence of ICT in their own home may cause parents to become ICT users. On the other hand, children may teach their parents how to use ICT or at least how to see the value of ICT, which can lead adults to use ICT and perhaps then to adopt it. It is even possible that giving children access to ICT at school would decrease ICT adoption, because children could still access ICT without the cost to their families. As analysis will show, the actual nature of spill-over effects can and do depend on a variety of factors. 


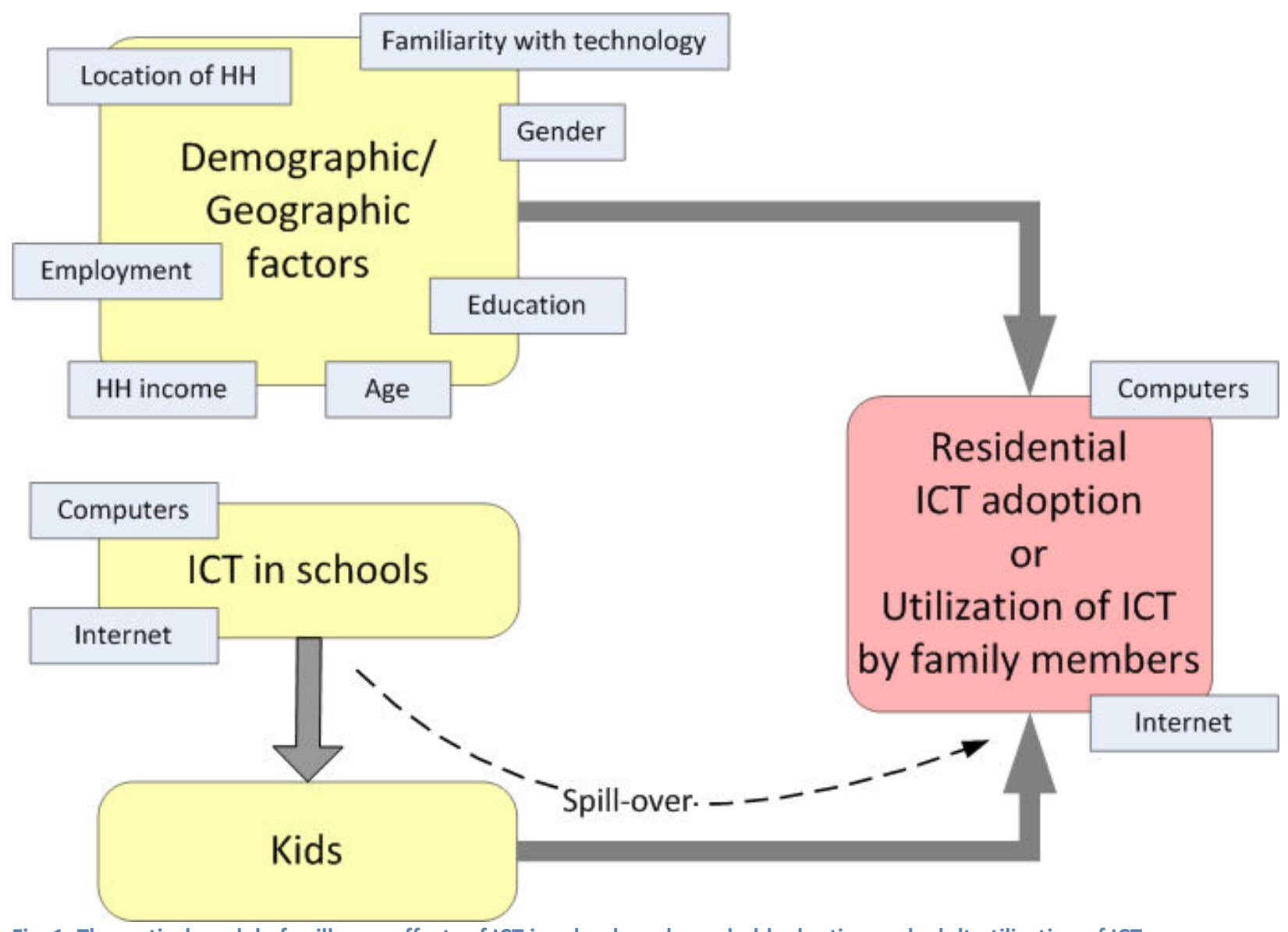

Fig. 1: Theoretical model of spill-over effects of ICT in schools on household adoption and adult utilization of ICT.

This study has both policy and theoretical implications. Results may help policymakers answer important questions. For example, should they invest even more in putting ICT into schools than the educational benefits alone would justify? Should they put limited funds into stand-alone computers, or Internet connections as well? How much of the funding should go to primary schools and how much to secondary schools? This paper will show that these investments can affect residential adoption and adult utilization of ICT in their communities, and that some investments have greater impact on these digital divide metrics than others. Policy-makers should allocate resources accordingly. This study also helps policy-makers to understand the policies that can help overcome impediments to ICT adoption and utilization. Since there are many cases where deploying ICT in schools encourages adults to put ICT in their homes for their children without using that ICT themselves, policies intended to increase utilization of such adults must go beyond just making ICT less expensive, perhaps by training adults on ICT use or producing compelling online content or services.

Besides the policy implications, this study has theoretical implications regarding information sharing among family members. While much of the research on intergeneration transmission of knowledge is focused on transmission from parents to kids (for example Black, Devereux, \& Salvanes, 2005; Oreopoulos, Page, \& Stevens, 2006), this study shows what appears to be transmission of important knowledge that kids learn in school to parents. This study hypothesizes that one spill-over effect of ICT in school is that adults learn to use ICT from their children. After all, children often have 
more total years in schools than their parents and invest more in learning new technology (Gardner, 2007).

Section 2 discusses related studies. Background information on ICT in Thailand and the SchoolNet project is presented in Section 3. Section 4 discusses the data set and research methodology. After presenting results in Section 5, the policy implications are discussed in Section 6.

\subsection{Literature Review}

Section 2.1 discusses studies related to the impact of having students in a household. Section 2.2 discusses studies on spill-over effects of having ICT in schools.

\subsection{Effect of having students in a household}

Studies have been conducted in wealthy nations to assess the effect of having students in a household on ICT adoption. Using survey data from the UK, both Selwyn (2004) and Holloway and Valentine (2003) concluded that having students is a main reason for the purchase of computers in households. The presence of students is also an important factor in the adoption of Internet at home as found by Newburger (2001) using survey data from the US, and Van Rompaey, Roe, and Struys (2002) using survey data from Belgium. This could happen because students ask for ICT, or because parents believe that ICT has educational benefit to their offspring, as Robertson, Soopramanien, and Fields (2004) found in the UK and Ortiz and Green (2011) found in the U.S. For example, more than $90 \%$ of parents in Ortiz and Green (2011) thought that access to a computer at home will have a positive effect on their children's success in life. The number of children in a household (which can be reflected by household size) was also found to be positively associated with Internet adoption (Rappoport, Kridel, Taylor, Alleman, \& Duffy-Deno 2003; Savage \& Waldman 2005).

The presence of students can also affect ICT use by family members. From a survey of Internet users in the US, Horrigan (2009) found that an individual is more likely to become an Internet user (in particular, a broadband user) if he or she is a parent of a minor child in the household. Some parents start using computers and the Internet to make sure that they stay ahead of their children (Selwyn, 2004). Even though living with students with ICT gives other family members opportunity to use that ICT, merely having physical access to ICT does not necessary make family members actually use it, as discussed in Selwyn (2004) and Gorand and Selwyn (2005) based on survey data from the UK.

These previous studies that showed the impact of having students in a household were conducted in developed countries. This study shows the extent to which there are similar effects in Thailand, where computer and Internet use is far less pervasive. As of 2007, there were 27 computer users and 16 Internet users per 100 people who are older than 5 years old in Thailand (NSO, 2007).

\subsection{Spill-over effect of putting ICT in schools}

Technological knowledge can spread from person to person within a family. Haddon and Silverstone (1996) and Haddon (2003) observed this in the U.K. Kraut, Mukhopadhyay, Szczypula, 
Kiesler, and Scherlis (1999) observed it in 110 households in the U.S. that had been given Internet access for the first time. Similarly, by giving computer access and training to 100 women in India, Umrani and Ghadially (2003) found that having at least one computer-literate family member other than the husband (presumably the children) in a household could encourage a woman to use a computer.

There is also evidence that the knowledge students gain in school can spread to parents outside school, at least for non-technical knowledge. Berniell, Mata, and Valdes (2010) found that a school health education program in the U.S. had a positive spill-over effect on parents' probability of doing physical activity because parents adjust their behavior in response to what their kids learn at school. This effect was stronger on parents with low education, low income, and that are not white. The spillover effects of school educational programs on parents can be either positive or negative. Kuziemko (2011) found that black American-born adults learn literacy skills from their own children, as this is less costly than alternatives such as attending school themselves. This is a positive spill-over from school education. However, Kuziemko (2011) also found that English skills acquired by children in school discouraged immigrant adults living with them from learning English. These negative spill-over effects exist because English-literate children can help their parents in tasks that require English.

Putting ICT in schools can also have spill-over effects on ICT adoption. Agyapong and Ferreira (2009) found that having schools that generate and receive more Internet traffic is associated with greater household Internet penetration in the surrounding municipality. Although they show a spill-over effect, it is different from the spill-over effects considered in this study. Unlike Agyapong and Ferreira (2009), this study makes comparisons based on whether schools have ICT at all, which is a direct result of high-level policy decisions, rather than the volume of traffic among schools that all have Internet access. In addition, this study observes spill-over effects of ICT in schools on ICT utilization by adults who live with students, and not just Internet adoption in the home. This study also looks at how the spill-over effects depend on many other factors, such as the age of the student and the income of the household or education of family members.

\subsection{SchoolNet project and ICT in Thailand}

Section 3.1 provides background information on ICT in Thailand, and Section 3.2 presents details of the SchoolNet project.

\subsection{Background of ICT in Thailand}

Unlike in developed countries, ICT adoption and utilization are not yet common in Thailand. Out of 60 million people who were older than 5 years old in 2007, 27\% and 16\% were computer and Internet users respectively (NSO, 2007). Out of 18 million households in Thailand, $17 \%$ and $8 \%$ had computer and Internet respectively. About $60 \%$ of households with Internet reported that they connect to the Internet via broadband, $20 \%$ via dial-up, and the rest were uncertain about their connection type.

Although Internet penetration is low today, a majority of households in Thailand could access the Internet via dial-up, and many could access it via broadband. As of 2007, there were about 60 
Internet service providers (ISP). Consumers in every province could access the Internet via dial-up by paying local telephone charges but no long distance charges. Broadband was available primarily in urban areas. Consumer broadband data rates varied from $256 \mathrm{Kbit} / \mathrm{s}$ to $16 \mathrm{MBit} / \mathrm{s}$, generally using ADSL technology, with a monthly fee starting from $\$ 20$ (NBTC, 2008). ${ }^{1}$ The main providers of residential broadband Internet services were TOT ${ }^{2}$, TRUE $^{3}$ and TT\& $\& T^{4}$. Besides these ISPs, there were also non-profit ISPs offering low-price or free Internet connections to specific groups; examples include SchoolNet ${ }^{5}$, $\mathrm{GITS}^{6}, \mathrm{PubNet}^{7}$, and UniNet ${ }^{8}$.

Many factors affect Internet adoption, such as price, and availability of relevant Internet content and services. Where these factors differ from one part of Thailand to another, there might be some differences in the observed spill-over effects. However, Internet content is the same across Thailand, so it should not affect this study's results. Availability, speed and price of Internet service do vary across the country, primarily between rural and urban areas (NBTC, 2008), but these factors are not correlated with whether or not schools participating in the SchoolNet project. As a result, these factors should not diminish this study's ability to estimate spill-over effects.

Nevertheless, these factors can influence the extent of spill-over effects as a result of the SchoolNet project. Probably the most important factor is that fixed-line infrastructure covered about $80 \%$ of Thailand's households nationwide (MICT, 2012), where nearly all unserved households are outside urban areas. Since most residential Internet service is over fixed-line infrastructure, it is unlikely to see spill-over effects with respect to Internet adoption and use in these rural areas, even if a parent's desire for Internet service has increased. Thus, spill-over effects on Internet adoption and use could have been even greater had Internet been available to the remaining $20 \%$ of the population at that time. Even where Internet is not available, one should still see spill-over effects on computer adoption and use. This has the potential to be considerable given that residential adoption of computers in Thailand has exceeded adoption of Internet even where Internet is available; as discussed in Tengtrakul and Peha (2011), about half of households with computers in Thailand choose not to adopt Internet, even though these computer-owners presumably can afford Internet and have the knowledge to use it.

\footnotetext{
$1 \quad$ Exchange rate as of December 2007. 1 US dollar $=30$ Thai Baht

2 The TOT Public Company is a government-owned incumbent providing broadband Internet services throughout the country.

3 TRUE provides broadband Internet services in Bangkok metropolitan areas.

$4 \quad$ TT\&T provides broadband Internet services in provincial areas.

5 SchoolNet connects K-12 schools and colleges throughout the country to the Internet via dial-up connections.

$6 \quad$ Government Information Technology Services (GITS) is a government agency facilitating Internet connection to government departments.

$7 \quad$ ThaiSarn Public Access Network (PubNet) is a government supported project providing access to public servers for academic institutions.

$8 \quad$ Inter-University Network (UniNet) is a government project providing Internet connection to support distance learning and help set up regional campuses of universities in Thailand.
} 


\subsection{SchoolNet project}

This study is possible because of the SchoolNet project in Thailand, which provides Internet connections to schools. The National Electronics and Computer Technology Centre (NECTEC) began the project in 1995. By 2002, it had reached several thousand schools throughout the country (Thuvasethakul \& Koanantakool, 2002). In 2003, administration of the project was transferred to the Ministry of Education, which expanded the goal to that of reaching all 38,000 K-12 schools in Thailand (UNESCO, 2007). Roughly 50\% of these schools had Internet access at the end of 2007, making 2007 the perfect time to compare ICT adoption and use in communities whose schools had ICT with adoption and use in communities whose schools did not. ${ }^{9}$

The 2003 expansion of SchoolNet to cover all schools is a natural consequence of the government of Thailand's national education policy of 2001 (PMO, 2001), which stated that ICT should be accessible to students throughout the country. Given this goal, systematic bias in the selection of schools to gain ICT in a given year seems unlikely, and this hypothesis is supported by analysis. Table 1 shows that households with students who gained access to ICT in school by 2007 are slightly more likely to be urban and high-income ${ }^{10}$ than those who did not, but the difference is small. This could reflect a slight selection bias, or it could reflect the fact that urban and high-income households are more likely to send their kids to school through high school. In any case, the effect is small enough that this study will perform analysis assuming that the SchoolNet project selected schools randomly without bias.

Table 1: Two samples t-test of mean values comparing households with students who have access to ICT in schools and households with students who do not have access to ICT in schools.

\begin{tabular}{llllll}
\hline & & Mean & Std. Err. & $\mathrm{t}$ & $\mathrm{P}>|\mathrm{t}|$ \\
\hline \multirow{2}{*}{ URBAN } & (1)HH w/ student ICT in school ${ }^{\mathrm{a}}$ & 0.287 & 0.004 & & \\
& (2) HH w/ student no ICT in school $^{\mathrm{b}}$ & 0.255 & 0.006 & & \\
& Difference (1-2) & 0.033 & 0.007 & 4.51 & 0.000 \\
& (1) HH w/ student ICT in school & 3.021 & 0.020 & & \\
INCOME & (2) HH w/ student no ICT in school & 2.842 & 0.033 & & \\
& Difference (1-2) & 0.179 & 0.039 & 4.56 & 0.000 \\
\hline
\end{tabular}

${ }^{\mathrm{a}, \mathrm{b}} 6.4$ million households have kids who have access to ICT in school and 2.2 million households have kids who do not have access to ICT in school * HH stands for households.

$9 \quad$ The number of schools participating in the project in 2007 was estimated by a linear regression model using 2 sources of data; 1) the number of schools participating in SchoolNet projects during 1997-2003 (Pansawat \& Khonklong, 2003) and 2) the percentage of schools connecting to the SchoolNet project in 2008, derived from the survey of ICT in schools by the National Statistics Office (NSO, 2008).

10 In 2007, 29\% of households with students in schools with ICT were urban, compared to $26 \%$ of households with students that lacked ICT. When looking at household income level, households with $\mathrm{K}-12$ students that have access to ICT in school also scored higher than their counterparts without school ICT by 0.18 on a 9 point scale. This is only $8 \%$ of a standard deviation of household income. 
Facilitated by the Telephone Organization of Thailand (TOT), each school originally connected to the Internet by dial-up access and paid only a local telephone connection charge of 3 THB. As the project progressed, an educational price leased line and telephone lines were available for schools. Each participating school was allocated free disk space on the central server for a mailbox and web storage. There was training from NECTEC to support teachers and students in developing website content, as well as managing the network (UNESCO, 2007).

Table 2 shows the percentage of students at different educational levels who used ICT at any time during the one-year period from October 2006 to September 2007 as derived from NSO (2007). The study defines student as someone who is currently in any K-12 school or college. On average, $56 \%$ and $11 \%$ of primary school students use computer and Internet, respectively. Perhaps in part because of the SchoolNet project, most students who use computer and Internet mainly use this ICT at schools.

Table 2: Mean statistics of students using ICT.

\begin{tabular}{llllll}
\hline Variables & Primary & Junior High & High & College & All students \\
\hline COM USER & 0.56 & 0.89 & 0.93 & 0.96 & 0.76 \\
NET USER & 0.11 & 0.48 & 0.74 & 0.86 & 0.42 \\
Use COM@School * & 0.51 & 0.85 & 0.87 & 0.74 & 0.69 \\
Use NET@School ** & 0.08 & 0.40 & 0.61 & 0.61 & 0.32 \\
\hline Total numbers & $5,974,336$ & $2,951,654$ & $2,779,651$ & $1,605,106$ & $13,310,747$ \\
\hline * Students answered "school" as one of their two main places of using computer & & \\
** Students answered "school" as one of the their two main places of using Internet & & & \\
Source: Derived from The National Statistics Office of Thailand (NSO, 2007) &
\end{tabular}

As shown in Fig. 1, attending primary and secondary schools is nearly universal in Thailand, and most children attend high school, whereas only a small portion attends college. Thus, for example, it can safely be assumed that the households with a ten-year-old student in primary school are representative of all households with a ten-year-old child, but the same may not be true for households with twenty-year-old students. 


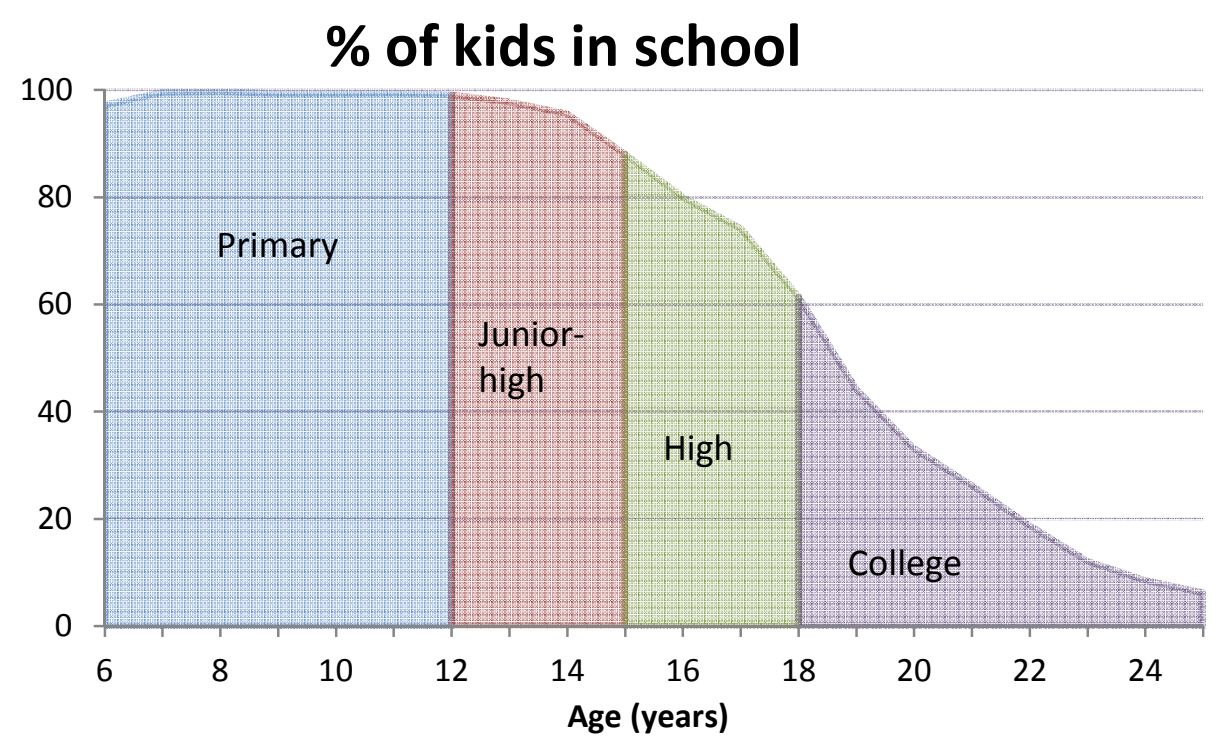

Fig. 2: Percentage of 6 to 25 -years olds who are currently in school.

Source: Derived from The National Statistics Office of Thailand (NSO, 2007)

\subsection{Methodology}

Section 4.1 discusses the data set and variables of interest used in this study. The analysis framework used in this study is illustrated in section 4.2. Various analysis methods applied to explore the possible spill-over effects of ICT in school are explained in section 4.3. Section 4.4 discusses methods used to explore whether the spill-over effects of ICT in school depend on the income of a student's household, or on the level of education of adults in the household.

\subsection{Data set}

The data set used in this study was collected in a census survey of Thailand's households and individuals within selected households in 2007. The National Statistical Office of Thailand (NSO) conducts a survey of 80,000 sampled households throughout Thailand annually about their household adoption of ICT and usage of ICT by every family member older than 5 years old. ${ }^{11}$ Variables representing geographic, demographic and other characteristics were collected. The head of household was asked to provide household information, including data about ICT adoption in the household. Each family member was asked to provide information about individual usage of ICT. Table 3 shows a list of variables at household and population level from the survey.

\footnotetext{
$11 \quad$ Households were selected using the Stratified Two-stage technique. The sampling method used geographical areas as units of selection (by villages and households). For more details about the method, see Hanson, Hurwitz, and Madow (1993).
} 
Telecommunications Policy, vol. 37, no. 6-7, July 2013, pp. 540-62

Table 3: Descriptive statistics of related variables at household level and population level.

\begin{tabular}{|c|c|c|c|c|}
\hline & $\begin{array}{l}\text { Household }(\mathrm{HH}) \\
\text { Variables }\end{array}$ & Definition (total households $=18,188,014$ ) & Mean & Std.Dev. \\
\hline 1 & COMPUTER & Existence of computer ( 1 is yes) & 0.17 & 0.38 \\
\hline 2 & INTERNET & Existence of Internet connection ( 1 is yes) & 0.08 & 0.27 \\
\hline 3 & BB & Existence of broadband Internet (1 is yes) & 0.04 & 0.21 \\
\hline 4 & URBAN & Household located in urban area ( 1 is yes) & 0.32 & 0.47 \\
\hline 5 & INCOME $^{a}$ & Monthly HH income level ( 1 is lowest, 9 is highest) & 2.90 & 2.13 \\
\hline 6 & $\mathrm{Hd} \mathrm{EDU}^{\mathrm{b}}$ & Educational level of head of $\mathrm{HH}$ ( 0 is no edu., 8 is highest) & 2.53 & 1.40 \\
\hline \multirow[t]{2}{*}{7} & Hd EMPLOY & Head of household is employed ( 1 is yes) & 0.80 & 0.40 \\
\hline & $\begin{array}{l}\text { Population } \\
\text { Variables * }\end{array}$ & Definition (total adults $=45,969,371$ ) & Mean & Std.Dev. \\
\hline 8 & COM USER & A person uses computer in the past year ( 1 is yes) & 0.13 & 0.33 \\
\hline 9 & NET USER & A person uses Internet in the past year ( 1 is yes) & 0.08 & 0.27 \\
\hline 10 & URBAN & A person lives in urban area (1 is yes) & 0.31 & 0.46 \\
\hline 11 & INCOME & Monthly HH income level ( 1 is lowest, 9 is highest) & 3.21 & 2.25 \\
\hline 12 & EMPLOY & A person is employed ( 1 is yes) & 0.81 & 0.39 \\
\hline 13 & MALE & A person is male ( 1 is yes) & 0.48 & 0.50 \\
\hline 14 & MOBILE USER & A person has mobile telephone ( 1 is yes) & 0.53 & 0.50 \\
\hline 15 & EDU PRIM ${ }^{c}$ & Highest education is primary school ( 1 is yes) & 0.56 & 0.50 \\
\hline 16 & EDU JUNI & Highest education is junior high school ( 1 is yes) & 0.14 & 0.34 \\
\hline 17 & EDU HIGH & Highest education is high school ( 1 is yes) & 0.11 & 0.32 \\
\hline 18 & EDU COLL & Highest education is college ( 1 is yes) & 0.13 & 0.33 \\
\hline 19 & AGE & Age (years) & 42.52 & 15.89 \\
\hline
\end{tabular}

* Population data only includes people $>15$ years old and currently not in school

${ }^{a}$ Monthly household income levels 1 through 9 are income less than 5,000 baht, between 5,000 and 9,999 baht , between 10,000 and 14,999 baht ..., more than 40,000 baht, respectively.

${ }^{b}$ Education levels 0 through 8 are no education, pre-primary school, primary school, secondary school ..., doctorate, respectively.

${ }^{\mathrm{c}}$ The base case educational variable (omitted) is education lower than primary school.

\subsection{Analysis framework}

This section describes the basic analytic framework used to measure the spill-over effects of placing ICT in schools. A spill-over effect appears in the form of a relationship between variables that indicate whether or not students in a household have access to ICT in school and variables that indicate whether or not the household adopts ICT or family members use ICT. When measuring a spill-over effect, one must often correct for other factors that influence ICT adoption or use. In addition, this study will explore how the spill-over effect, for instance this relationship between the ability of students to use ICT in schools and the adoption and use of ICT outside school, is affected by other variables such as household income and education of family members. 
To achieve this, this study adopts the multi-step process illustrated in

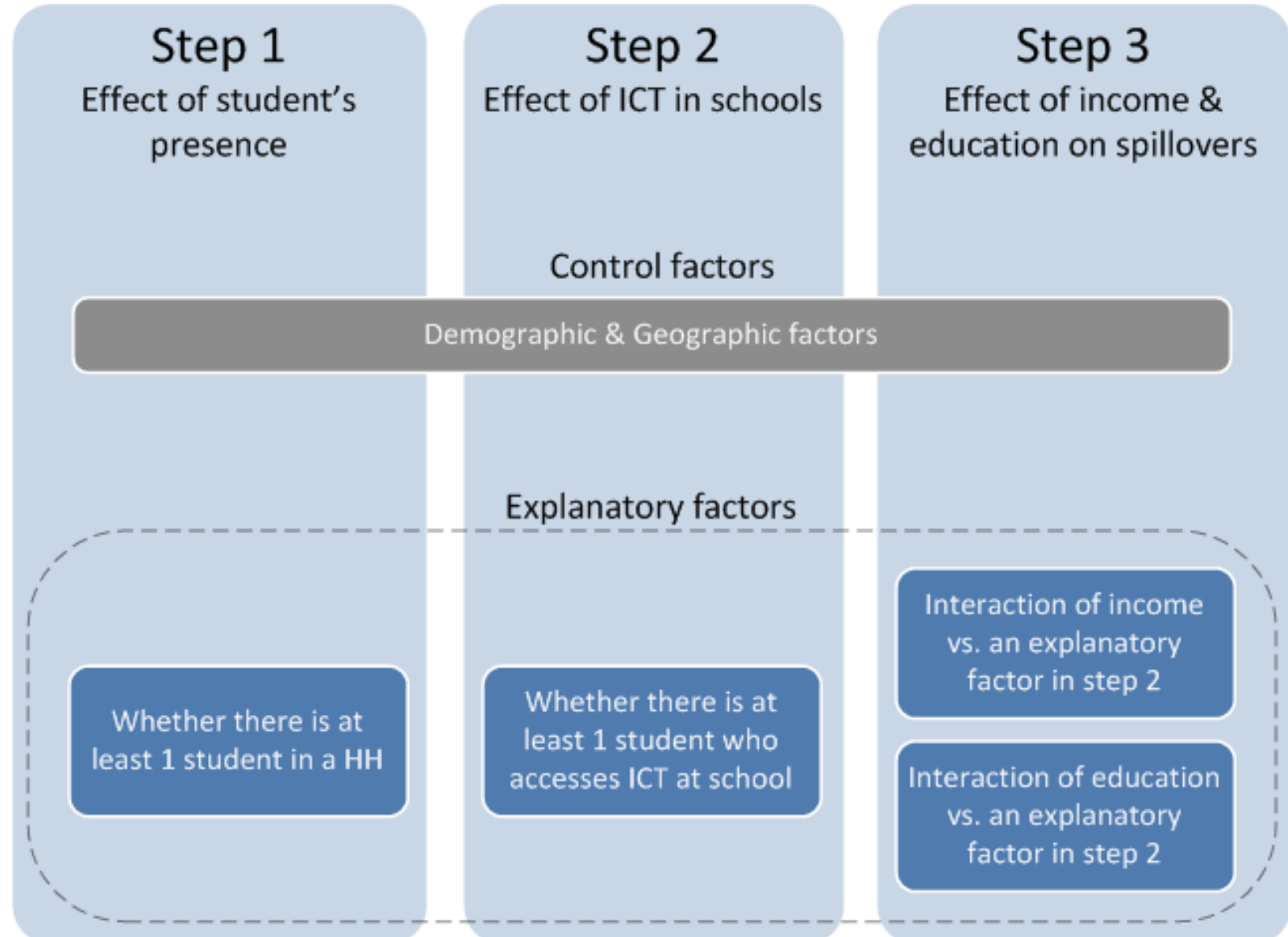

Fig. 3. Before assessing the impact on household ICT adoption and use of having a student present who used ICT in school, the first step is to quantify the impact of having a student present who does not use ICT in school, which is step 1 in 


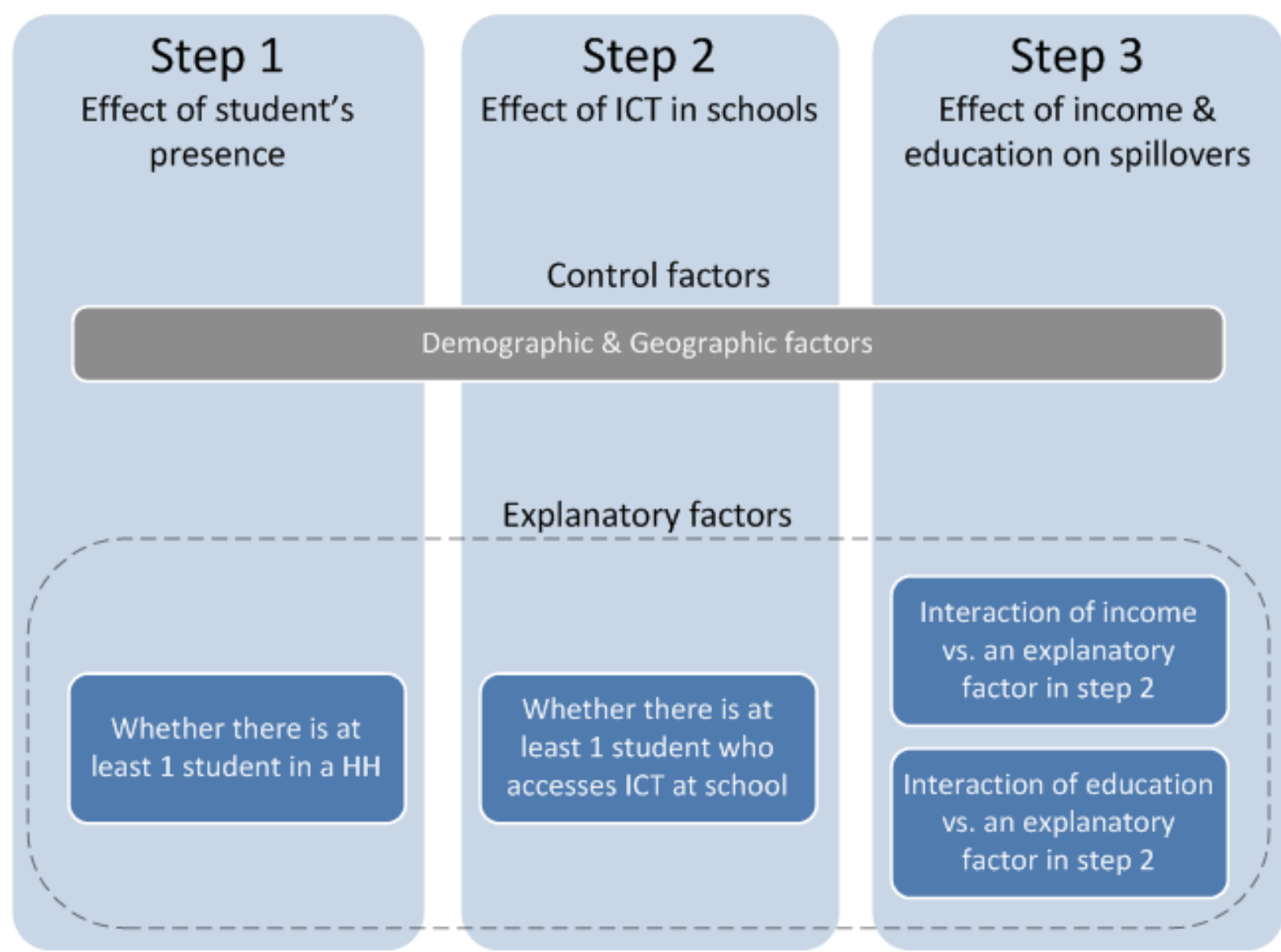

Fig. 3. With this as a basis, it is possible to observe how this effect changes depending on the extent to which students can access ICT at school, which is step 2 . Finally, the third step examines whether and how these spill-over effects depend on other factors of interest, such as household income, or the extent of education of family members in the household. For all these steps, a series of binary logistic regression models are applied. By controlling the observations (individuals or households) included in each regression, the models can effectively help answer the key research questions.

In each empirical step, control factors that past studies have shown to be important and might influence household adoption of ICT and usage of ICT by family members of students are accounted for. Most control factors relate to socio-economic status, demographic characteristics, or geographic characteristics. For household adoption, the key control factors were whether a household is located in an urban area, household income, and education and employment status of the head of household. For adult utilization, the key control factors were location of the household, household income, personal education, personal employment status, gender, age, and familiarity with technology (as represented by use of a mobile phone). The correlation matrix of these factors and ICT adoption or use is presented in Table 8 and

Variables

(1)

(2)

(3)

(4)

(5)

(6)

(7)
(1) COMPUTER
1.00 


$\begin{array}{llllllll}\text { (2) INTERNET } & 0.62 & 1.00 & & & & & \\ \text { (3) BB } & 0.47 & 0.75 & 1.00 & & & & \\ \text { (4) URBAN } & 0.23 & 0.24 & 0.22 & 1.00 & & & \\ \text { (5) INCOME } & 0.52 & 0.47 & 0.40 & 0.35 & 1.00 & & \\ \text { (6) HdEDU } & 0.41 & 0.37 & 0.31 & 0.30 & 0.51 & 1.00 & \\ \text { (7) HdEMPLOY } & 0.00 & -0.01 & -0.01 & -0.04 & 0.06 & 0.14 & 1.00\end{array}$

Coefficients of correlation are shown. All coefficients are statistically significant at 0.01

Table 9 in the Appendix.

Previous studies indicate that some or all of these factors are likely to influence ICT adoption or utilization. Using Thailand as a case study, Tengtrakul and Peha (2011) showed that ICT adoption in urban areas is significantly higher than rural. Various studies have found that income, education, and young age are positively associated with ICT adoption (OECD, 2000; NTIA, 2001; Norris, 2003). Some believe that education can be a proxy for ICT skills (Warschauer, 2003). Familiarity with technology has a positive relationship with ICT adoption. For example, Robertson et al. (2004) showed that households that have adopted various technologies including mobile phones are more likely to adopt ICT. The relationship between employment status and ICT adoption is inconclusive. While Kovacic and Vukmirovic (2008) found that there is a huge disparity in employment between the ICT adopters and non-adopters, Savage and Waldman (2005) found employment status as insignificant to ICT access. The relationship between gender and ICT adoption is also inconclusive. As ICT has become more ubiquitous, the gender gap in digital divide has diminished in some nations. For example, it has reached parity in the U.S. (U.S. Census, 2009). However, other studies have found that even in region with high ICT penetration, the gender digital divide still exists (Chen \& Wellman, 2004). 


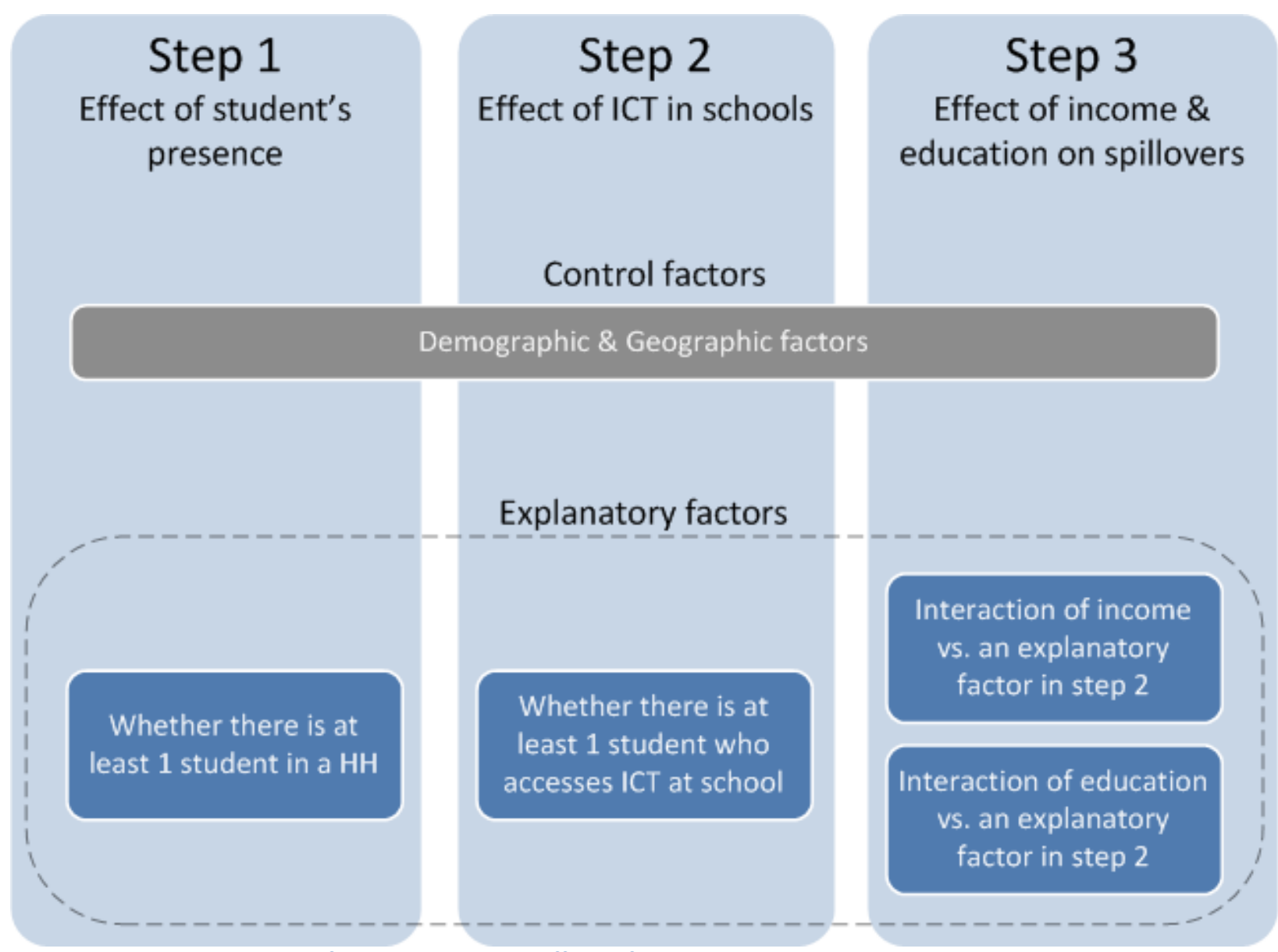

Fig. 3: Empirical steps models of analyzing spill-over effects of ICT in schools.

\subsection{Analysis of ICT in school}

As described in Section 4.2, this study uses logistic regression to analyze the spill-over effects of ICT in schools on household adoption of ICT and ICT utilization by adult family members. Household adoption is expressed with three binary variables representing whether or not the household has one or more computer, Internet connection (either dial-up or broadband), and broadband connection, respectively. Utilization of ICT by adult family members is defined as two binary variables representing whether or not an adult has used computers or the Internet in the past 12 months, where an adult means a person who is over 15 years old and not in school.

This study first examines the impact of having students who do not use ICT at school, and then examines how this impact differs if students have access to ICT at school (step 1 and 2 shown in 


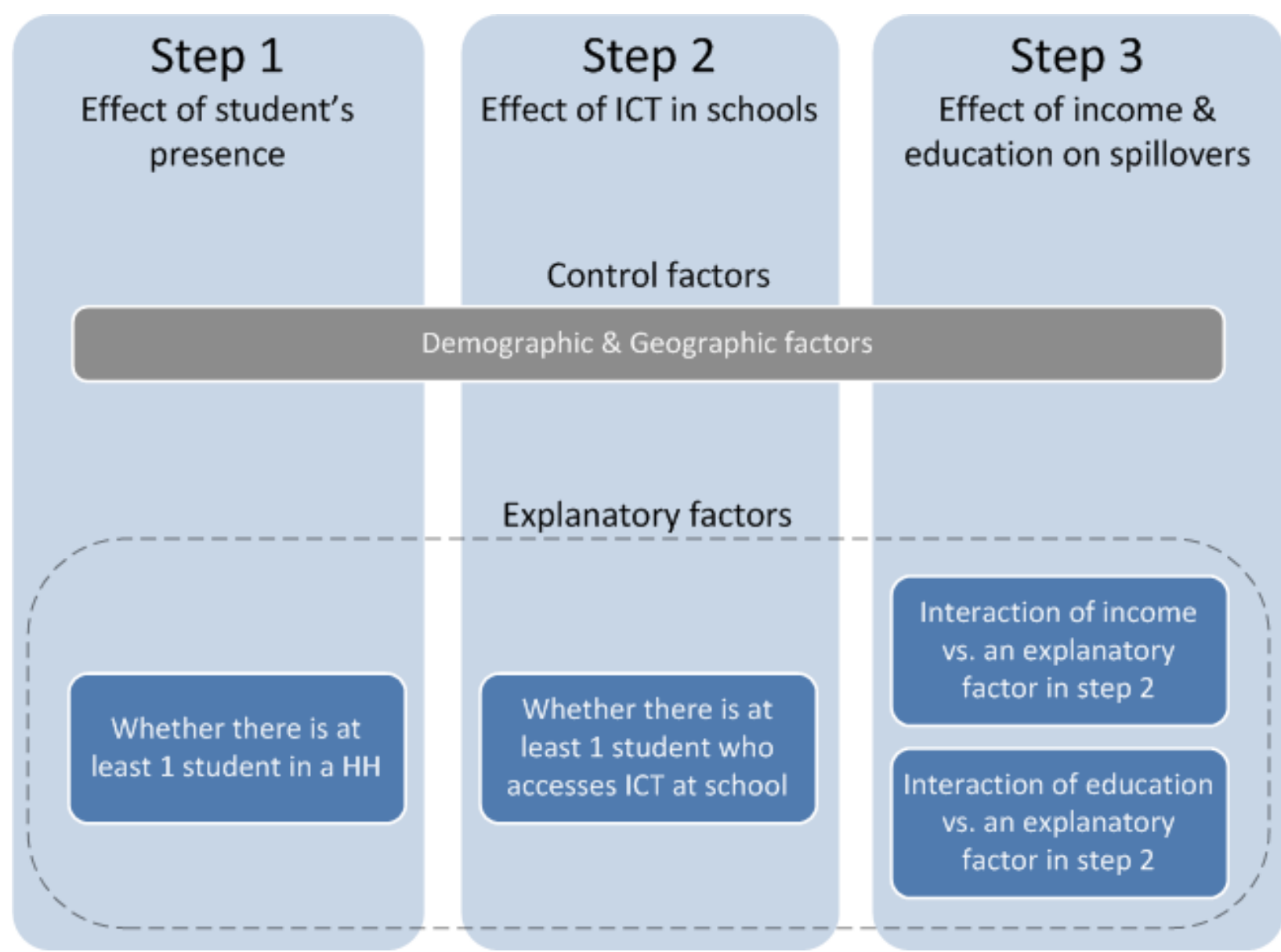

Fig. 3). A student is defined as a person who is currently in a K-12 school or college. Because the SchoolNet project is designed to bring ICT into the curriculum in those schools in which ICT has been deployed, a K-12 student is considered to have access to ICT in school if and only if the student identified school as one of the places where the student uses ICT frequently. ${ }^{12}$ Note that results must be viewed very differently for college students. All Thai colleges make ICT available to students, but unlike their K-12 counterparts, a college student may choose not to make use of this ICT. Thus, for K-12 students, these variables indicate school capabilities, whereas for college students these variables indicate student decisions.

The study predicts household adoption of ICT and ICT utilization by adult family members by using demographic and geographic factors as predictors of the regression models. Specifically the study controls for variables at the household level and population level as shown in Table 3. A factor controlling for the existence of student(s) who access ICT in school is included in the model. Eq. (1) shows a logistic regression model to study household adoption of ICT:

$\operatorname{logit}(Y)=\beta_{0}+\beta_{1} U R B A N+\beta_{2} I N C O M E+\beta_{3} H d E D U+\beta_{4} H d E M P L O Y+\theta_{1} S T U D E N T+\varepsilon$

12 A question in the survey asked family members to identify the two places at which they most frequently use ICT. Possible choices are home, school, office, Internet Café, Telecenters, and friend's house. 
where $\operatorname{logit}(Y)$ is a logit transformation of household ICT adoption ${ }^{13}$, various household characteristics are defined in Table 3, and STUDENT is a dummy variable (as shown in

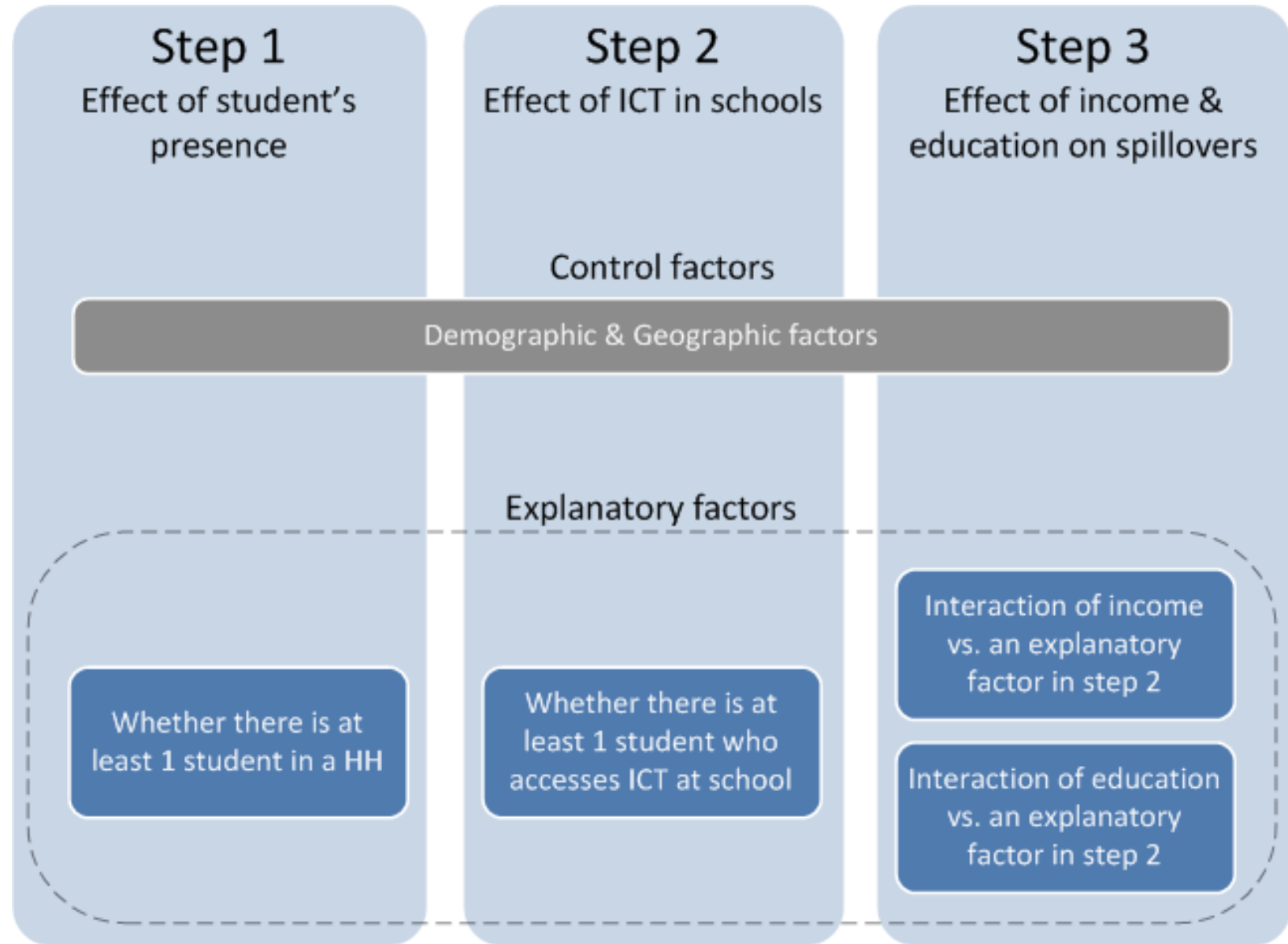

Fig. 3) . When studying the effect of a student's presence on household ICT adoption, STUDENT equals 1 if a household has at least one student who does not access ICT in school and equals zero otherwise. When studying the effect of ICT in school on household ICT adoption, STUDENT equals 1 if a household has at least one student who accesses ICT in school and equals zero otherwise, as shown in

13 Logit transformation of household ICT adoption, $\operatorname{logit}(Y)$, equals $\ln \left[\frac{p}{1-p}\right]$ where $p$ is the probability that a household will adopt ICT. Likewise when applying logit transformation to utilization of ICT by an adult family member (Eq. (2)), $p$ is the probability that an adult family member will use ICT. See more details of logit transformation in Hosmer and Lemeshow (2000). 


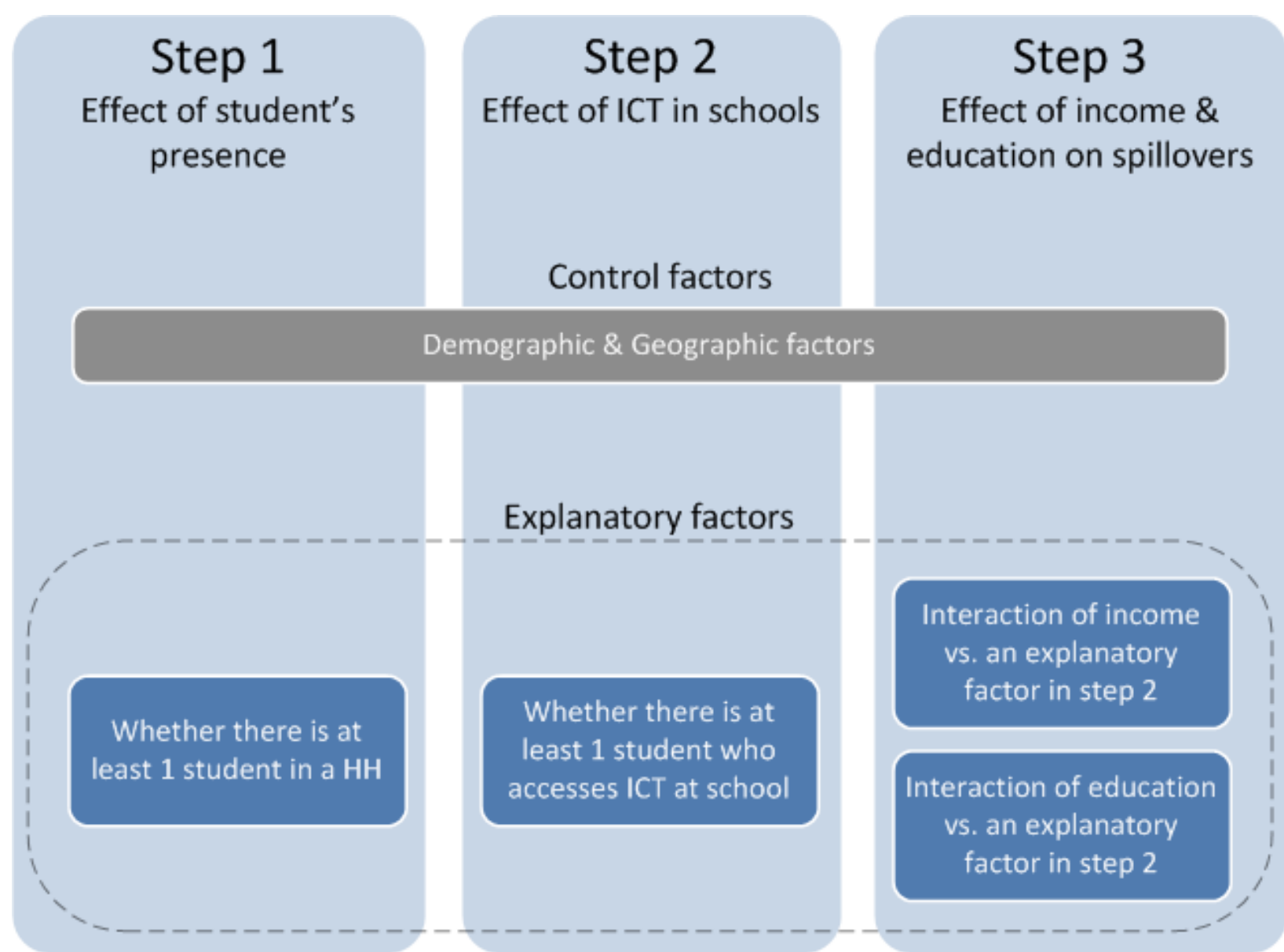

Fig. 3. This study analyzes the effect of a student's presence or ICT in school by observing the coefficient $\theta_{1}$ associated with STUDENT.

When studying utilization of ICT by adult family members, this study applies the following logistic regression model:

$$
\begin{aligned}
\operatorname{logit}(Y)= & \beta_{0}+\beta_{1} U R B A N+\beta_{2} I N C O M E+\beta_{3} E M P L O Y+\beta_{4} M A L E+\beta_{5} M O B I L E U S E R+ \\
& \alpha E D U C A T I O N+\gamma A G E+\theta_{1} S T U D E N T+\varepsilon
\end{aligned}
$$

where $\operatorname{logit}(Y)$ is a logit transformation of utilization of ICT by an adult family member, other explanatory variables are defined in Table 3, and STUDENT is a dummy variable as defined in Eq. (1).

Additionally, this study explores how spill-over effects depend on the educational level of a student by applying the same logistic regression approach on different sets of households. There are four educational levels in this study; primary school, junior high school, high school, and college. To see the impact of having students at a certain educational level in a household, households with students at that educational level are compared to households that do not have any students at that level. For example, the impact of a high school student's presence in a household is analyzed by comparing households with one or more high school students to households without any high school students. As a result, $\theta_{1}$ in Eq. (1) represents the ratio of ICT penetration for households with one or more students at the given educational level to ICT penetration for households that have no students at this educational 
level, regardless of whether or not households have students at any other educational level. Although not shown here for brevity, this study found that the probability of having a student at one educational level in a household is nearly uncorrelated with having a student at a different educational level (Tengtrakul, 2013). Thus, this ratio for a given educational level (for example high school) is a good measure of an effect related to that educational level and no other. The same approach is used to see the impact of having students at a certain educational level who access ICT at school. In this case, households with students at this level who use ICT in school are compared to households that also have students at the same educational level but the students do not access ICT in school.

\subsection{Impact of household income and adults' education on effects of ICT in school}

This section investigates whether the spill-over effects described in Section 4.2 depend on the income of a student's household and on the level of education of adults in that household (step 3 in

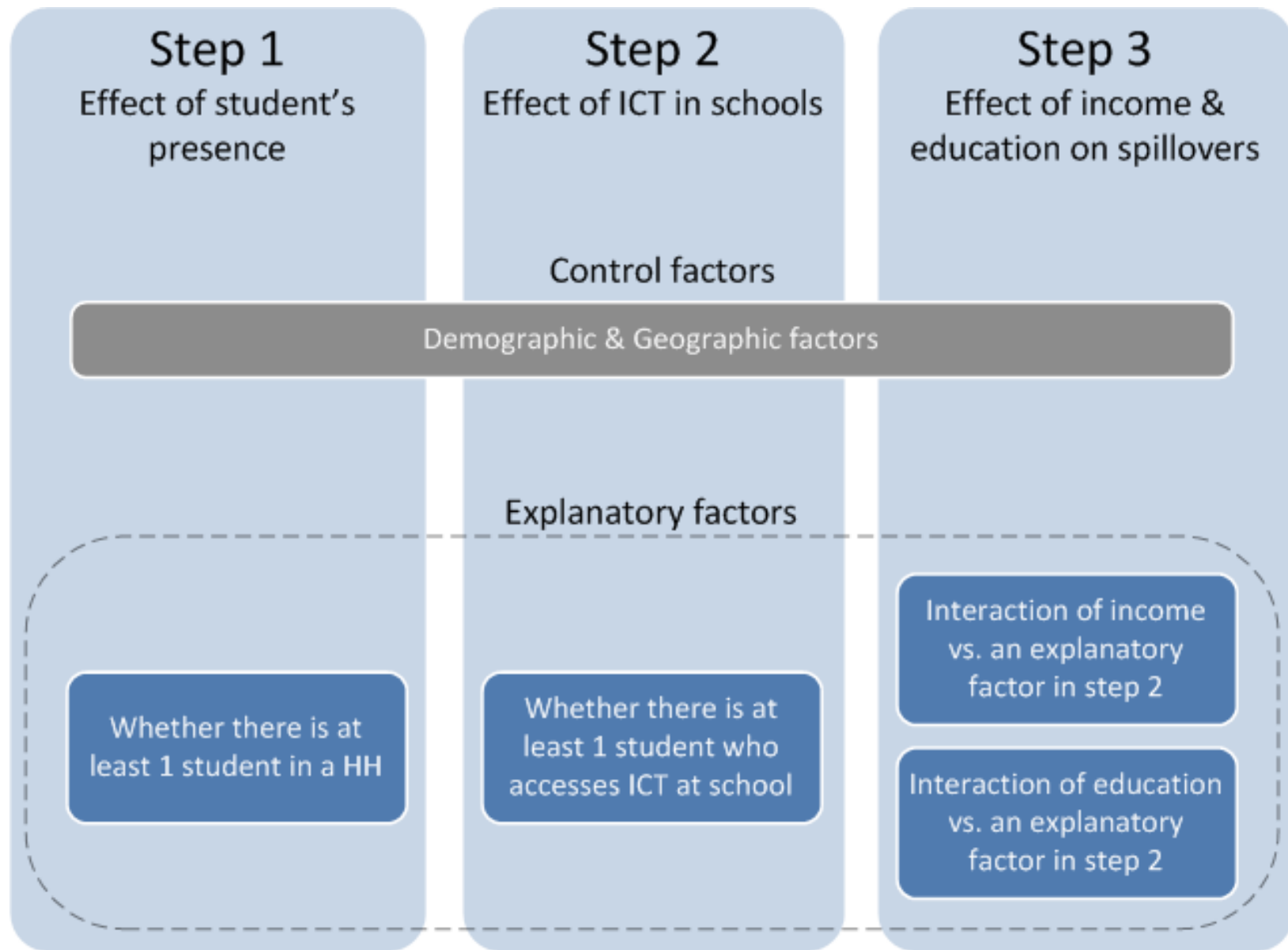

Fig. 3). This is achieved by introducing an interaction variable (Kleinbaum, Kupper, Nizam, \& Muller, 2007) to the regression models discussed in Section 4.3. When assessing the impact of household income on the spill-over effect of ICT in schools, the interaction variable is the product of the presence in a household of one or more students who access ICT in school and that household's income. This approach can be used to quantify the impact of household income on the spill-over to both household adoption of ICT and to ICT utilization by adults in the household. The logistic regression model to study the impact of household income on the spill-over effect of ICT in schools is as follows: 
$\operatorname{logit}(Y)=\beta_{0}+\beta$ Predictors $+\theta_{1}$ STUDENT $+\theta_{2}$ STUDENT $* I N C O M E+\varepsilon$

where $\operatorname{logit}(Y)$ is a logit transformation of household ICT adoption or utilization of ICT by adult family members, Predictors are a set of household characteristics as used in Eq. (1) or a set of adult characteristics as used in Eq. (2), STUDENT indicates the presence of at least one student who accesses ICT in school, and INCOME is household income level. This study analyzes the effect of household income on the spill-over effects of ICT in school by observing the coefficient $\theta_{2}$ associated with STUDENT*INCOME.

When assessing the impact of the level of education of adults on the spill-over effect of ICT in schools on residential adoption, a useful interaction variable is the product of the presence in a household of one or more students who access ICT in school and the education level of the head of household. Similarly, when assessing the spill-over effect on utilization by individual adults, a useful interaction variable is the product of the presence in a household of one or more students who access ICT in school and the education level of that adult. The logistic regression model to study the impact of adult educational level on the spill-over effects of ICT in schools is as follows:

$\operatorname{logit}(Y)=\beta_{0}+\beta$ Predictors $+\theta_{1}$ STUDENT $+\theta_{2}$ STUDENT $* E D U+\varepsilon$

where logit $(Y)$, Predictors, and STUDENT are defined in the same way as Eq. (3). EDU is the education level of the head of household or the adult family members. This study analyzes the effect of adult educational level on the spill-over effects of ICT in school by observing the coefficient $\theta_{2}$ associated with STUDENT*EDU.

Besides the spill-over effect of ICT in schools on household ICT adoption or ICT use by family members, reverse spill-over effects are also theoretically possible, for instance where parents' ICT use or adoption of ICT affects whether the schools their children attend have ICT. Becker (2000) found that computer experience of family members affects computer use of children at school as well as at home, although this probably would not affect whether schools obtain computers and other ICT in the first place. Henderson and Mapp (2002) discussed a nationwide trend in the US where families or communities get involved in improving their children's' schools. For example, families could contribute to the upgrade of schools' ICT facilities. However, given that it is the federal government rather than local communities or individuals that are directing resources towards ICT in the schools considered in this study, it is likely that the deployment of ICT in schools may affect the decisions of parents and others in the community but not the reverse. 


\subsection{Results}

Results of the analysis described in

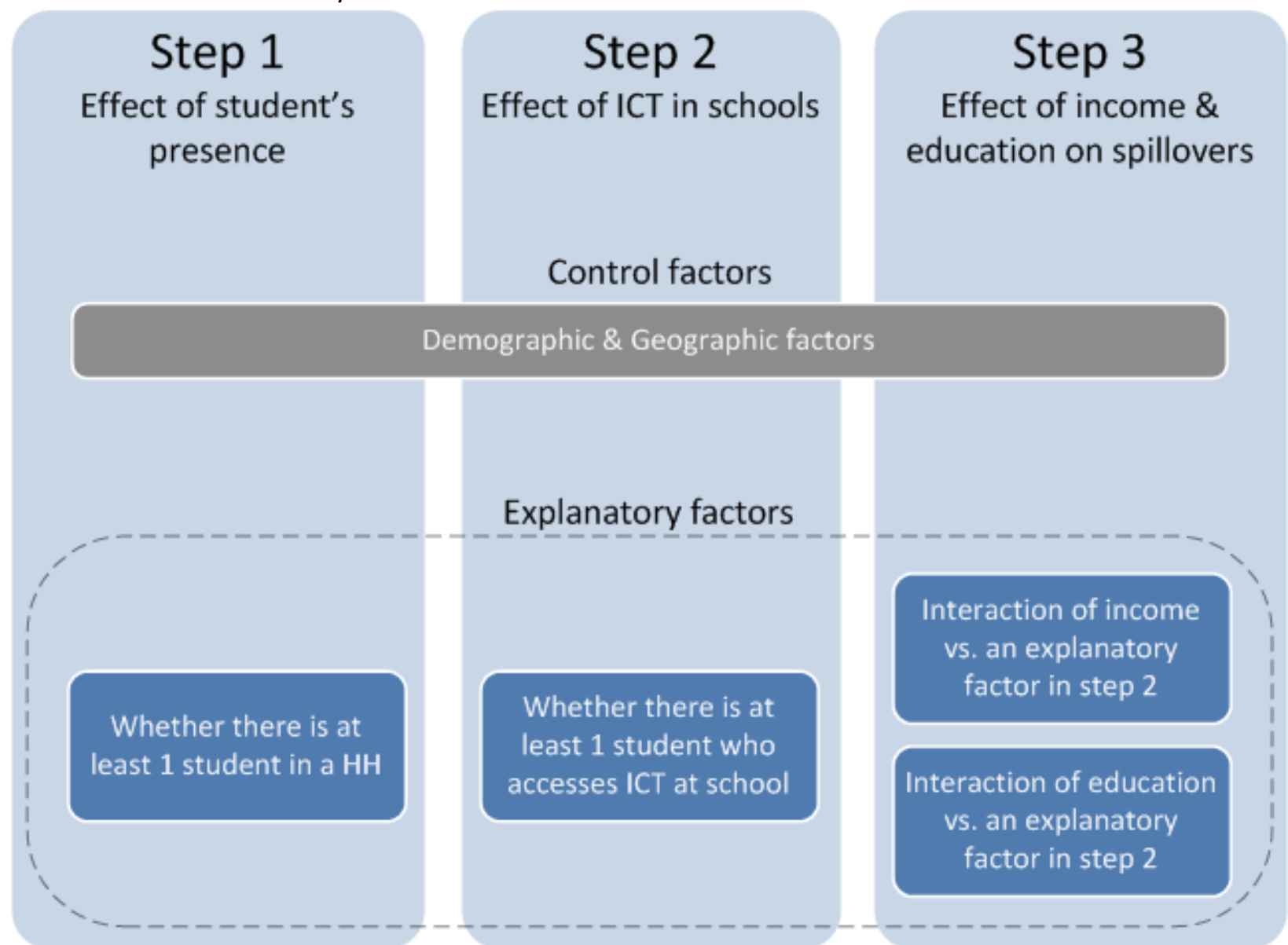

Fig. 3 are presented in the following three sections. Section 5.1 shows how the mere presence of students in a household affects household adoption of ICT and ICT utilization by adult family members. In the process, this section also explores the extent to which ICT adoption in a home can affect whether adults living in that home choose to utilize ICT. Section 5.2 discusses the spill-over effects of putting ICT in schools on households' ICT adoption and family members' ICT use. Section 5.3 discusses how the effect of student's presence, both when students have and do not have access to ICT in schools, changes when households have different levels of income and adult residents have different levels of education.

\subsection{Effect of having students in a household}

Section 5.1.1 discusses how the presence of a student in a household affects the household's adoption of ICT. Section 5.1.2 discusses the student's impact on family members' use of ICT. 


\subsubsection{Effect on household adoption of ICT}

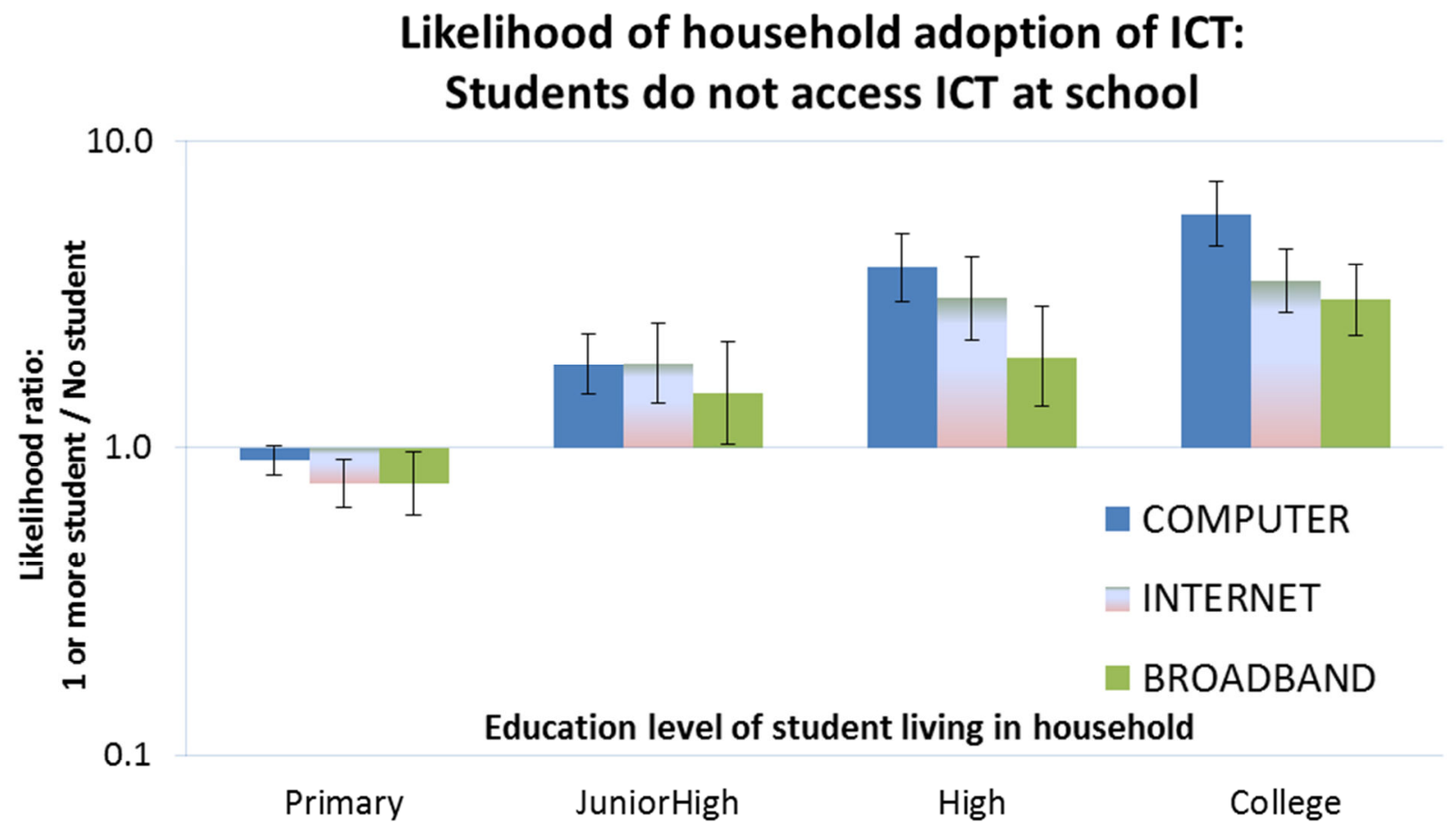

Fig. 4 shows likelihood ratios that a household will adopt ICT when there is at least one student, none of whom uses ICT at school, at the given educational level in the household. For example, having at least one high school student makes a household nearly 4 times more likely to adopt a computer, 3 times more likely to adopt Internet (either dial-up or broadband), and 2 times more likely to adopt broadband Internet compared to a household without a high school student.

Except for students in primary school, having at least one student in a household makes it much more likely to adopt computers and Internet. The higher the educational level of students, the stronger the increase in likelihood that a household will adopt. At least for students in high school and college, this effect is strongest for household adoption of computers, followed by adoption of Internet and broadband, respectively. It is unlikely that the presence of ICT in a household will cause people to have children, so this correlation implies that the presence of students causes households to adopt ICT in fairly large numbers. 


\section{Likelihood of household adoption of ICT: Students do not access ICT at school}

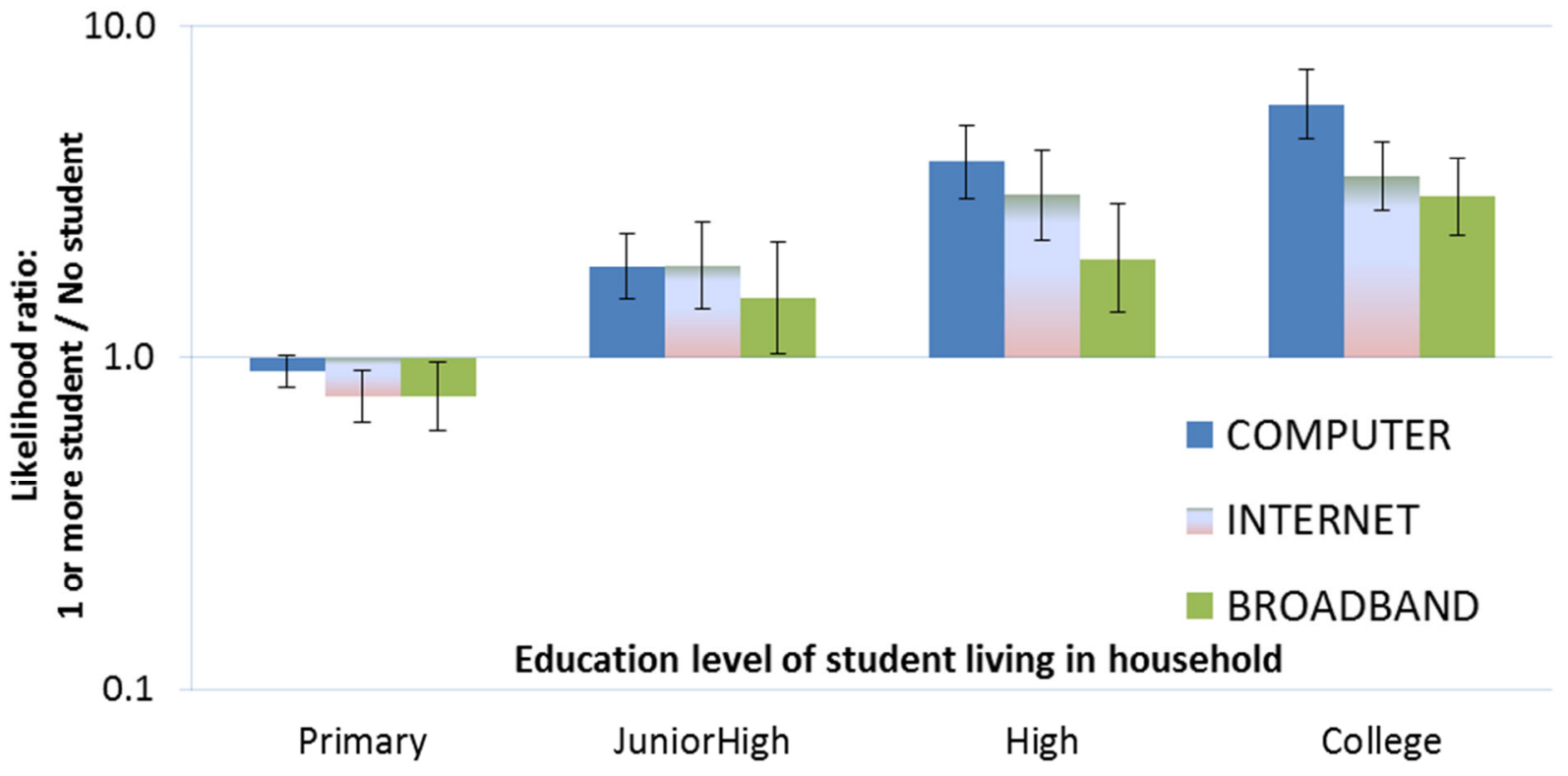

Fig. 4: Likelihood ratio that a household will adopt ICT when the household has one or more students, none of whom use ICT at school, at the given educational level. Error bars show the $95 \%$ confidence interval.

The above results are similar to those of studies in other nations, although not identical. Previous studies in developed nations have found that the presence of students positively affects ICT adoption at home (Newburger, 2001; Van Rompaey et al., 2002; Holloway \& Valentine, 2003), although they do not report the large disparity between primary-school and older students. A study in Paraguay similarly reports that the presence of students increases the probability of residential computer adoption, but unlike what is found here for Thailand, Grazzi and Vergara (2008) report no marginal effect on residential Internet adoption. ${ }^{14}$

\footnotetext{
14 This study also analyzed the marginal effect of student's presence on the probability that a household will
} adopt ICT as shown in Table 5 in the Appendix. 


\subsubsection{Effect on ICT utilization by adult family members}

This section analyzes the extent to which adult family members use ICT when living with students.

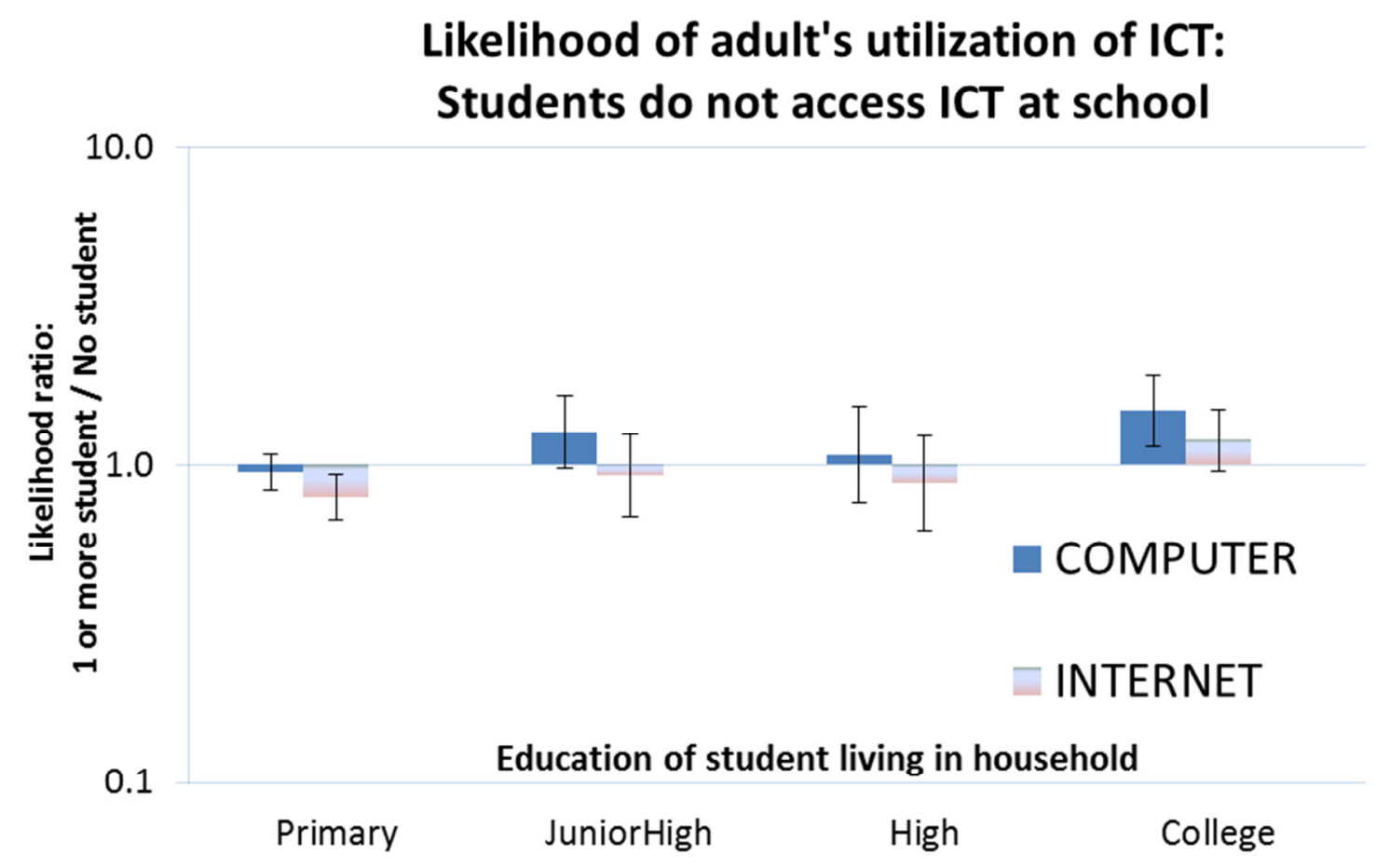

Fig. 5 shows the likelihood ratio that a non-student adult family member will use ICT when living with one or more students, none of whom uses ICT at school. For example, living with a junior high school student makes an adult family member about 1.2 times more likely to use computers, but slightly 
less likely to use Internet, compared to an adult living with no junior high school student. Overall,

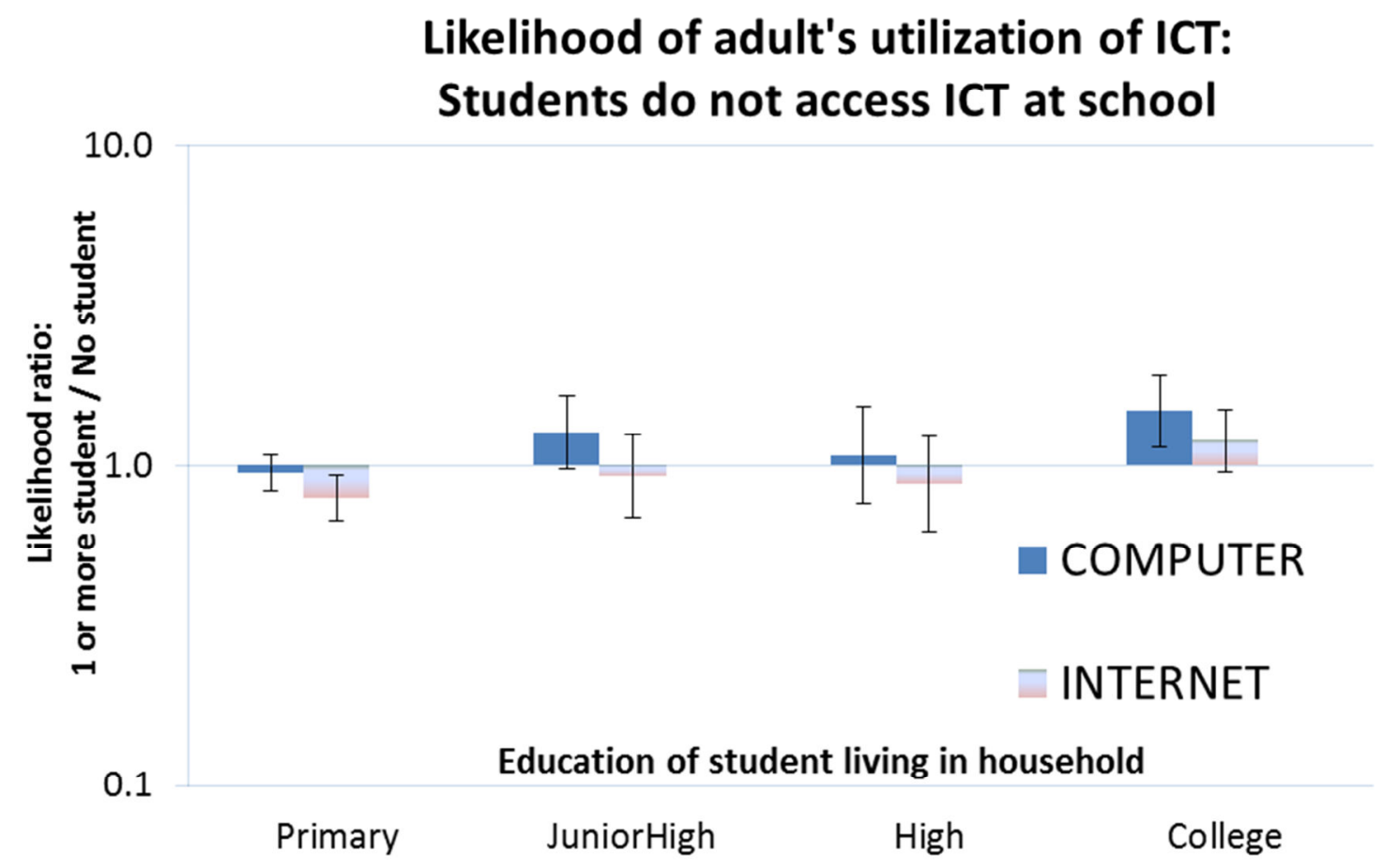

Fig. 5 shows that living with a K-12 student has very little impact on adult ICT utilization.

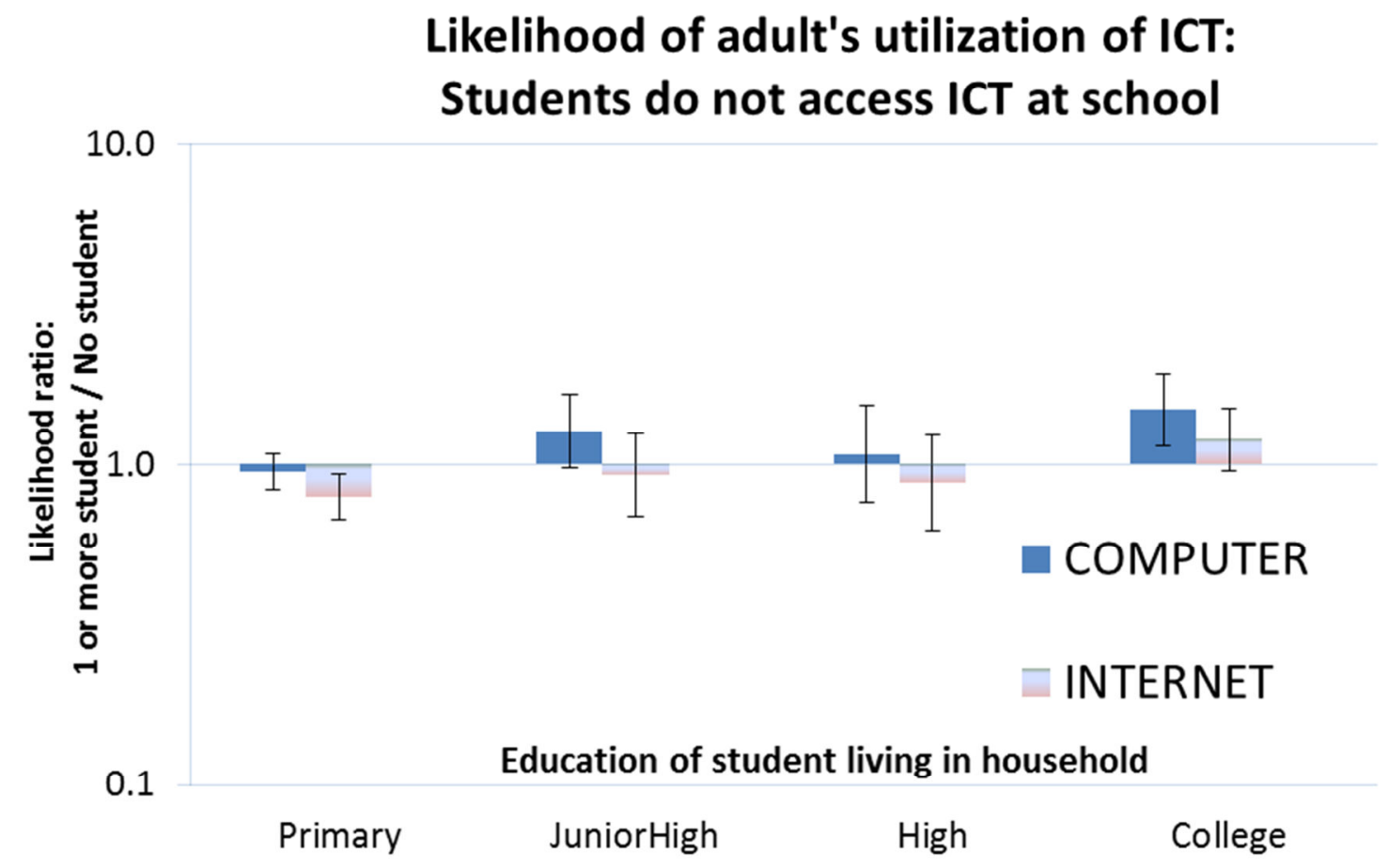

Fig. 5: Likelihood ratio that an adult will use ICT when living with one or more students, none of whom use ICT at school, at the given educational level. Error bars show the $95 \%$ confidence interval. 
The results from

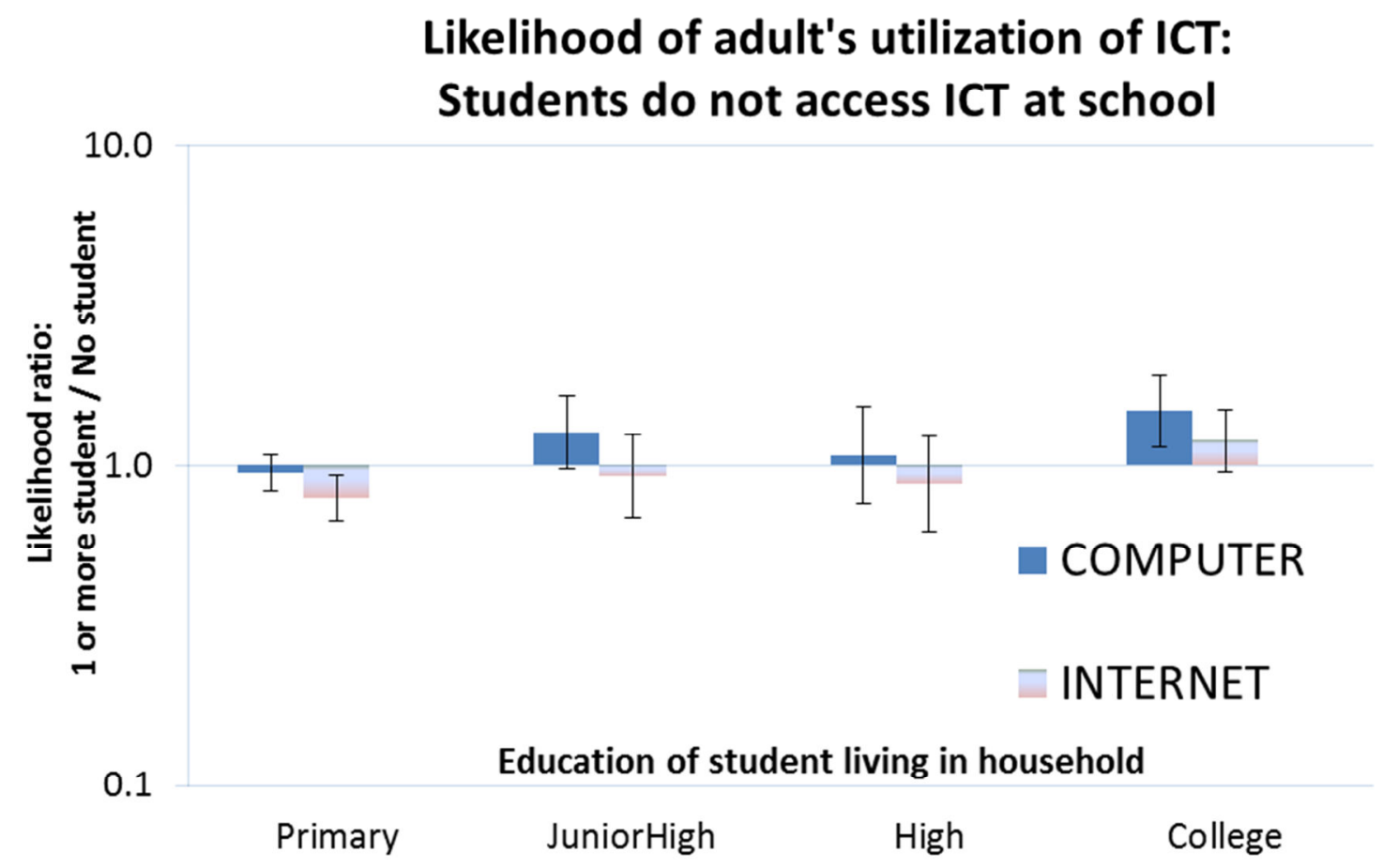

Fig. 5 are particularly surprising when the results of

\section{Likelihood of household adoption of ICT: Students do not access ICT at school}

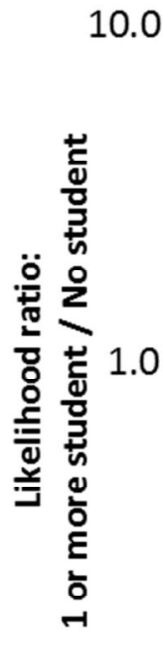

0.1
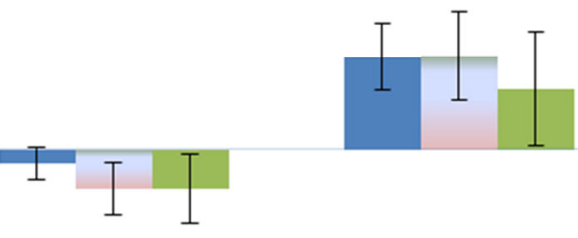

Education level of student living in household

$$
\text { Primary }
$$
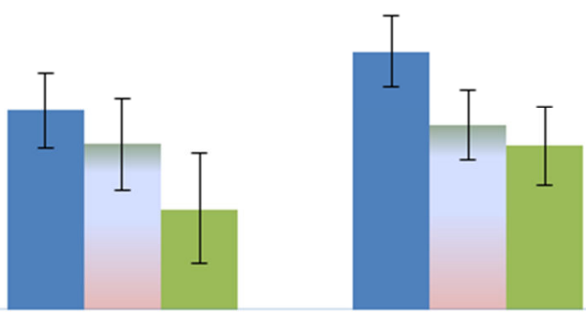

COMPUTER

INTERNET

BROADBAND

High

Fig. 4 are also considered. This study finds that households with students are far more likely to have adopted ICT, but the adults in those households are not more likely to use ICT. Again, it is reasonable to 
assume that the presence of students leads to ICT adoption rather than the other way around. Consequently, even after adults have gone to the expense of adopting ICT because of their children, those adults choose not to utilize the ICT that resides in their own homes. Thus, neither cost nor convenience is the reason they do not use ICT.

To further understand how the presence of students affects adoption and utilization, one would ideally separate those households that adopted ICT specifically for their children from those that would have adopted anyway. While it is impossible to do this exactly, it can be approximated using the Propensity Score Matching (PSM) technique, which matches each observation from the treatment group to an observation in the control group that has similar characteristics (Rosenbaum \& Rubin, 1983; Dehejia \& Wahba, 2002). For example, Tengtrakul and Peha (2011) used PSM to estimate ICT penetration in areas without ICT if the service were available. The villages in an area without ICT are matched to villages in areas with ICT that have similar demographic and geographic characteristics. The predicted ICT penetration of a village without ICT then equals penetration in the matched village.

To predict how computer adoption would change if there was a change in the presence or absence of students, the treatment group is those households with students, and the control group is those households without students. Each household in the treatment group is matched to a household in the control group that has similar demographic and geographic characteristics. ${ }^{15}$ Estimated computer adoption of a household in the treatment group then equals adoption in the matched household.

Table 4: Predicted computer adoption in households with students if the households did not have students using PSM. Households are differentiated into 4 groups based on their current (COM) and predicted (pCOM) adoption of computers.

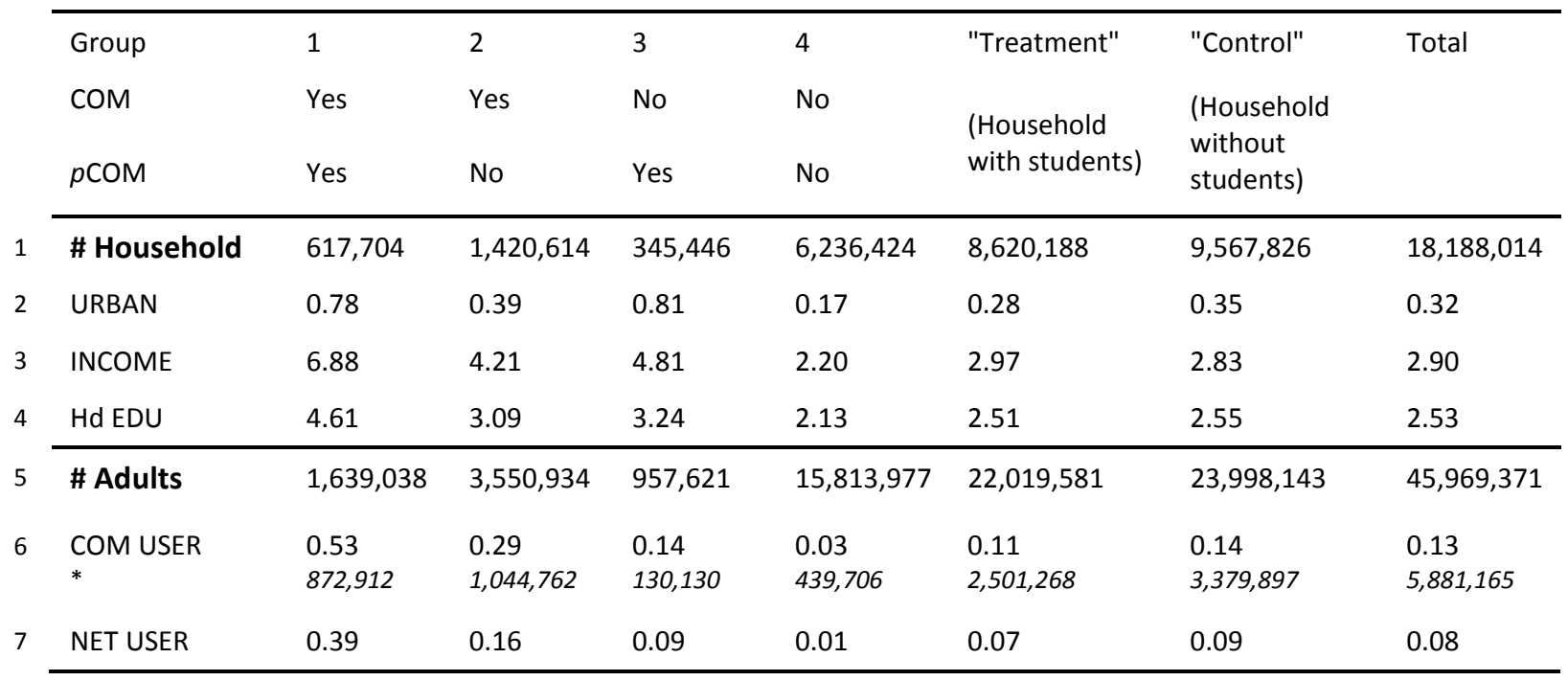

15 Demographic and geographic characteristics used in PSM are household level variables shown in Table 3 (URBAN, INCOME, HdEDU, and HdEMPLOY). The characteristics of each household is represented as a "propensity score" which is a conditional probability of a household being in a treatment group given its demographic and geographic factors. The propensity score is calculated using logistic regression model and the applied matching technique is "nearest neighbor matching with replacement". See Tengtrakul and Peha (2011) for more details. 
$\mathrm{HH}$ w/o adult

using computer

0.26

0.57

0.76

0.95

0.83

0.81

0.82

* numbers in italic represents absolute numbers of computer users in each household group

Table 4 shows observed and predicted computer adoption in households that have students and their demographic and geographic characteristics. COM indicates whether the household has a computer, $p C O M$ is a prediction as to whether the household would have a computer if it did not have students. Households with students are differentiated into 4 groups: households that currently have computers and are predicted to have computers even when they have no student, households that currently have computers but are predicted to have no computer in the absence of students, households that currently have no computer and are predicted to adopt computers if they had no student, and households that currently have no computer and are predicted to stay that way even if the households did not have students.

From those households that currently have one or more students and have adopted computers (groups \#1 and \#2), PSM predicts that $70 \%$ of them have computers only because they have students. In these households (group \#2), only $29 \%$ of adults use computers, as compared to $53 \%$ in those households that PSM predicts would adopt even without students (group \#1). Indeed, the majority (57\%) of those group \#2 households contain no adult who uses computers or the Internet, even though they all live with computers in their homes. Although there is uncertainty in PSM results, there is good reason to believe that a large number of adults are choosing not to use ICT despite having easy access. This means there is a sizable portion of the adult population that is not likely to become ICT users only through policies designed to make ICT less expensive or more accessible. These adults have less education than their counterparts who use computers but also live in households that are predicted to have computers only because they have students (group \#2). ${ }^{16}$ Warschauer (2003) suggested that skills

16

\begin{tabular}{lllllll} 
& \multicolumn{2}{l}{ Group A $^{\mathrm{a}}$} & \multicolumn{2}{c}{ Group B $^{\mathrm{b}}$} & \multicolumn{2}{l}{ Group C $^{\mathrm{c}}$} \\
\cline { 2 - 7 } Variables & mean & std.dev. & mean & std.dev. & mean & std.dev. \\
\hline COM USER & 0.10 & 0.29 & 0.12 & 0.32 & 0.14 & 0.34 \\
NET USER & 0.05 & 0.23 & 0.07 & 0.26 & 0.10 & 0.29 \\
URBAN & 0.23 & 0.42 & 0.29 & 0.45 & 0.32 & 0.46 \\
INCOME & 3.02 & 2.13 & 3.28 & 2.24 & 3.50 & 2.37 \\
EMPLOY & 0.83 & 0.37 & 0.83 & 0.37 & 0.84 & 0.37 \\
MALE & 0.48 & 0.50 & 0.47 & 0.50 & 0.47 & 0.50 \\
MOBILE USER & 0.48 & 0.50 & 0.53 & 0.50 & 0.54 & 0.50 \\
EDU: ${ }^{\text {aa }}$ PRIM & 0.62 & 0.49 & 0.61 & 0.49 & 0.60 & 0.49 \\
$\quad$ JUNI & 0.13 & 0.34 & 0.13 & 0.33 & 0.12 & 0.33 \\
$\quad$ HIGH & 0.10 & 0.30 & 0.11 & 0.31 & 0.11 & 0.31 \\
$\quad$ COLL & 0.08 & 0.28 & 0.11 & 0.31 & 0.13 & 0.33 \\
AGE: ${ }^{\text {bb }}$ 15- 19 & 0.03 & 0.18 & 0.03 & 0.17 & 0.03 & 0.16 \\
20- 24 & 0.07 & 0.26 & 0.06 & 0.24 & 0.07 & 0.25
\end{tabular}


are necessary for individuals to use ICT. As those skills are sometimes obtained through education, it is possible that many of these adults do not use ICT because they lack such skills.

While having one or more students in a household has a large impact on residential adoption and utilization of ICT, the number of students in a household does not.

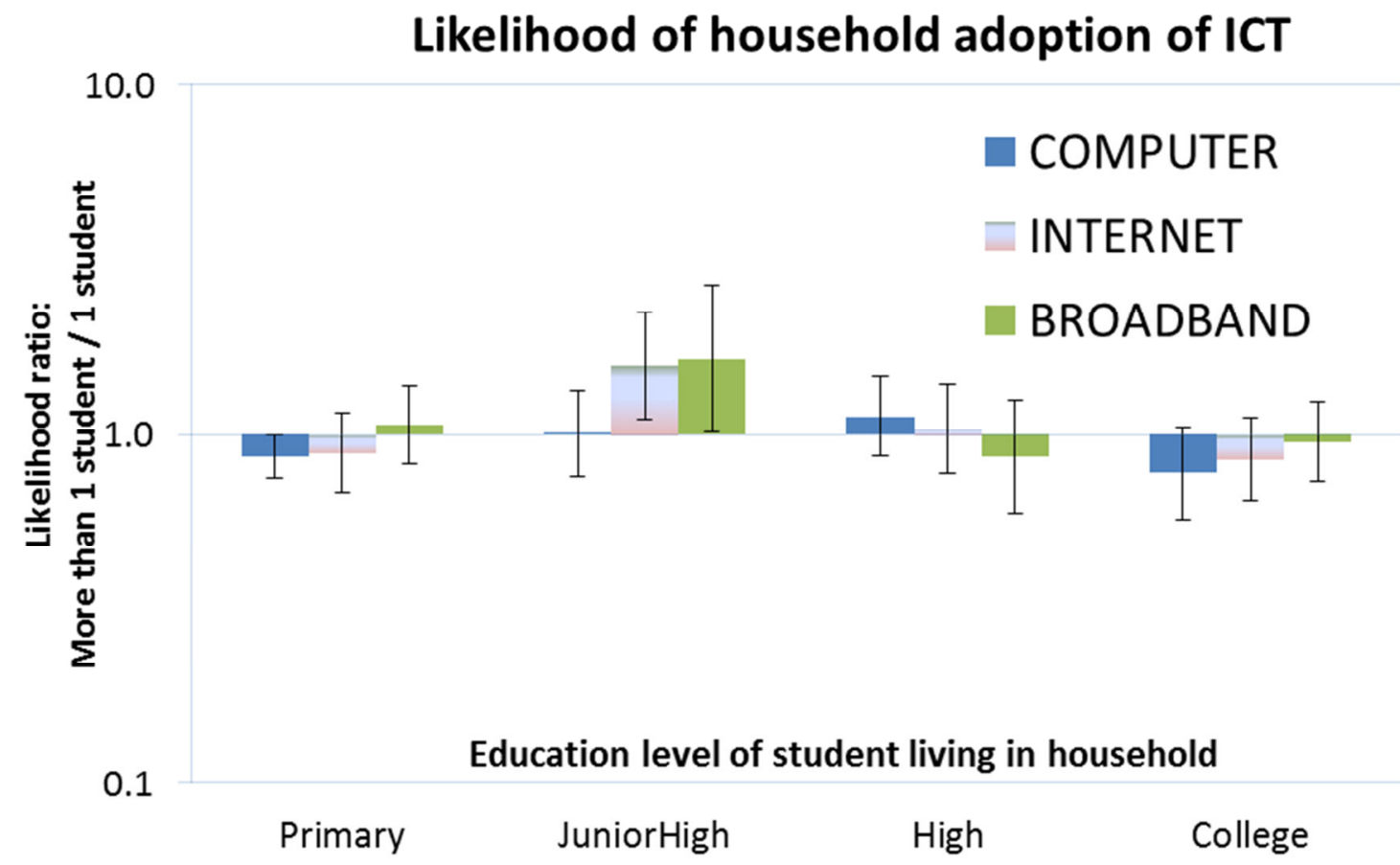

Fig. 6 shows the likelihood ratio that a household will adopt ICT when a household has more than one student compared to a household that has only one. Except for students in junior high school,

\begin{tabular}{|c|c|c|c|c|c|c|}
\hline $25-29$ & 0.10 & 0.30 & 0.06 & 0.24 & 0.05 & 0.22 \\
\hline 30- 34 & 0.15 & 0.36 & 0.10 & 0.31 & 0.07 & 0.26 \\
\hline 35- 39 & 0.16 & 0.37 & 0.17 & 0.38 & 0.15 & 0.36 \\
\hline $40-44$ & 0.13 & 0.34 & 0.18 & 0.38 & 0.20 & 0.40 \\
\hline $45-49$ & 0.09 & 0.29 & 0.13 & 0.33 & 0.15 & 0.36 \\
\hline 50- 54 & 0.07 & 0.25 & 0.08 & 0.27 & 0.09 & 0.29 \\
\hline 55- 59 & 0.06 & 0.24 & 0.06 & 0.23 & 0.05 & 0.23 \\
\hline $\mathrm{N}$ (individuals) & \multicolumn{2}{|c|}{$8,702,444$} & \multicolumn{2}{|c|}{$15,965,795$} & \multicolumn{2}{|c|}{$7,079,218$} \\
\hline \multicolumn{7}{|c|}{ aa Omitted (base case) educational variable is education less than primary school. } \\
\hline \multicolumn{7}{|c|}{${ }^{\mathrm{bb}}$ Omitted (base case) age variable is age more than 60 years old. } \\
\hline \multicolumn{7}{|c|}{ adults living with students who do not access ICT in school } \\
\hline \multicolumn{7}{|c|}{${ }^{\mathrm{b}}$ Adults living with students who access only computers and not Internet in school } \\
\hline
\end{tabular}

Table 12 (in the Appendix) shows that, in households group \#2, average educational level is 4.8 for adults who use computers and 2.8 for those who do not use computer or Internet respectively. The table also shows that adults in this group who do not use computers are older ( 49 years old) than their counterparts ( 37 years old). 
there is little or no effect. For students in junior high school, the effect is small and positive. Although not shown here, the impact of multiple students on utilization of ICT by family members was also found to be small.

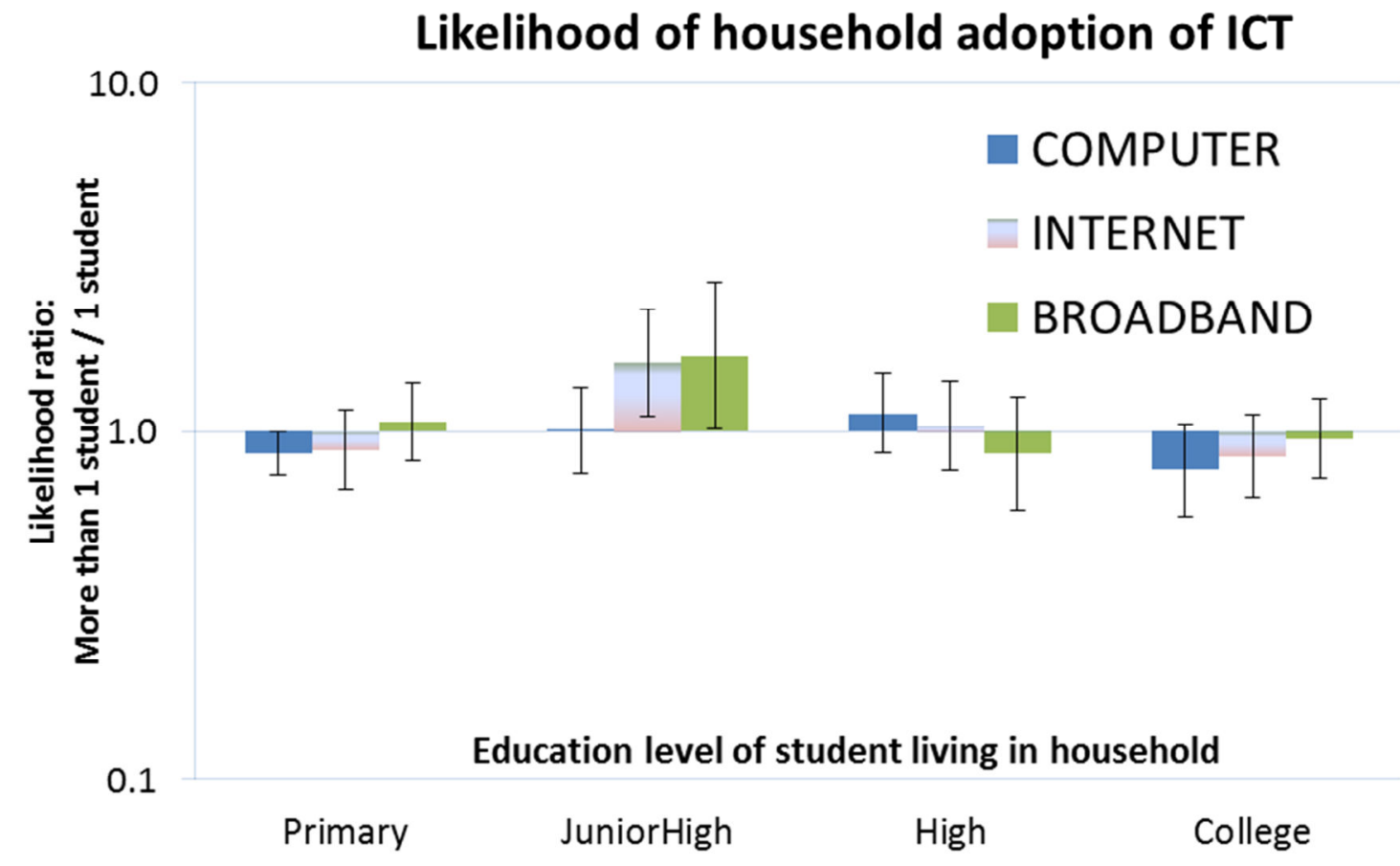

Fig. 6: Likelihood ratio that a household will adopt ICT when the household has more than 1 student at the given educational level. Error bars show the $95 \%$ confidence interval.

\subsection{Spill-over effect of putting ICT in school}

This section discusses how putting ICT in schools has spill-over effects on ICT adoption at home (Section 5.2.1) and ICT utilization by adult family members (Section 5.2.2).

\subsubsection{Effect on households adoption of ICT}

This section analyzes the spill-over effect of putting ICT in schools on adoption of ICT at students' homes by comparing three groups of households: A) households that have students who do not access ICT in school, B) households that have students who access computers and not Internet in school, and C) households that have students who access both computers and Internet in school. ${ }^{17}$

17 Descriptive statistics of related variables for each household group are shown in

Variables

(1)

(2)

(3)

(4)

(5)

(6)

(7)

(8)

(9)

$\begin{array}{lllll}\text { (1) COM USER } & 1.00 & & & \\ \text { (2) NET USER } & 0.78 & 1.00 & & \\ \text { (3) URBAN } & 0.22 & 0.20 & 1.00 & \\ \text { (4) INCOME } & 0.45 & 0.41 & 0.38 & 1.00\end{array}$


Comparing groups A and B shows the spill-over effect of computers in schools, and comparing groups B and $\mathrm{C}$ shows the additional impact of Internet in schools.

The impact of ICT in schools differs greatly depending on the grade level of the student. Somewhat surprisingly, the effect is largest in primary school. Perhaps this is because the presence of older students increases the likelihood of residential ICT adoption even when those students do not have access to ICT in schools, but this is not the case for primary school students.

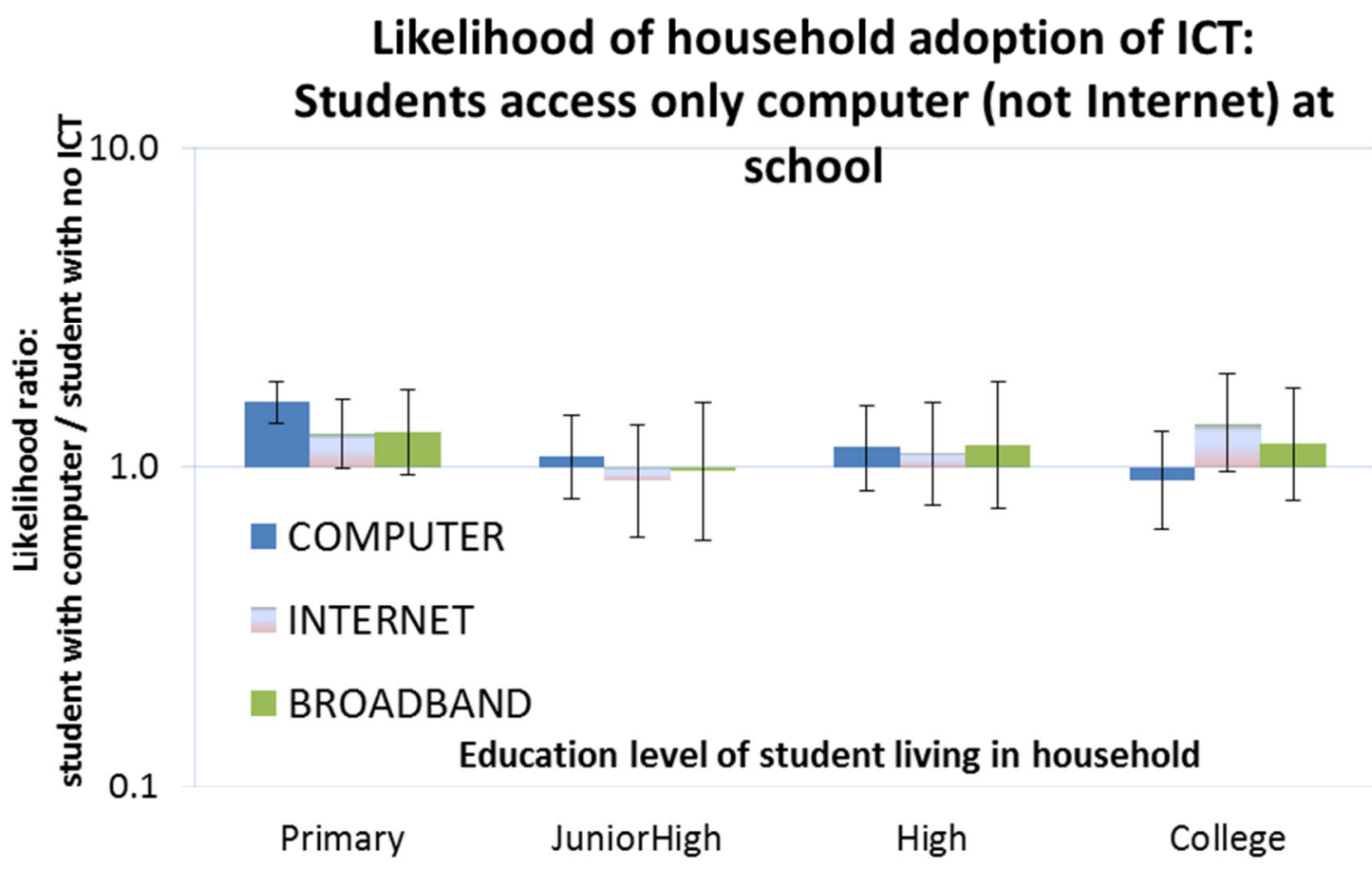

Fig. 7 shows the likelihood ratios of household ICT adoption when their students access computers (and no Internet) at school. Computers in primary schools make households with primary school students 1.5 times more likely to adopt computers at home, but only a slight 1.1 times more likely to adopt Internet compared to households with students who do not use a computer (or Internet) at school. For junior high, high schools and college, computer access in schools alone has little impact on ICT adoption at home

\begin{tabular}{lllllllllll}
\hline (5) EMPLOY & 0.11 & 0.08 & -0.05 & 0.03 & 1.00 & & & & \\
(6) MALE & 0.00 & 0.00 & -0.02 & -0.01 & 0.19 & 1.00 & & & \\
(7) MOBILE USER & 0.31 & 0.26 & 0.19 & 0.31 & 0.21 & 0.07 & 1.00 & & \\
(8) EDU & 0.64 & 0.56 & 0.26 & 0.50 & 0.14 & 0.04 & 0.41 & 1.00 & \\
(9) AGE & -0.19 & -0.15 & -0.01 & -0.07 & -0.35 & -0.05 & -0.27 & -0.33 & 1.00
\end{tabular}




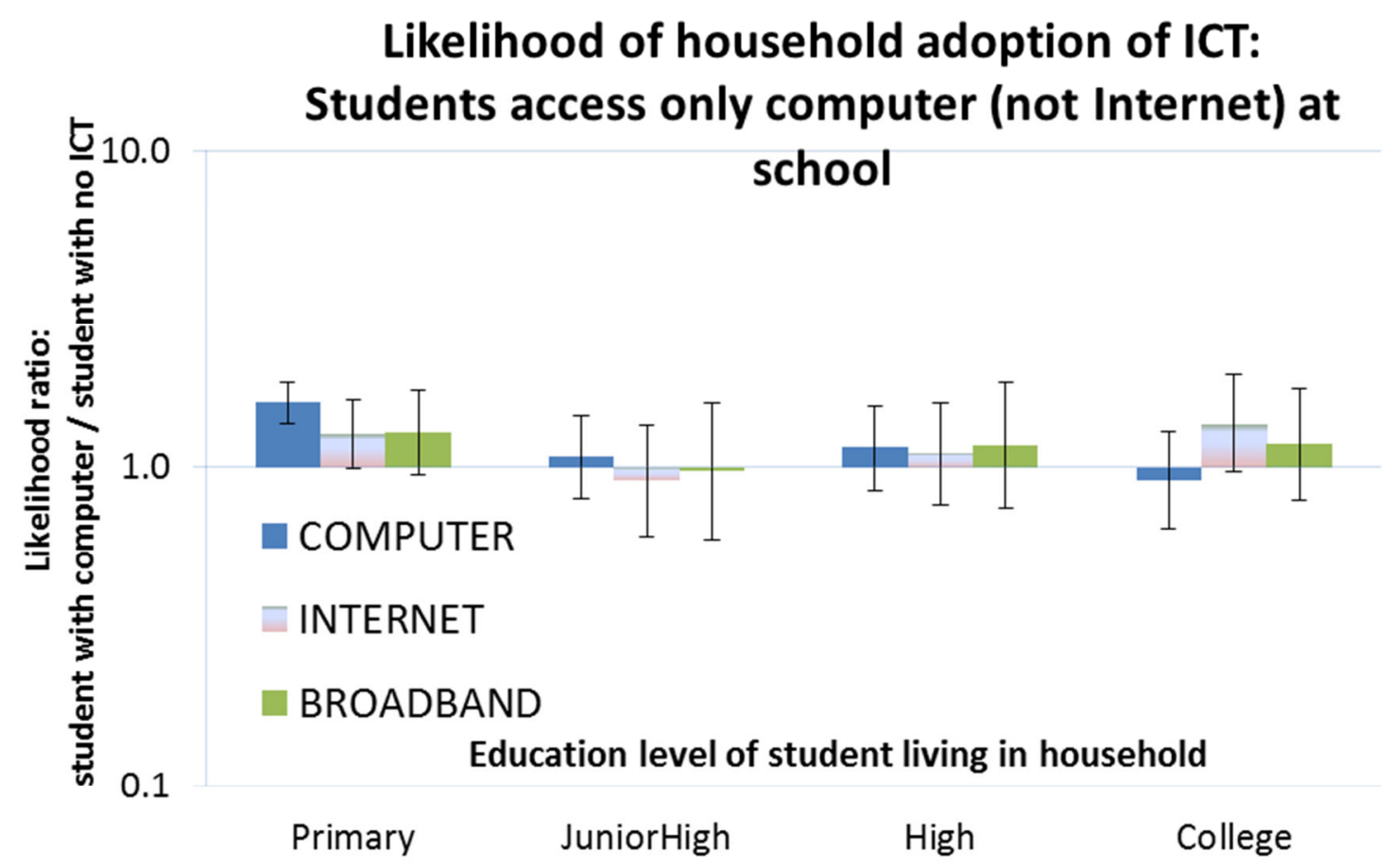

Fig. 7: Likelihood ratios that a household will adopt ICT when there are computers (no Internet) in the kids' school. Error bars show the $95 \%$ confidence interval.

Household Internet adoption can also be affected by a student's presence, but this requires the student's access to internet and not just computers at school.

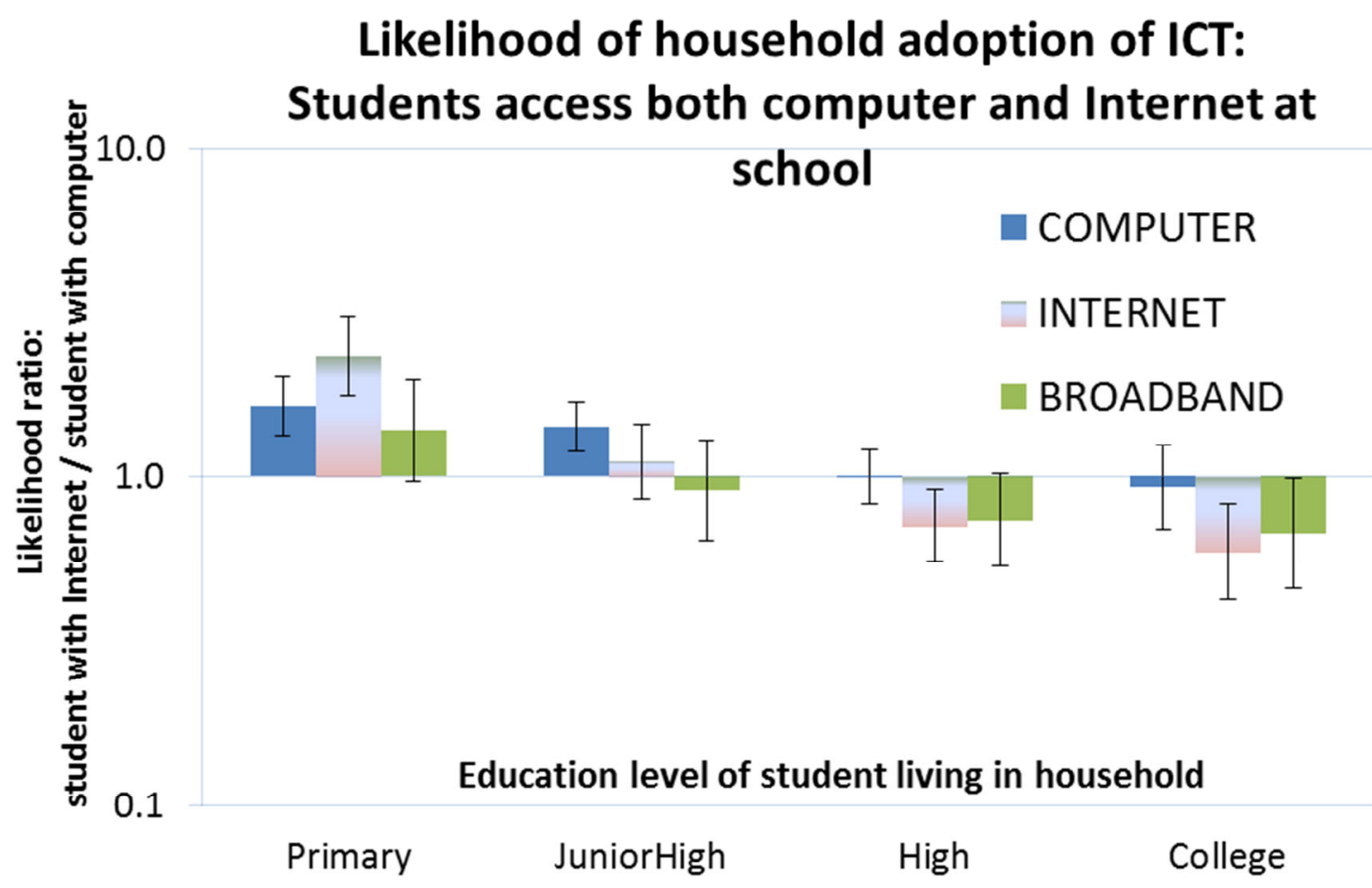


Fig. 8 shows that households with students who access both computers and Internet in primary schools are 1.5 and 2.3 times more likely to adopt computers and Internet at home, respectively, compared to households with students who access only computers (and no Internet) at primary schools. However, putting Internet access into high schools is inversely related to Internet adoption at home, which would seem to imply a substitution effect; once high school students have access to Internet in school, it is possible that parents decide not to subscribe to an Internet service at home. Thus, deployment of Internet in high schools may actually reduce residential Internet penetration.

From

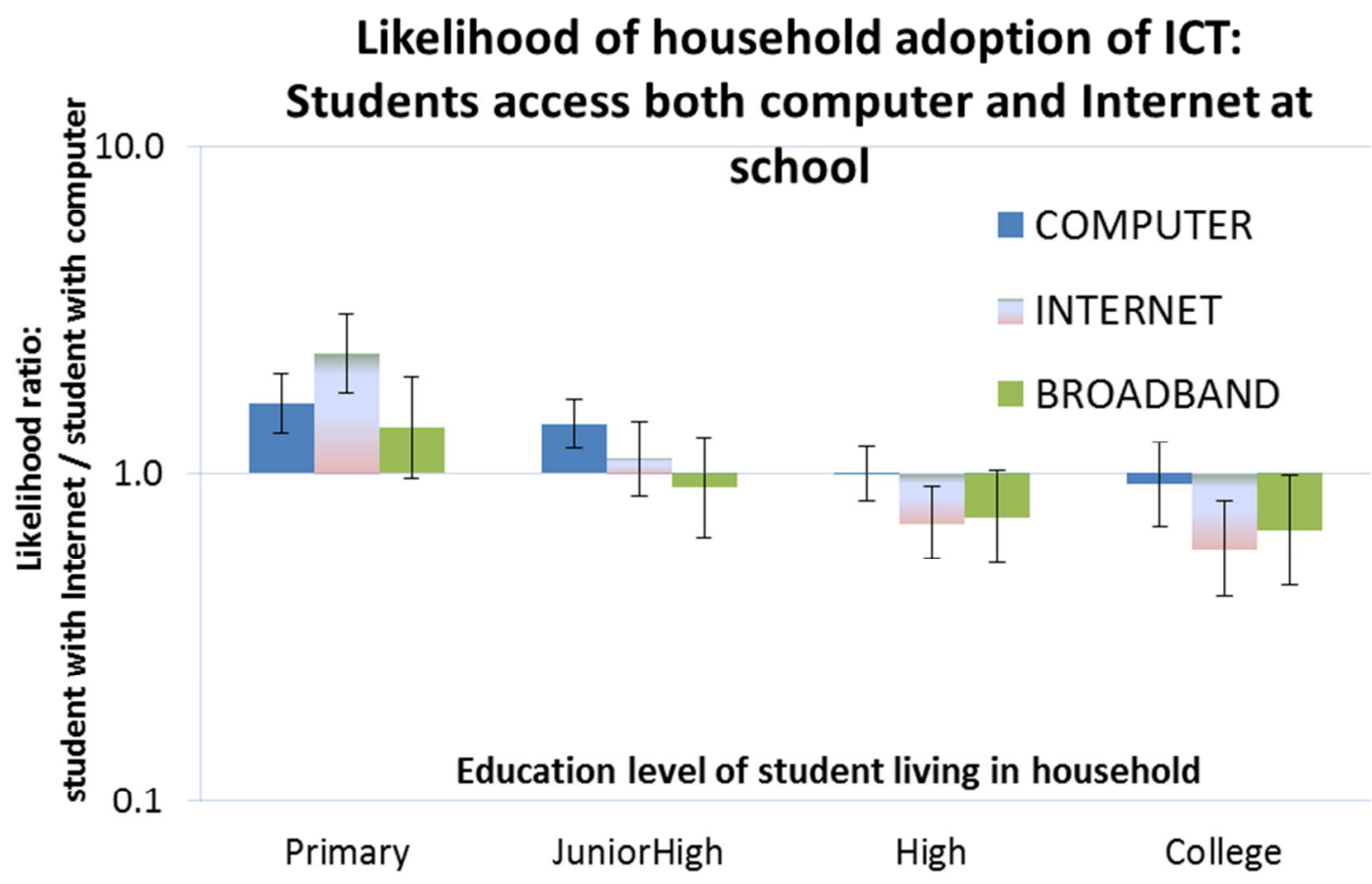

Fig. 8, there also appears to be a substitution effect for college students between Internet usage at college and Internet adoption at home. However, as discussed in Section 4.2, use of ICT on campus by college students reflects choices made by college students, whereas in $\mathrm{K}-12$ schools this usage reflects choices that schools impose on students. Thus, it is impossible to tell whether households are less likely to adopt because their college students choose to use Internet on campus, whether college students choose to use Internet on campus because there is no Internet at home, or both. 


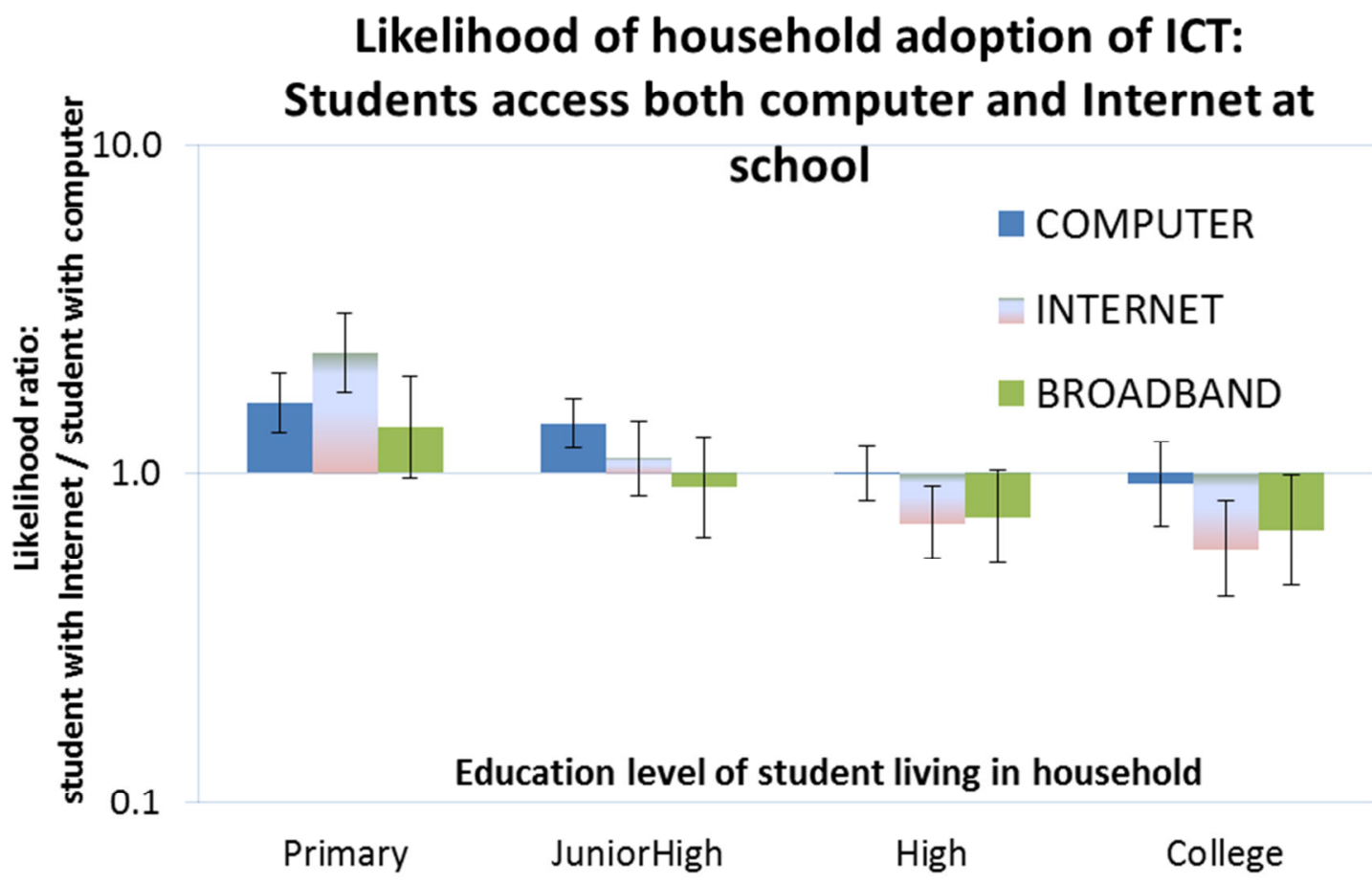

Fig. 8: Likelihood ratios that a household will adopt ICT when there are both computers and Internet in the kids' school. Error bars show the $95 \%$ confidence interval.

\subsubsection{Effect on ICT utilization by adult family members}

This section analyzes the spill-over effect of putting ICT in schools on ICT utilization by adult family members. Using the same method as the previous section, Fig. 9 shows this spill-over effect by comparing 3 groups of adults: A) adults living with students who do not access ICT in school, B) adults living with students who access only computers and not Internet in school, and C) adults living with students who access both computers and Internet in school. ${ }^{18}$ Fig. 9 shows that putting computers

18 Descriptive statistics of related variables for each adults group are shown in

\begin{tabular}{lllllll} 
& \multicolumn{2}{l}{ Group A $^{\mathrm{a}}$} & \multicolumn{2}{l}{ Group B $^{\mathrm{b}}$} & \multicolumn{2}{l}{ Group C $^{\mathrm{c}}$} \\
\cline { 2 - 7 } Variables & mean & std.dev. & mean & std.dev. & mean & std.dev. \\
\hline COMPUTER & 0.18 & 0.38 & 0.26 & 0.44 & 0.32 & 0.47 \\
INTERNET & 0.07 & 0.26 & 0.10 & 0.31 & 0.13 & 0.34 \\
BB & 0.04 & 0.20 & 0.06 & 0.23 & 0.07 & 0.25 \\
URBAN & 0.23 & 0.42 & 0.29 & 0.45 & 0.32 & 0.47 \\
INCOME & 2.78 & 2.03 & 3.02 & 2.15 & 3.18 & 2.25 \\
HdEDU & 2.40 & 1.26 & 2.54 & 1.32 & 2.62 & 1.36 \\
HdEMPLOY & 0.83 & 0.38 & 0.83 & 0.38 & 0.82 & 0.39 \\
\hline N (households) & $3,304,175$ & $6,413,282$ & $2,970,408$
\end{tabular}

${ }^{\mathrm{a}} \mathrm{HH}$ that have students who do not access ICT in school

${ }^{\mathrm{b}} \mathrm{HH}$ that have students who access only computers and not Internet in school

${ }^{\mathrm{c}} \mathrm{HH}$ that have students who access both computers and Internet in school 
without Internet in K-12 schools has little impact on the ICT use of the students' family members. For example, adults living with students who access computers without Internet at primary school are equally likely to use ICT as adults living with students who do not access ICT at school.

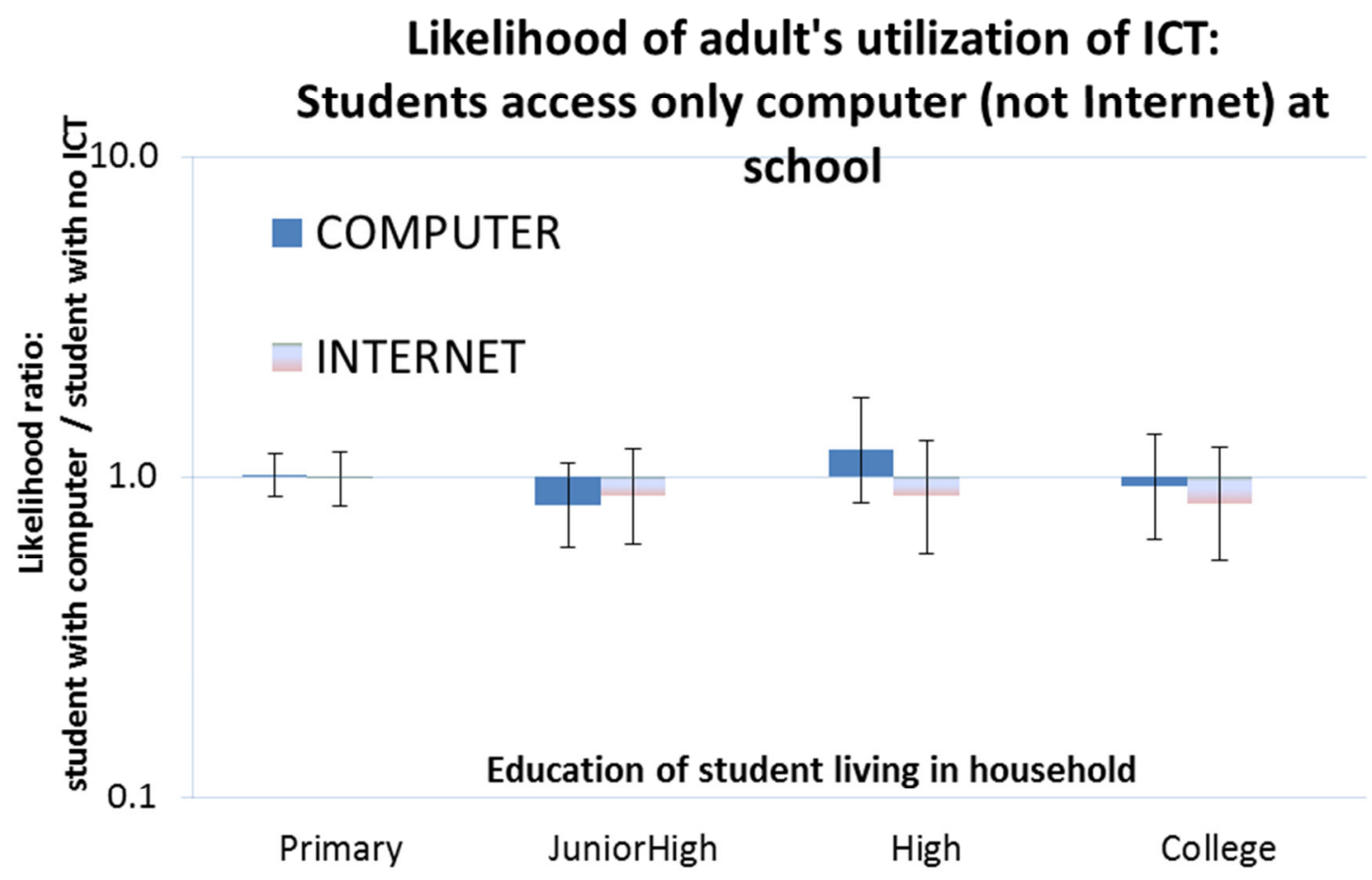

Fig. 9: Likelihood ratios that an adult will use ICT when there are computers (no Internet) in the kids' school. Error bars show the $95 \%$ confidence interval.

Table 11 of the Appendix. 
However, there is clear relationship between student Internet access at school and adult ICT utilization at home. At least at the K-12 levels, adult ICT utilization cannot affect access at school. Thus

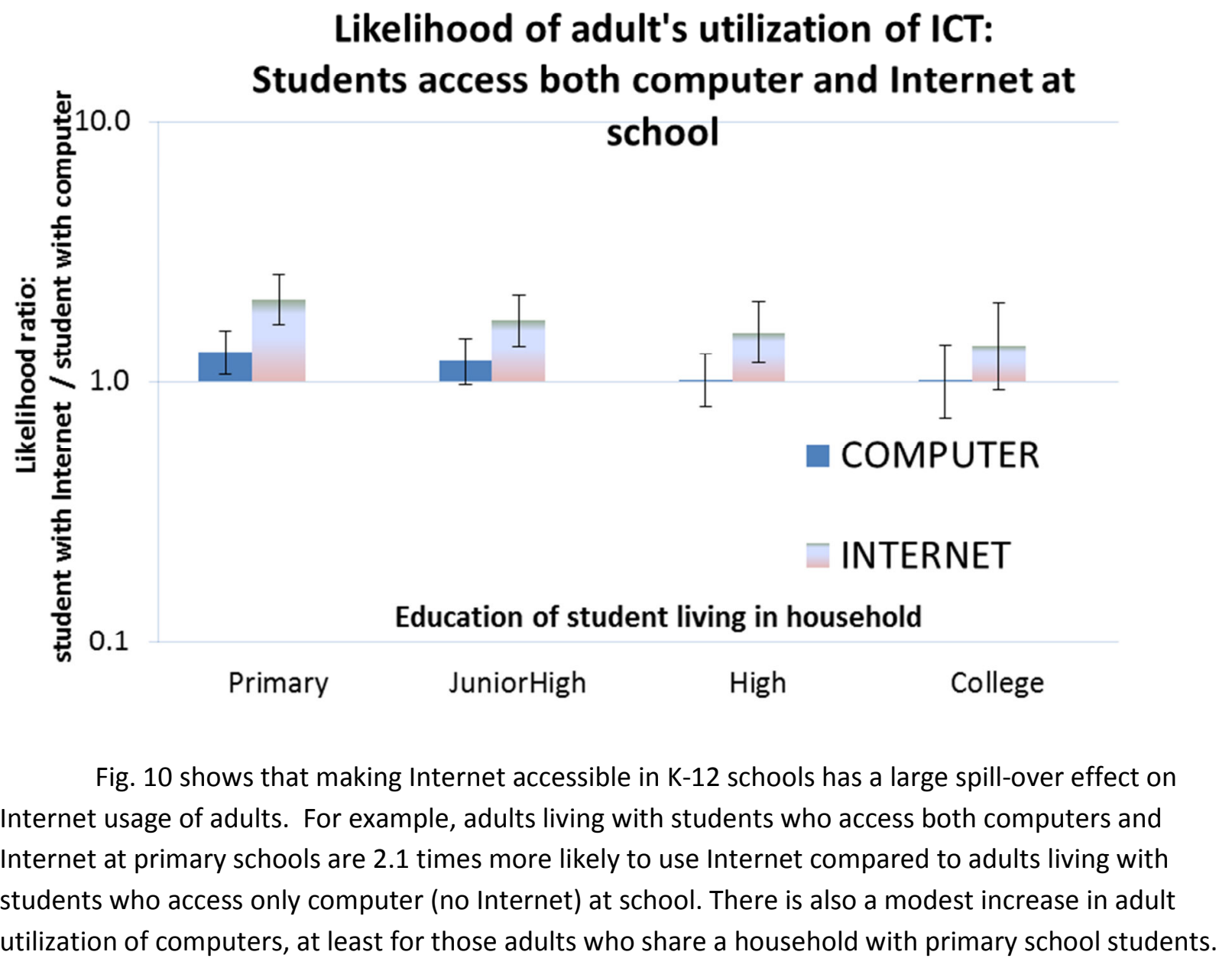




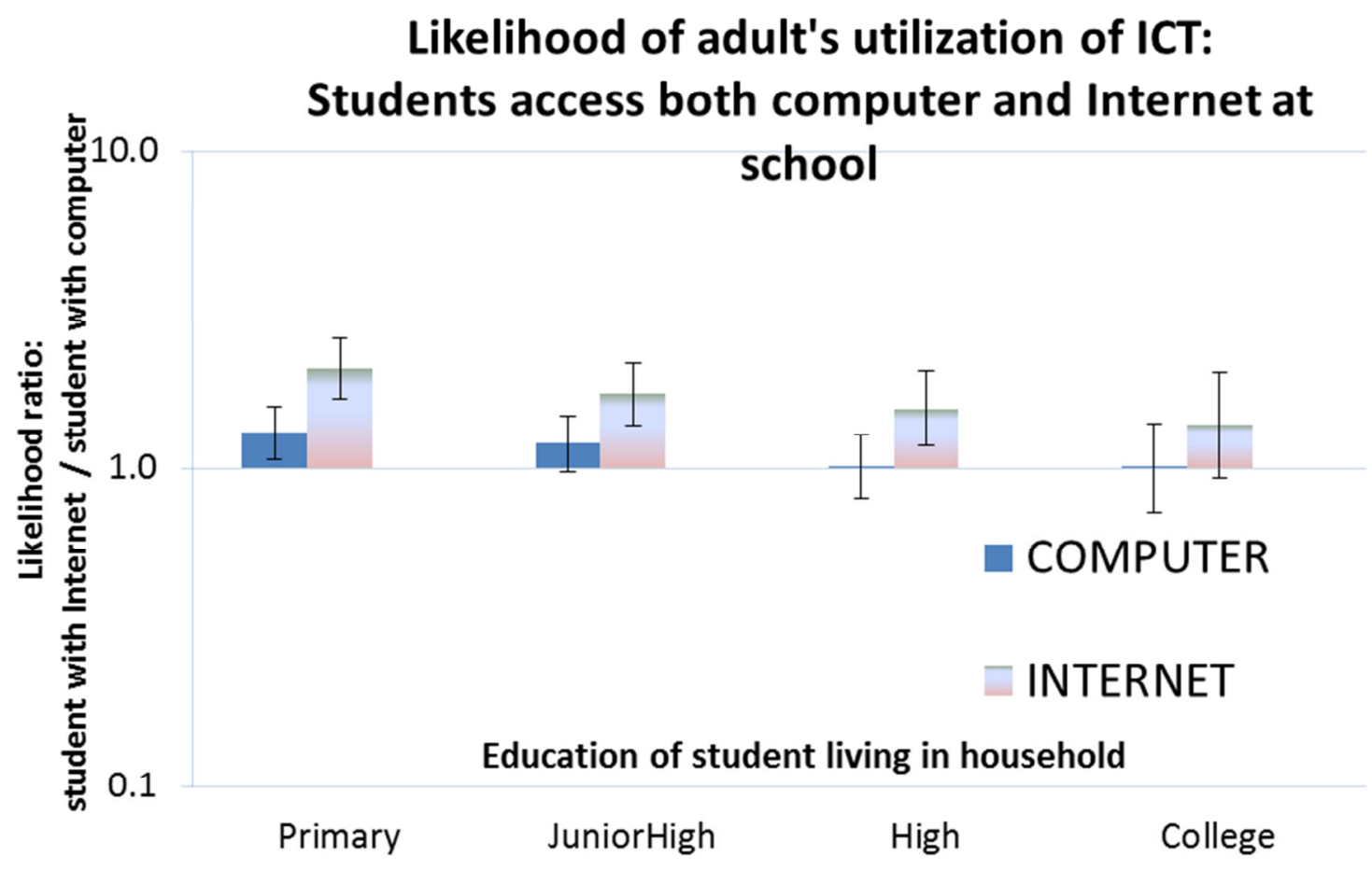

Fig. 10: Likelihood ratios that an adult will use ICT when there are both computers and Internet in the kids' school. Error bars show the $95 \%$ confidence interval.

This study finds that none of these spill-over effects changes very much with the number of students in a household, provided that this number is at least 1 . The presence of additional students at a given educational level does not significantly affect ICT adoption or utilization of ICT by family members, whether the student has access to computers, or both computers and Internet at school.

\subsection{Effects of household income and education level of adults in household}

One might expect that the spill-over effect of ICT in schools may differ between low and high-income households or low and high-education households. For example, Berniell et al. (2010) found that teaching health in school has a greater effect on family members with less education and income. However, this study finds no significant impact of household income and education level of a household's adult residents in most scenarios discussed in Section 5.1 and 5.2. Although household income and the education level of adults certainly affect residential adoption and adult utilization of ICT, the extent of the 
spill-over effect from ICT in schools was independent of household income and adult education levels. As shown in

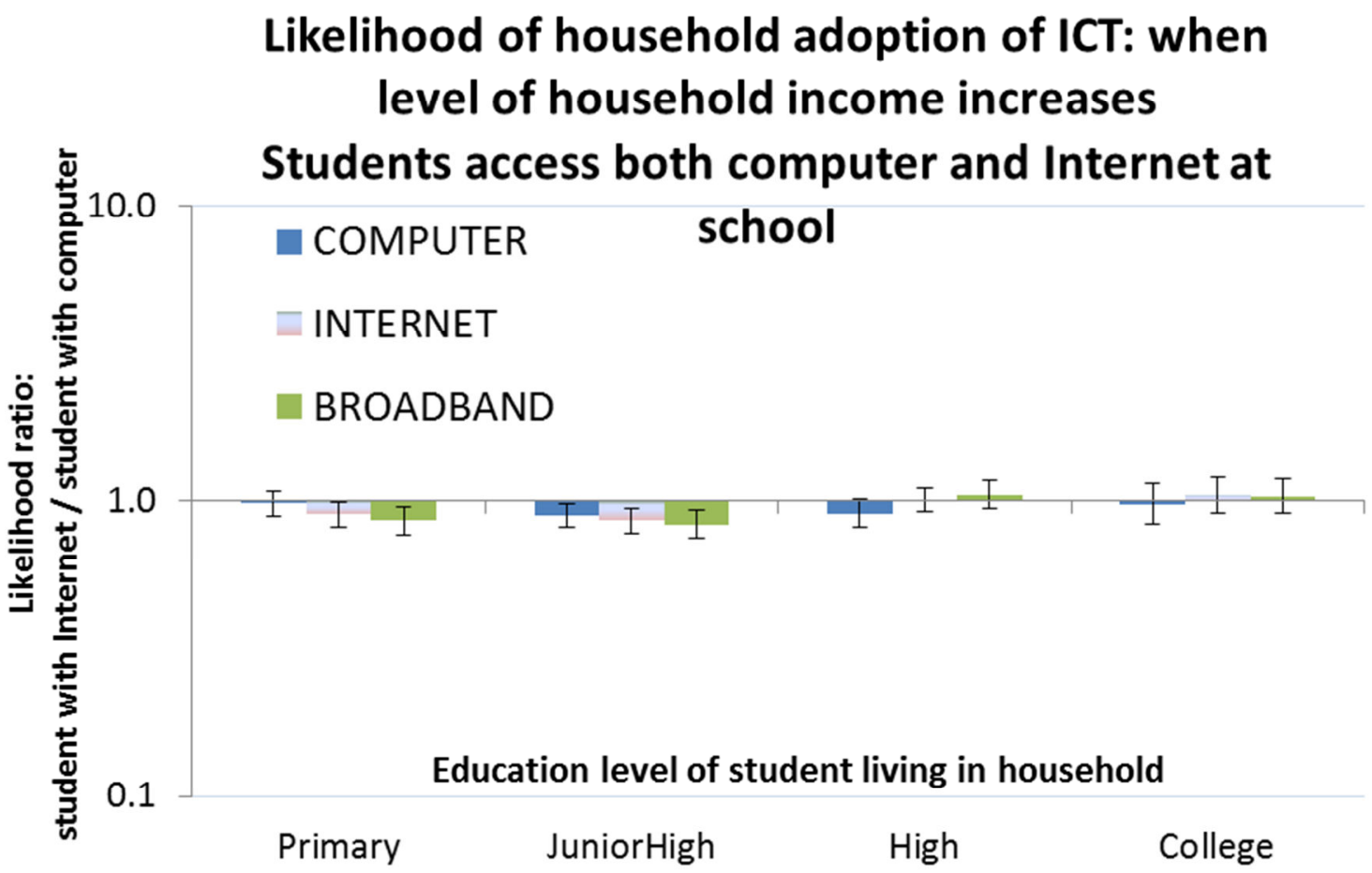

Fig. 11, the logistic regression coefficients of interaction variables between household income and student's use of ICT in schools are statistically insignificant and close to 1 in every case when the interaction variables are included in the prediction of ICT adoption.

To assess the impact of a household's income level and an adult's education level on the spillover effects described in Section 5.2, interaction variables were calculated for every permutation of the following characteristics: (i) students could be in primary school, junior high school, high school, or college, (ii) students could have access to no ICT in school, computers in school, or computers and Internet in school, (iii) impact could be assessed on residential adoption of computers, residential adoption of Internet, residential adoption of broadband, adult utilization of computers, or adult utilization of Internet, (iv) interaction variables could be based on household income or adult education level. In nearly every case, there was no statistically significant difference between the interaction variable and $1 \mathrm{implying}$ that that the income of a household and the education level of adult residents do not greatly alter the effects described in Section 5.2. 
As one representative example, consider the impact of placing both computers and Internet in schools on residential adoption of ICT, as shown above in

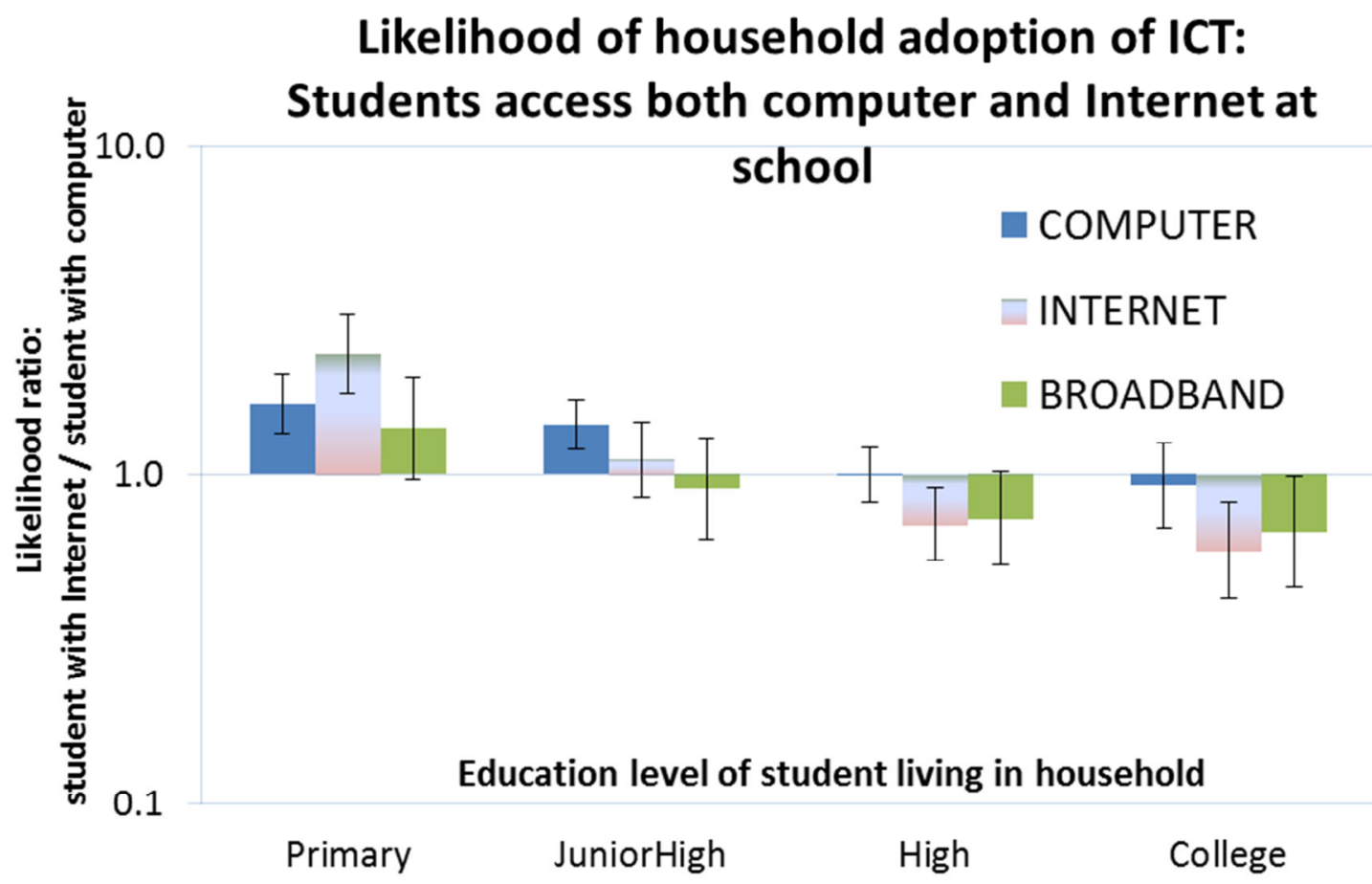

Fig. 8. Recall the observation that placing Internet in primary schools leads to significantly increased ICT adoption at home, placing Internet in junior high school has little impact, and placing Internet in high school can even serve as a modest substitute for ICT at home in some cases. Although the authors initially expected this increased ICT adoption in the households of primary school students would be strongest in high-income households and the substitution effect in the households of high 
school students would be strongest in low-income households,

\section{Likelihood of household adoption of ICT: when} level of household income increases

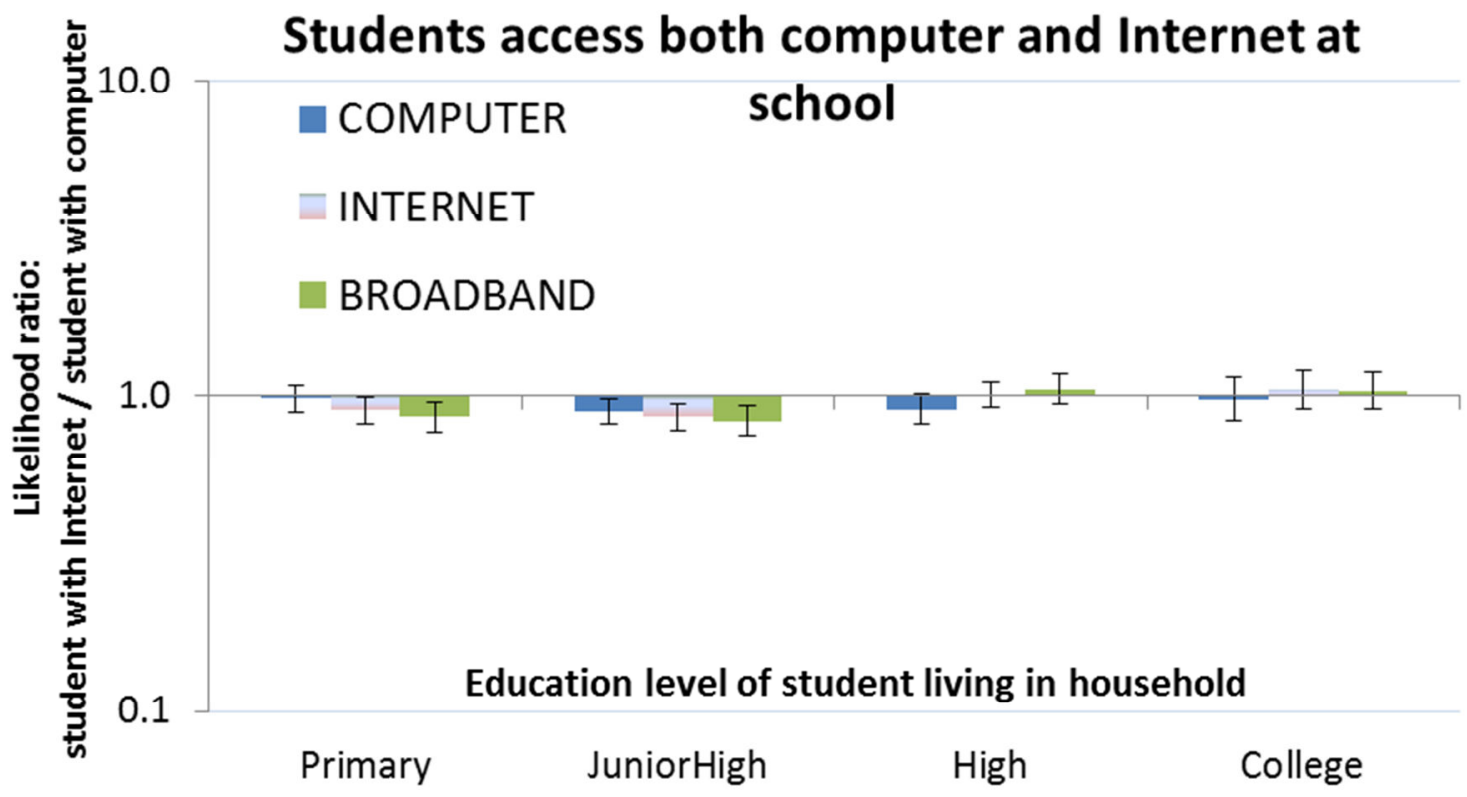

Fig. 11 shows that the interaction variables (as explained in Section 4.3) associated with household income are close to 1 in every case shown in

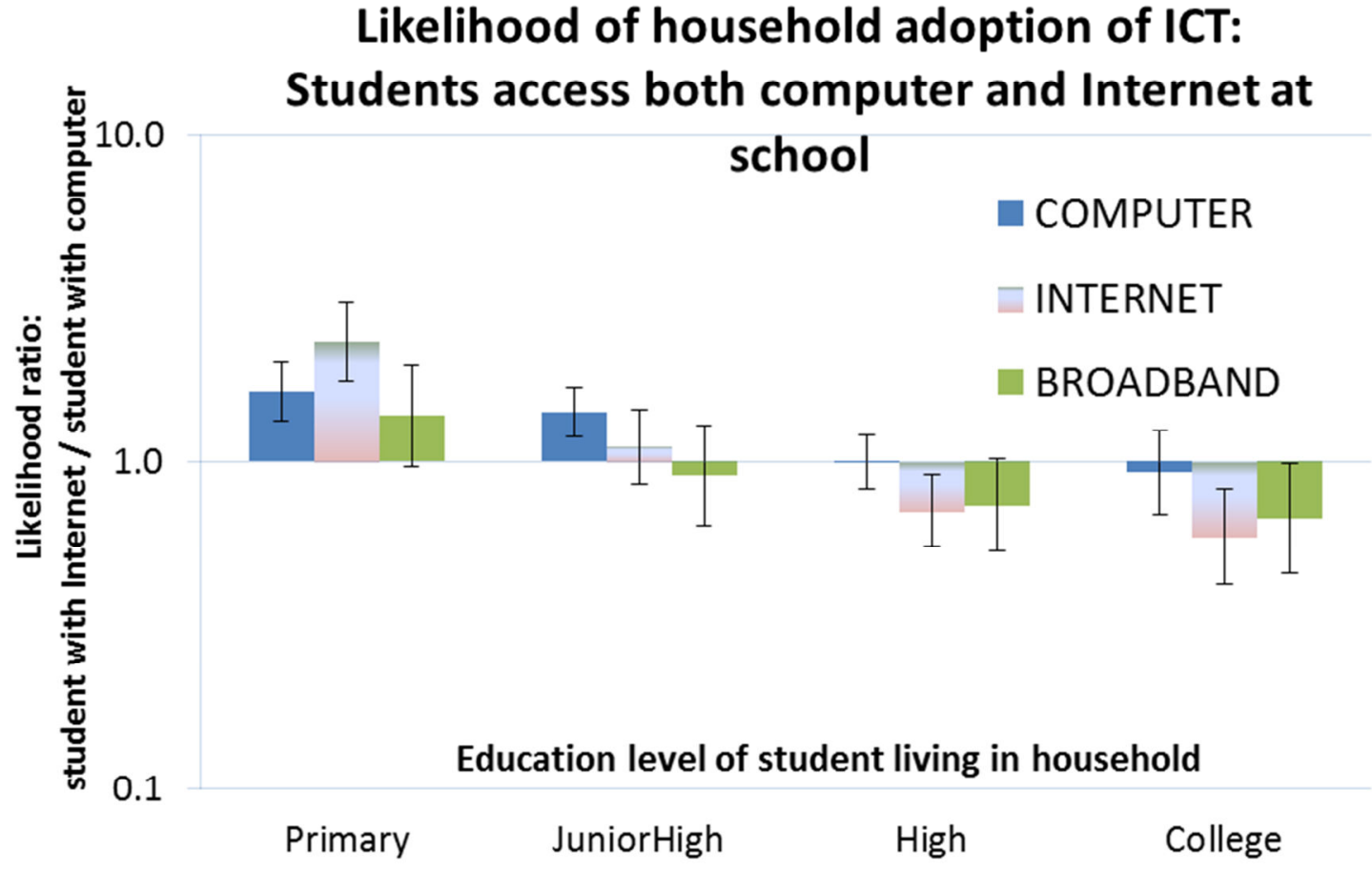


Fig. 8. Thus, there is no evidence that household income alters the relationship between Internet availability in schools and ICT adoption in homes.

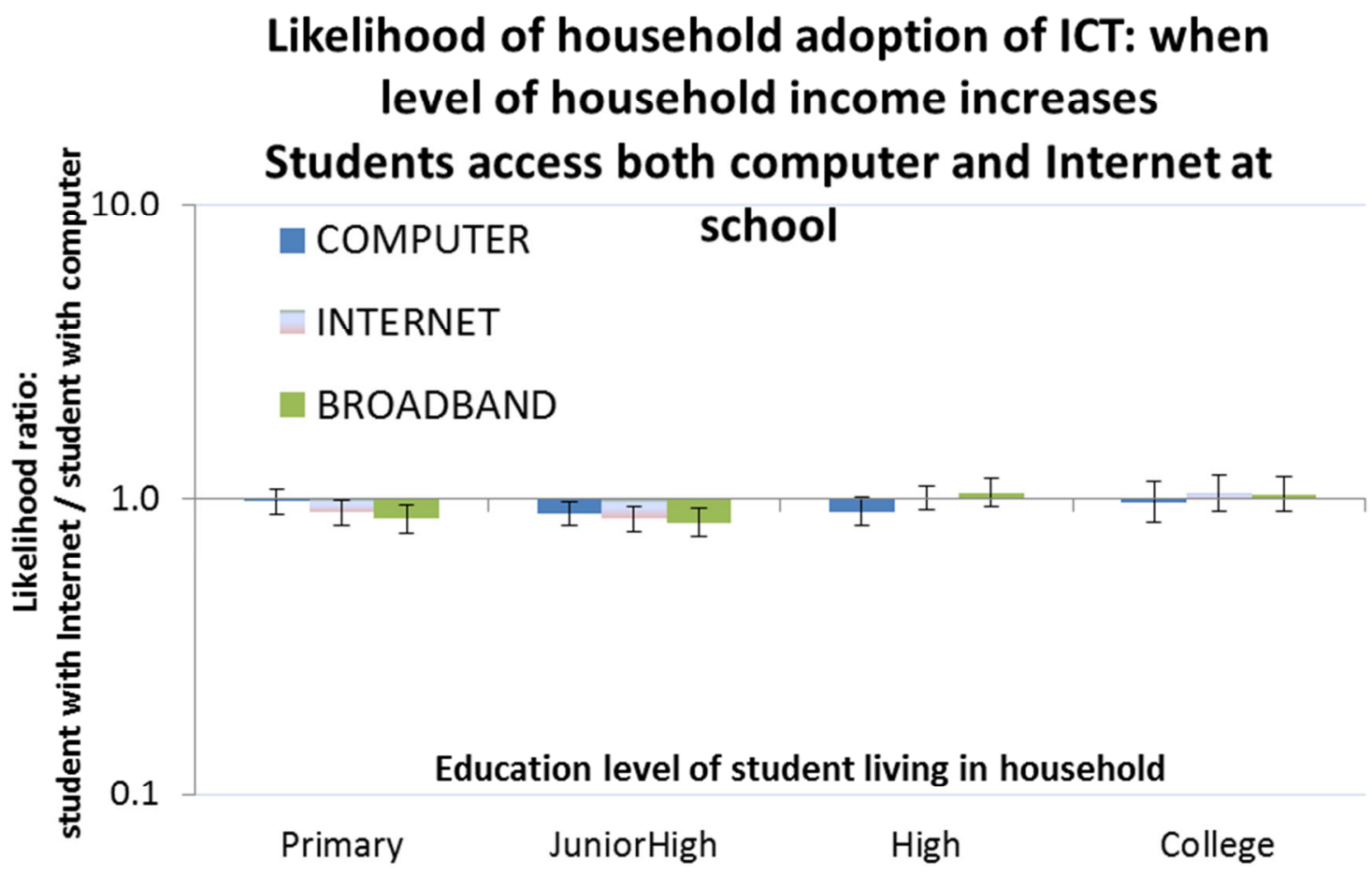

Fig. 11: Likelihood ratio that the effect of Internet in schools on household adoption of ICT (shown in

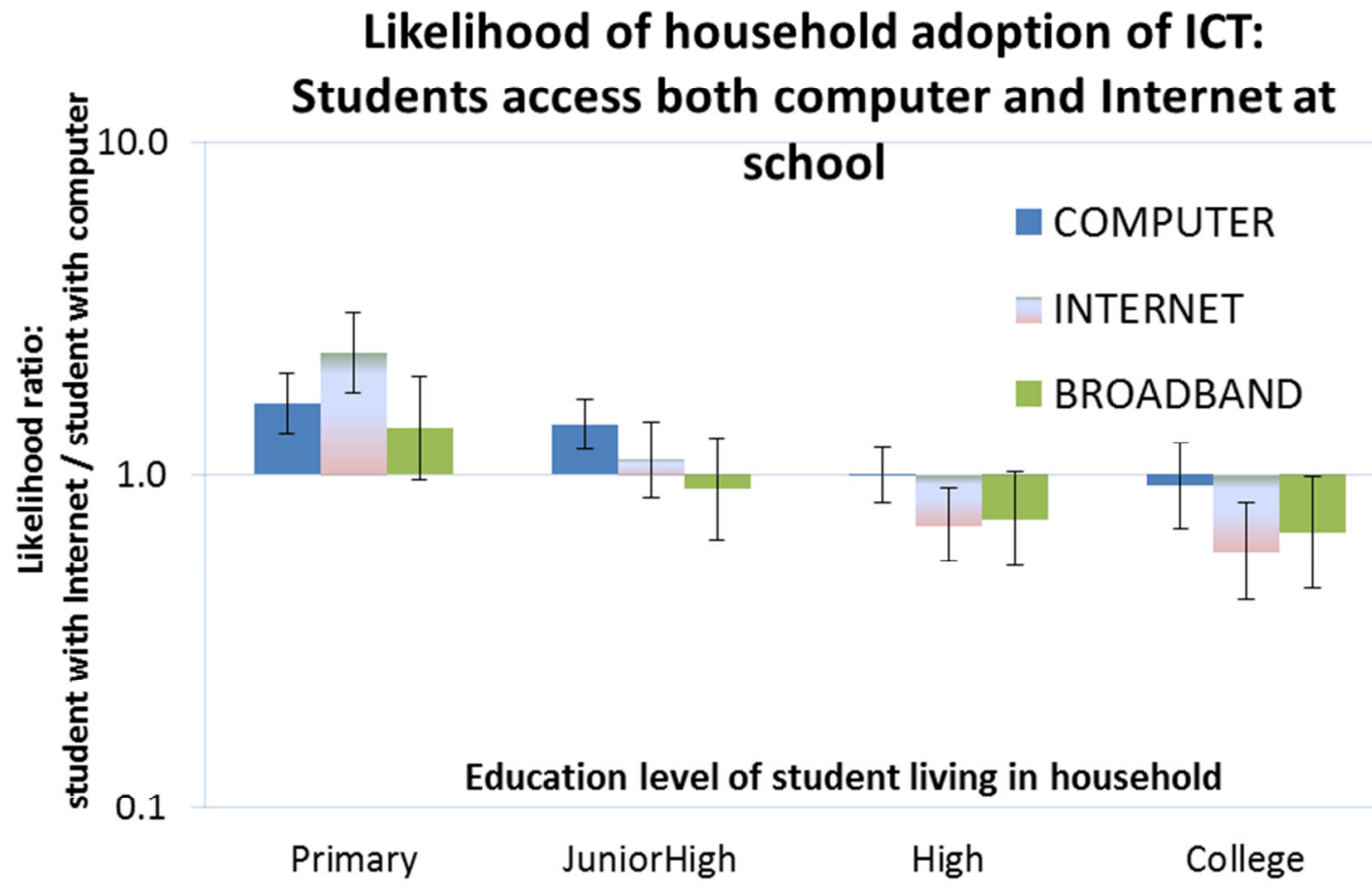

Fig. 8) will change when household income increases. Error bars show the $95 \%$ confidence interval. 
One of the few cases where the spill-over effect of ICT in schools was affected by one of these factors is shown in

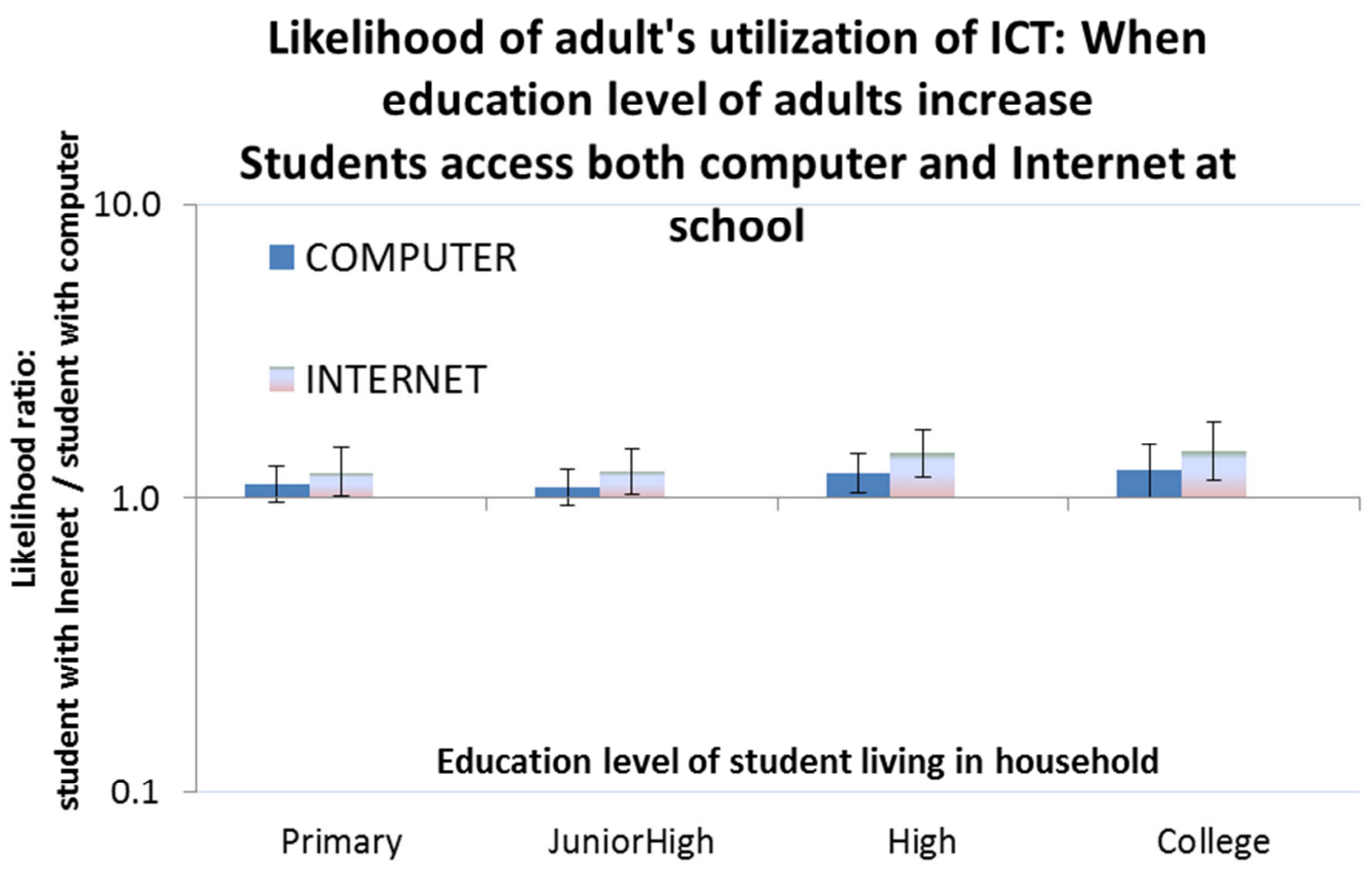

Fig. 12. In particular, the impact of giving a junior high school or high school student access to Internet in schools has a slightly greater impact on ICT utilization by an adult who lives in the same household if that adult has more education. Together with the results from

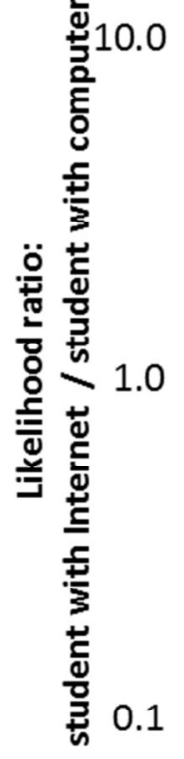

\section{Likelihood of adult's utilization of ICT:} Students access both computer and Internet at school

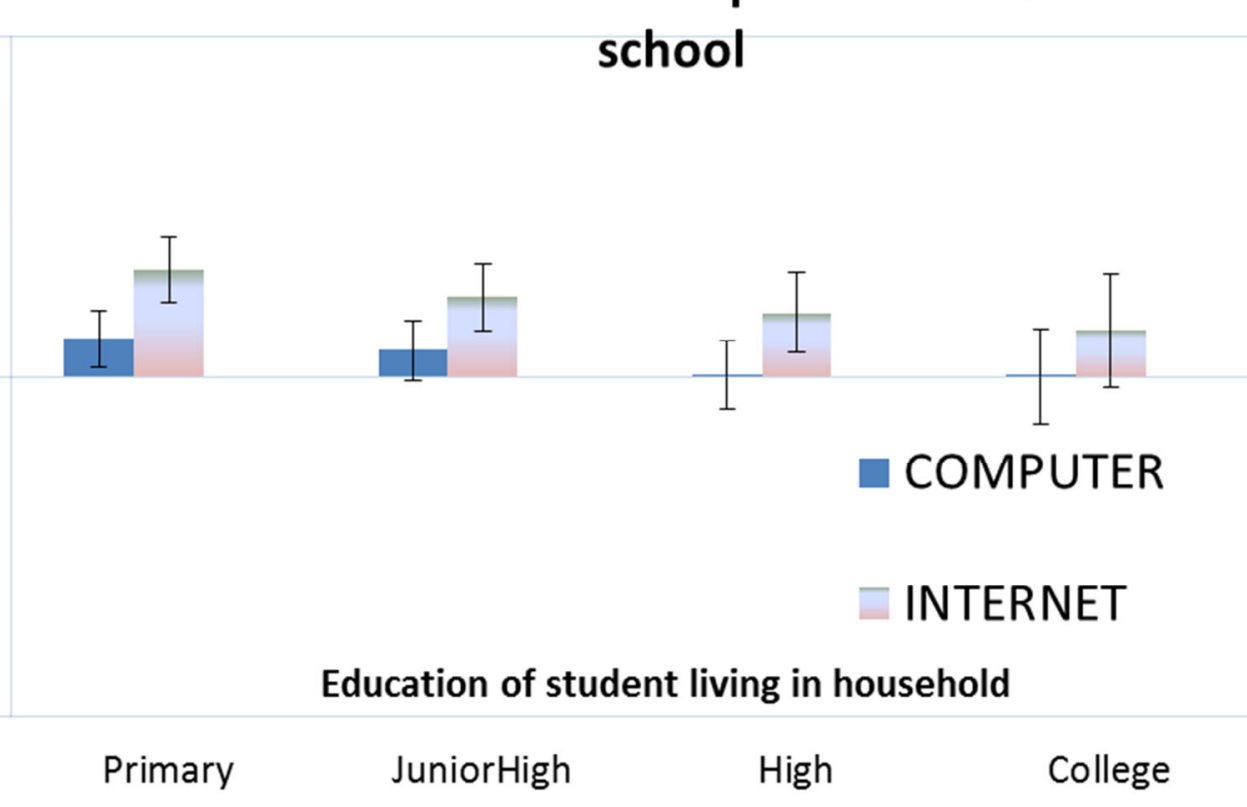


Fig. 10 that Internet in schools positively impacts utilization of ICT by non-student adult family members, this study finds that the effect is somewhat greater when adults have more education. Greater education could imply a greater knowledge of technology, or greater willingness to spend money on ICT as an educational tool.

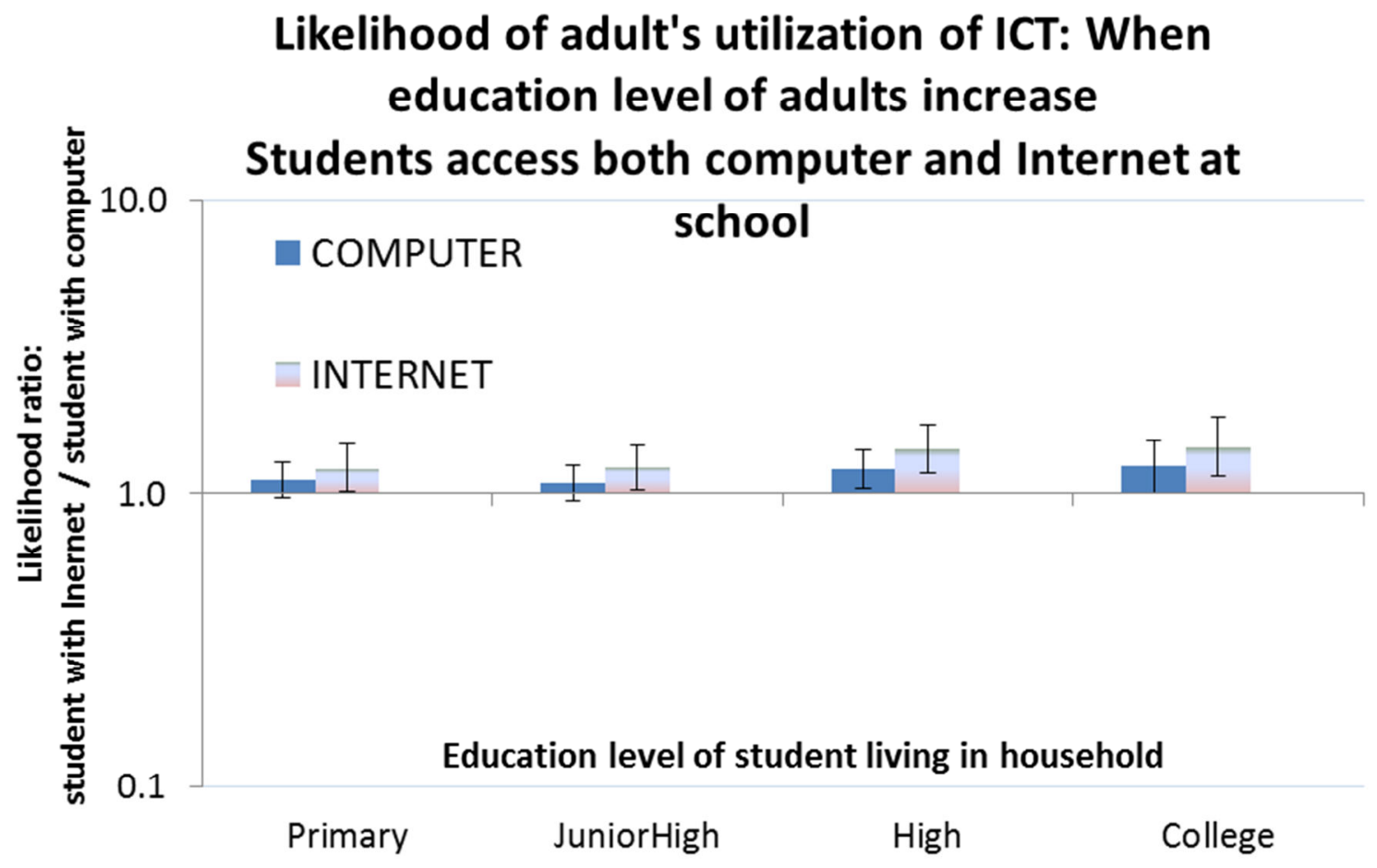


Fig. 12: Likelihood ratio that the effect of Internet in schools on utilization of ICT by adult residents (shown in

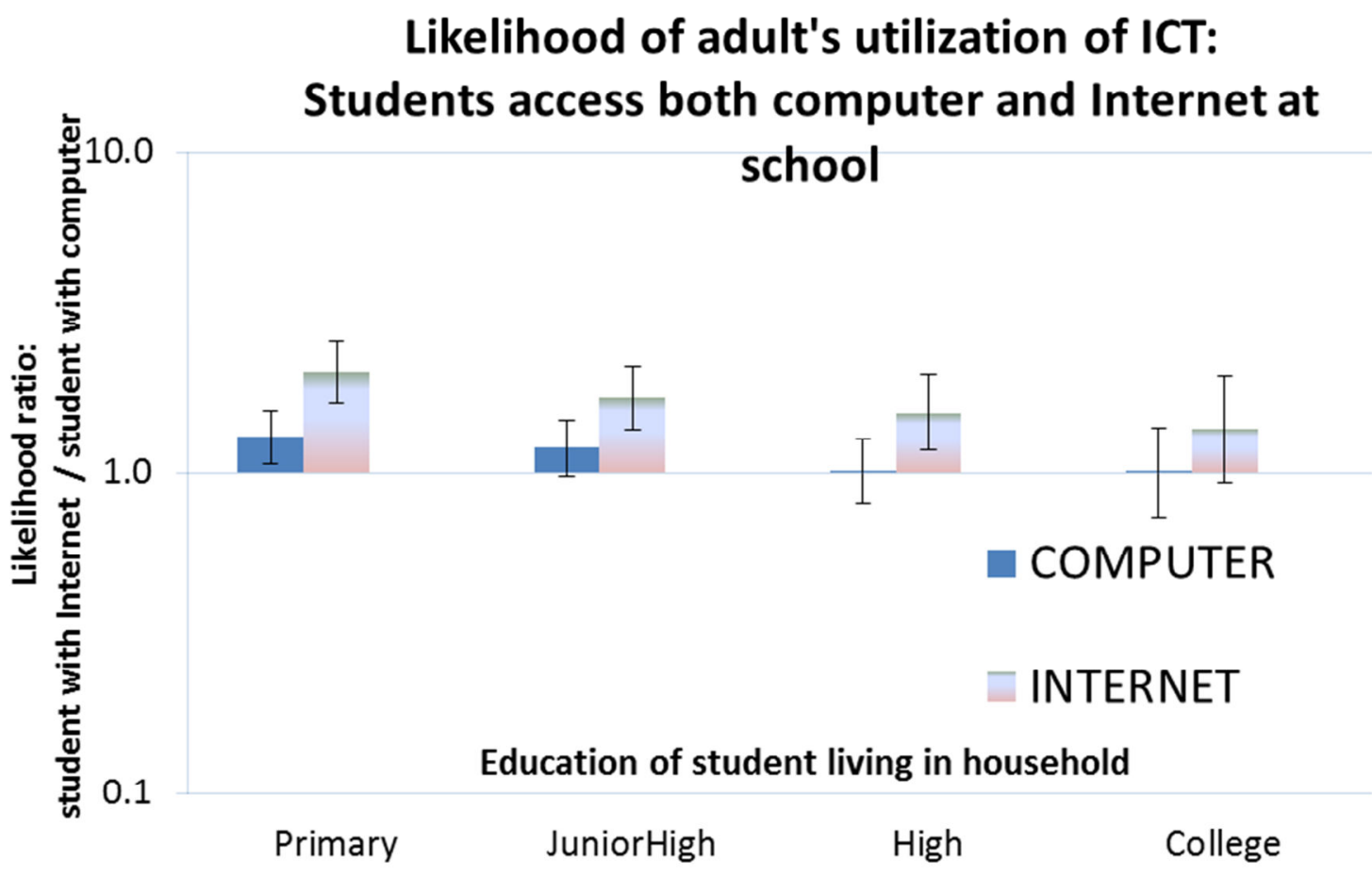

Fig. 10) will change when the adults have higher education. Error bars show the $95 \%$ confidence interval.

Another unusual case where the difference between the interaction variables and 1 was statistically significant, although still modest, occurs with household income. Somewhat surprisingly, the spill-over effects shown in Section 5.1 are slightly stronger in households with lower incomes for students in either high school or college. For example,

\section{Likelihood of household adoption of ICT: when} level of household income increases Students do not access ICT at school

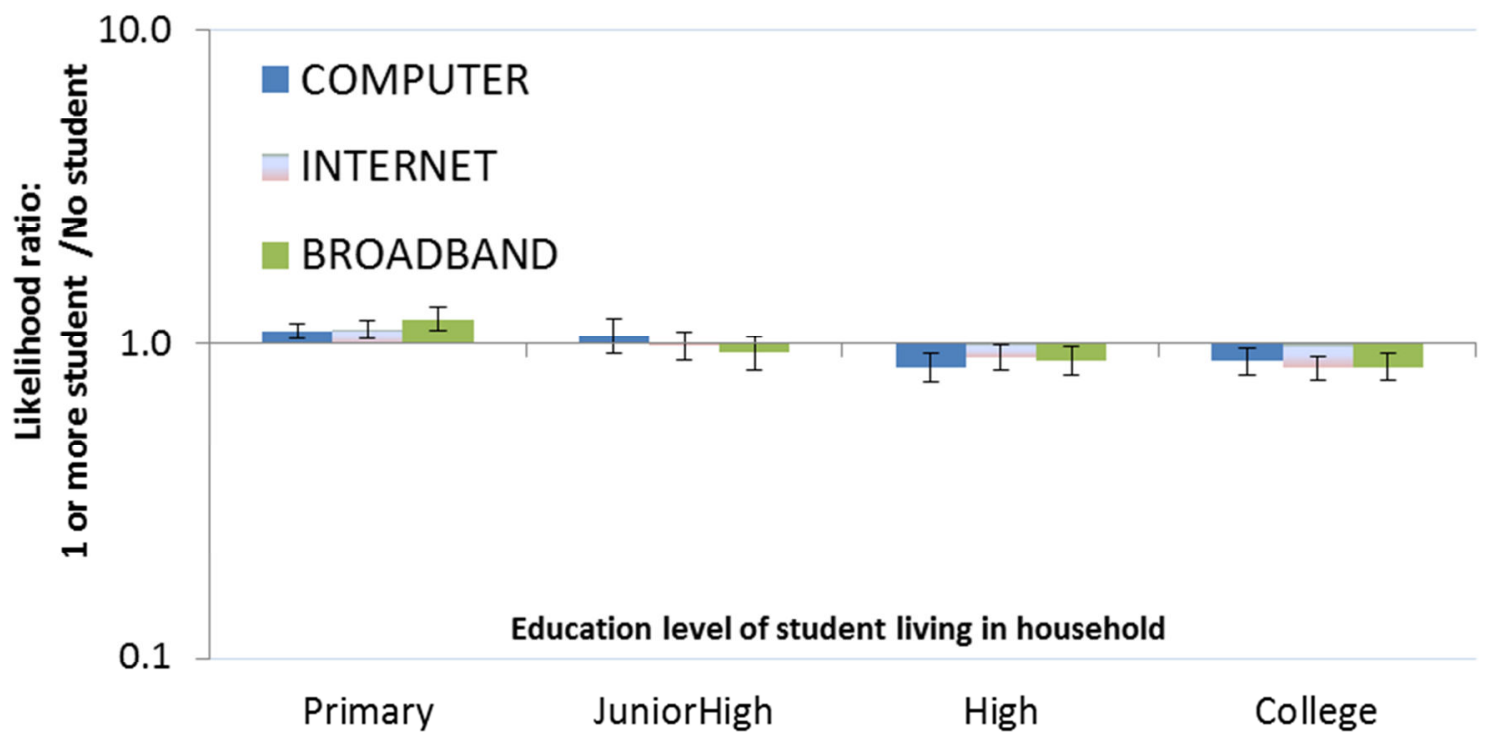


Fig. 13 shows interaction variables when considering residential adoption of ICT. This counterintuitive result may occur because low-income households are less likely to send their children to high school or college in Thailand, whereas primary and junior high school attendance are nearly universal. For example, an individual from a household with the highest level of income is two times as likely to be in school between ages 15 and 18, and five times as likely between ages 19 and 22, as compared to an individual from a household with the lowest level of income (Tengtrakul, 2013). Thus, those households that do choose to send their children to high school and college despite a low income may have traits not captured in the study's basic demographic and geographic data that make them far more inclined to adopt ICT for their school-age children, such as a strong belief in the importance of education.

\section{Likelihood of household adoption of ICT: when level of household income increases Students do not access ICT at school}

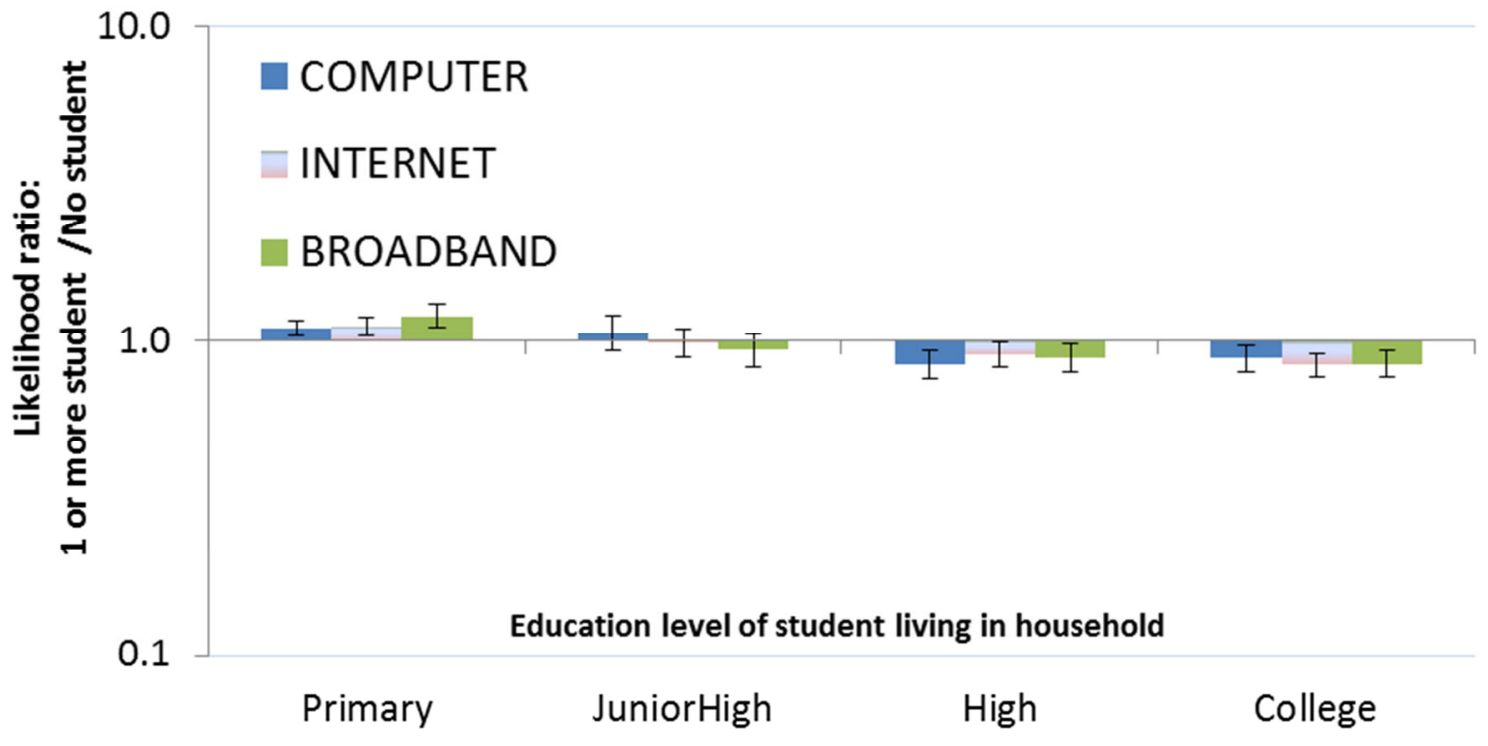

Fig. 13: Likelihood ratio that an effect of student's presence (none of whom use ICT at schools) on household adoption of ICT (shown in 


\section{Likelihood of household adoption of ICT: Students do not access ICT at school}

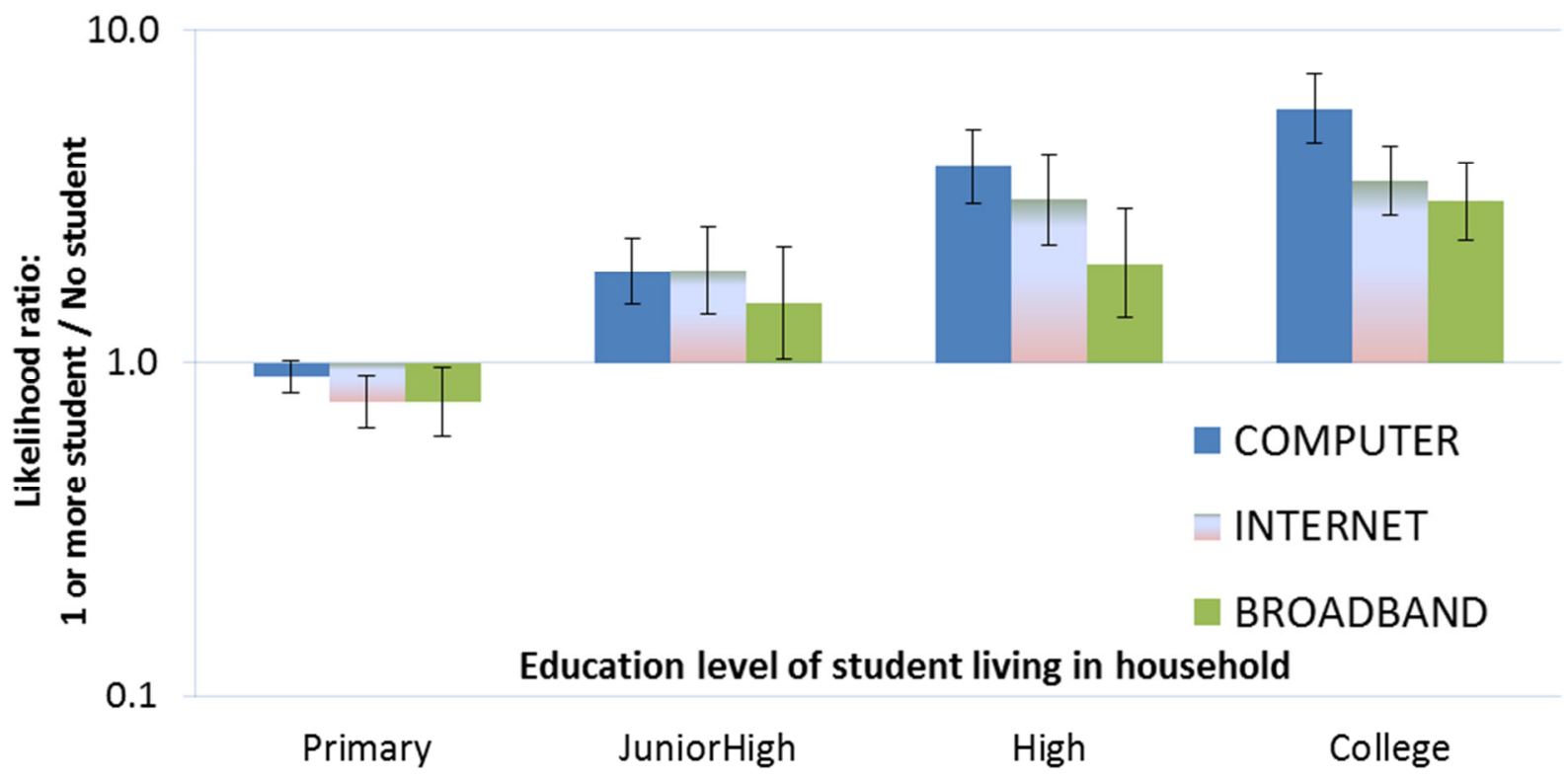

Fig. 4) will change when level of household income increases. Error bars show the $95 \%$ confidence interval.

\subsection{Conclusions and Policy Implications}

Even though computer and Internet adoption in Thailand is not yet common, this study finds results consistent with past studies in developed countries that the presence of students in a household strongly affects both computer and Internet adoption at home, whether students have access to ICT at school or not. It has previously been found that ICT is viewed by parents in developed countries as a useful tool that can provide educational benefit to their offspring (Robertson et al., 2004). This study supports the belief that it is viewed the same by parents in developing countries. The higher the educational level of students, the stronger the increase in likelihood of a household adopting ICT. This may be related to the fact that homework in higher education benefits more from the use of ICT. The presence of additional students at a given educational level does not matter much for ICT adoption in households or utilization of ICT by family members, whether these students have no access to ICT, have access to computers but not the Internet, or have access to both computers and Internet at school. Although household size (or number of children in household) has been found to positively affect residential Internet adoption in the US (Rappoport et al., 2003; Savage \& Waldman, 2005), it may not play the same role in developing countries.

The effects of students on adult utilization of ICT are far less dramatic than the effects on household adoption described above. Putting aside whether students have access to ICT at school, merely living with a K-12 student has very little impact on adult ICT utilization. Putting the adoption and utilization results together, this means that households with students are far more likely to have 
adopted ICT, but the adults in those households are still no more likely to use ICT. Thus, not only is adult utilization relatively unaffected by the presence of students, but it is also relatively unaffected by the presence of ICT in the adult's own home. Thus, there is a sizable portion of the adult population for which neither cost nor convenience is important to their decision to use computers and Internet. It may be that these adults do not use ICT because of lack the ICT knowledge or literacy (Warschauer, 2003; Gelb, Maru, Brodgen, Dodsworth, Samii, \& Pesce, 2008), or perhaps because they are not aware of enough useful online content or services in a language they know (Kabamba, 2008). Thus, policy-makers seeking to increase Internet penetration should look for other approaches in addition to just the traditional policies that make ICT less expensive or more accessible.

Results show that placing ICT in schools does have a spill-over effect outside schools. This effect is strongest when that ICT includes Internet as well as computer access. The effect differs greatly depending on the grade level of the student. Generally, the spill-over effects are positive with respect to both household ICT adoption and utilization of ICT by family members. As a result, policies that aim to increase student ICT competency by putting ICT in school can also indirectly benefit penetration of ICT in the community as well. However in one particular case, the effects can also be modestly negative, as previously discussed in Kuziemko (2011). More specifically, putting Internet access into high schools is inversely related to Internet adoption at home, which would seem to imply a small substitution effect. In such cases, parents may decide not to adopt ICT at home once their kids can use ICT at school, thereby reducing residential penetration.

These results can help policy-makers decrease the digital divide. Given the finding that deploying ICT in schools has spill-over effects outside schools, policy-makers should allocate even more resources for ICT in schools than are justified based on the direct educational benefits to students alone. Considering spill-over effects when allocating resources should lead to greater welfare gains for the public for the amount of resources spent, which is especially important in developing regions where government resources can be scarce. Moreover, because computer vendors and Internet service providers also profit from spill-over effects, it may be in the interest of these commercial companies to assist schools with the cost of ICT deployment or operation, perhaps focusing on primary school where the effect is greatest.

Also, policy-makers should look for other approaches to increase ICT adoption beyond traditional policies that make ICT less expensive or more accessible, because there is a sizable portion of the adult population that choose not to adopt ICT even after any barriers caused by cost and convenience are eliminated. Literacy and skills required for computer and Internet use are also important for the effective use of ICT (Warschauer 2003). A policy that increases ICT literacy and skills, such as the creation of public ICT training courses, should be considered. Given that the policy to put ICT in schools is already in place, schools could be used as community training centers for ICT.

Besides the policy implications, there are theoretical implications regarding information sharing among family members. While research typically focuses on transfer from parents to kids, these results show what might be transmission of knowledge that kids learn in school to parents. Although this study can only show that adults are more likely to use ICT if they live with children who learn about ICT in 
school, without observing how these adults learned to use ICT, a likely possibility is that adults learn from their children. Especially in developing countries where children often have more total years in schools than their parents, the transmission of knowledge or skills from children to adults should not be ignored (Kuziemko, 2011). Even in regions where parents and kids receive equivalent formal education, children often invest more in learning new technology (Gardner, 2007). The transmission of knowledge or skills from children to adults can then play an important role in adoption of technology.

Regardless of how these adults learn about ICT, a number of common theories may explain their motivation, such as theories associated with innovation diffusion and network externalities. Innovation diffusion theory would predict that the decision to adopt an innovation depends heavily on the decisions of others in one's social group (Rogers, 2003), and peer-to-peer communications is very influential (Mahajan, Muller, \& Bass, 1990), including in the adoption of new technology (Jang, Dai, \& Sung, 2005). Similarly, as kids who access ICT in school communicate with their parents, this peer-topeer communication may accelerate the diffusion of ICT by reducing parents' perceived uncertainties or increasing parents' perceived utility of ICT. Through this communication channel, giving kids access to ICT in school can play an important role in ICT diffusion within a household. Moreover, the theory of network externalities would predict that more adults would want to adopt ICT as others with whom they would communicate adopt ICT (Liebowitz \& Margolis, 1994). In this case, parents may have greater reason to use ICT when it can be used to communicate with their kids, or their kids' teachers. 


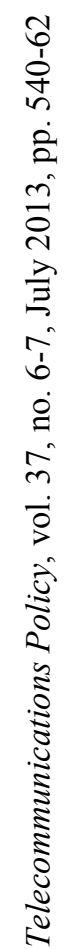

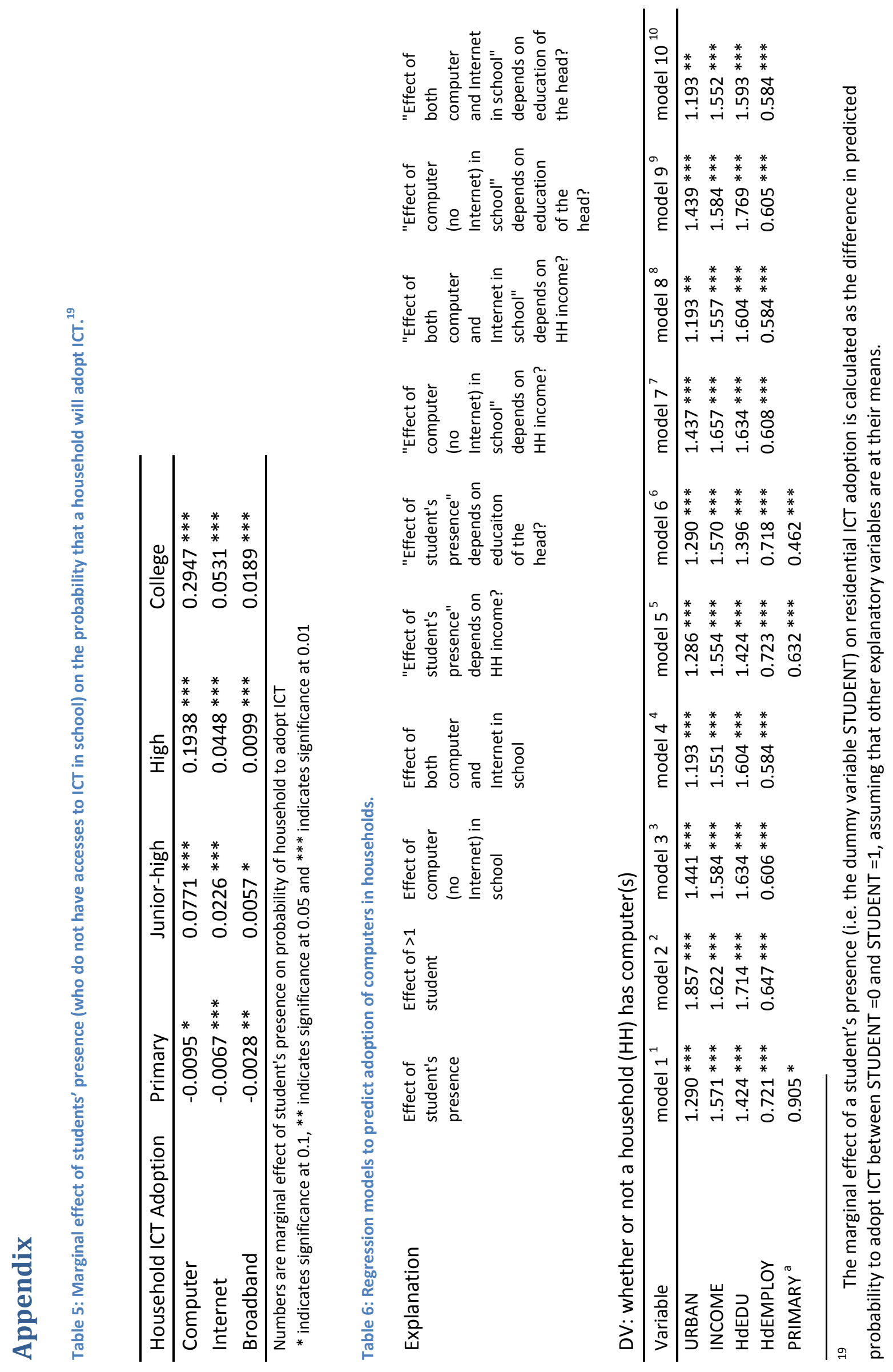




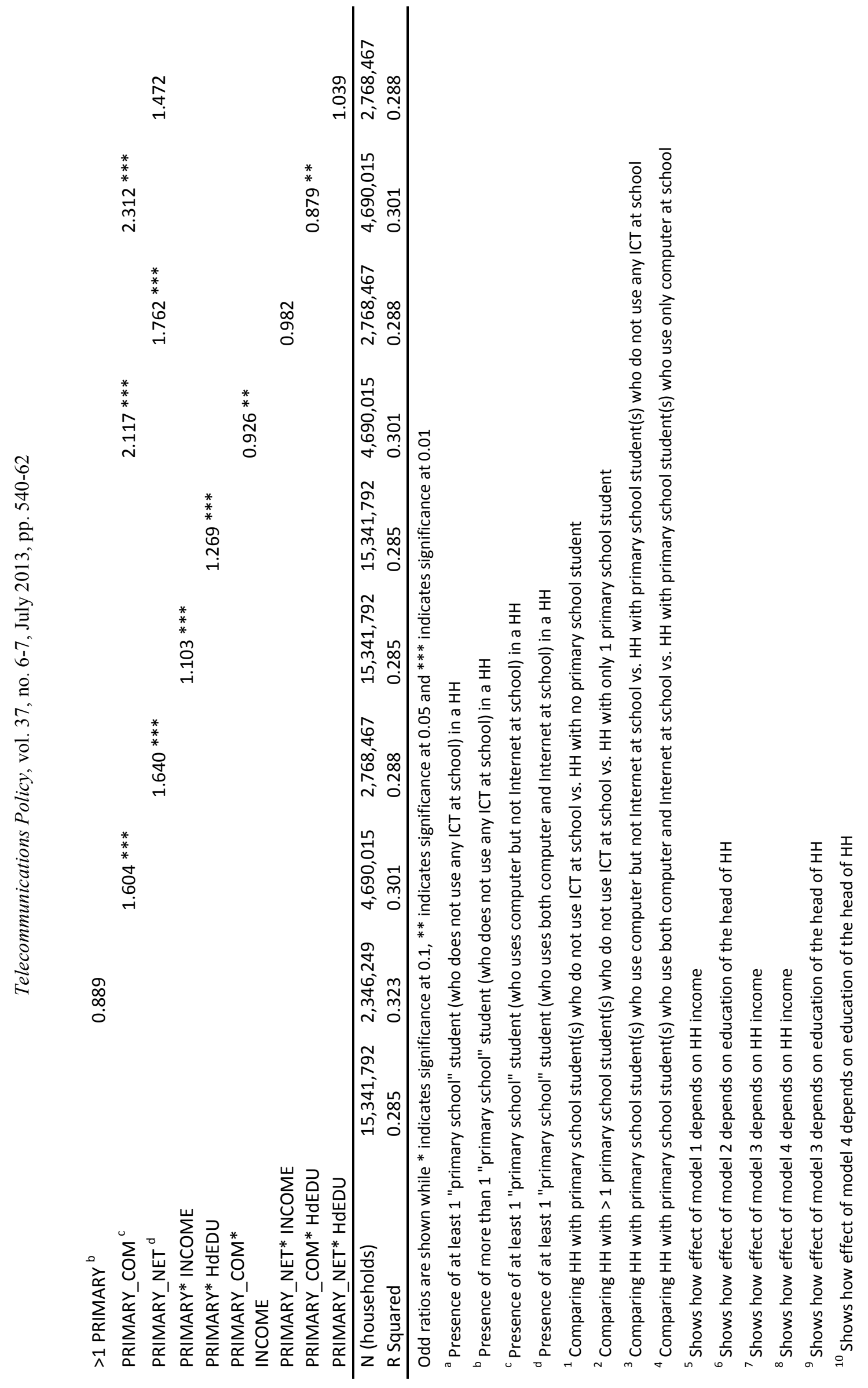




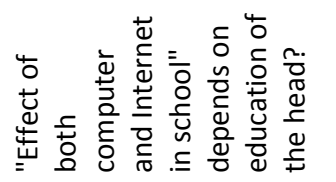

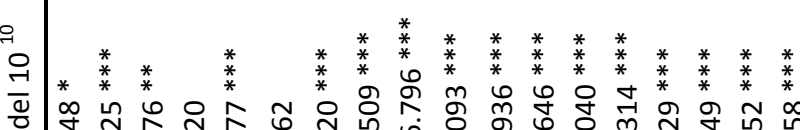

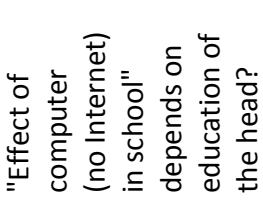

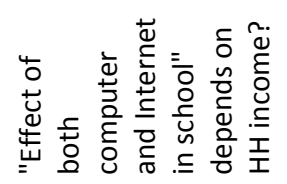

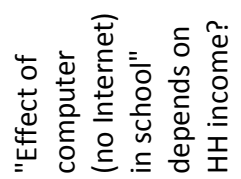

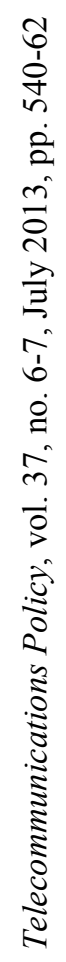
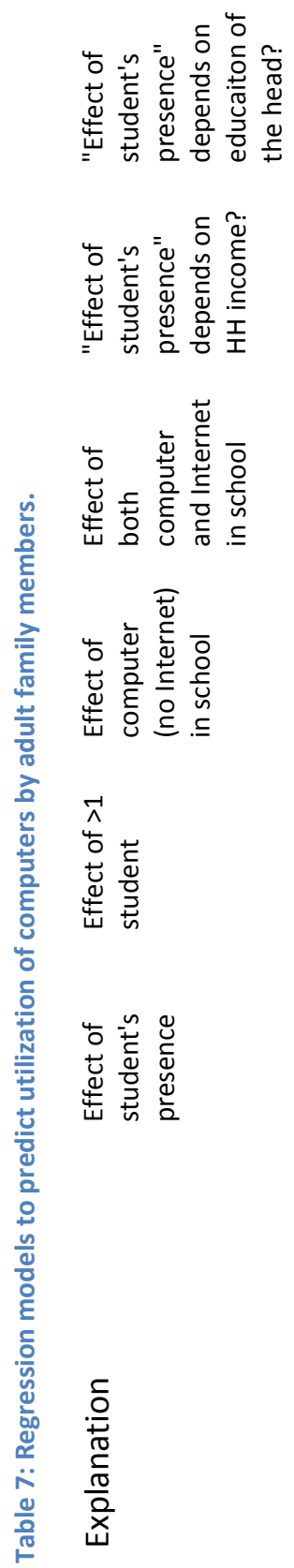

|

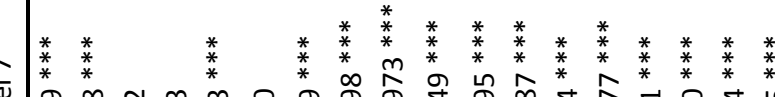

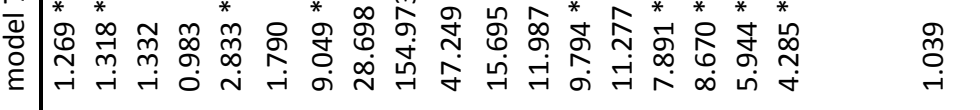

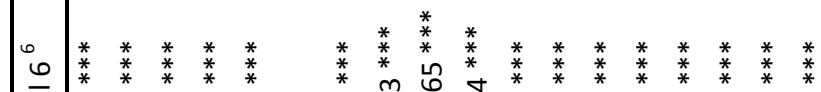

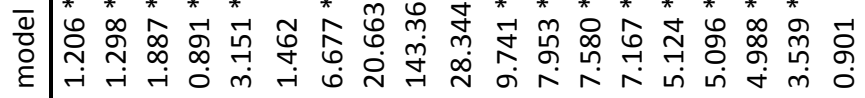

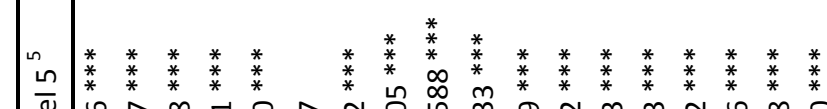

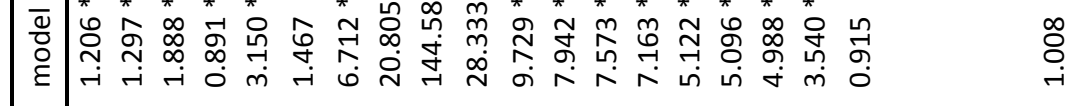

$\dot{9}$

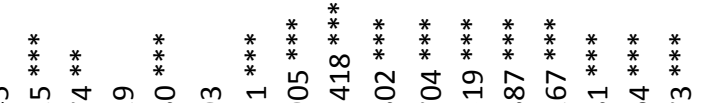

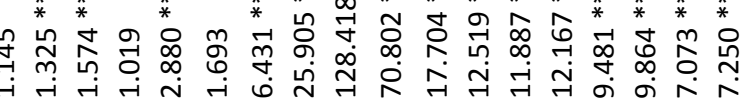

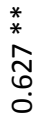

$\stackrel{n}{\sim}$

$\infty$
$\infty$
$\infty$
0

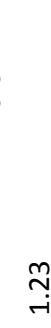



i

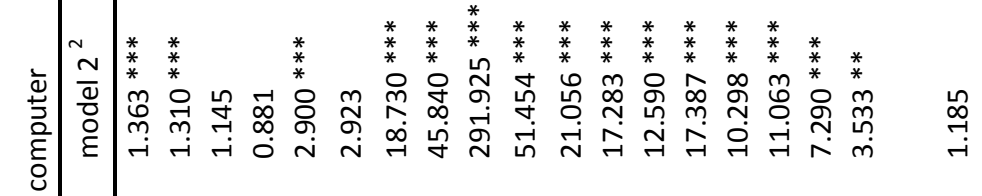

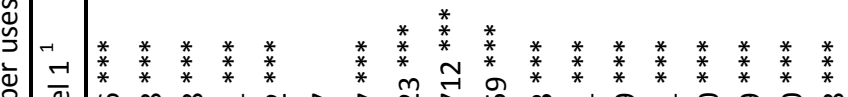

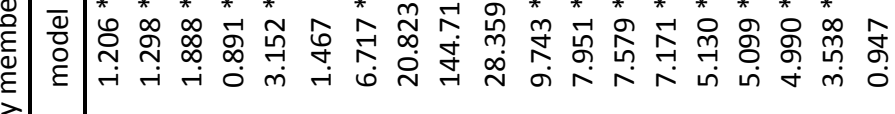

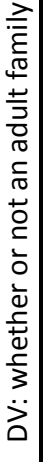

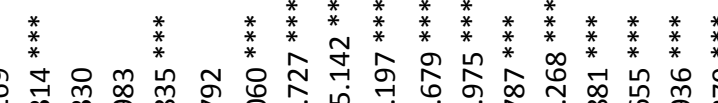

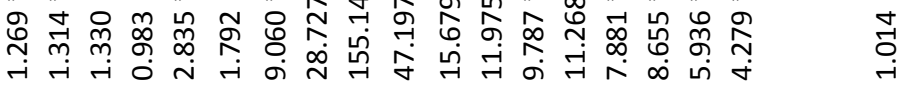




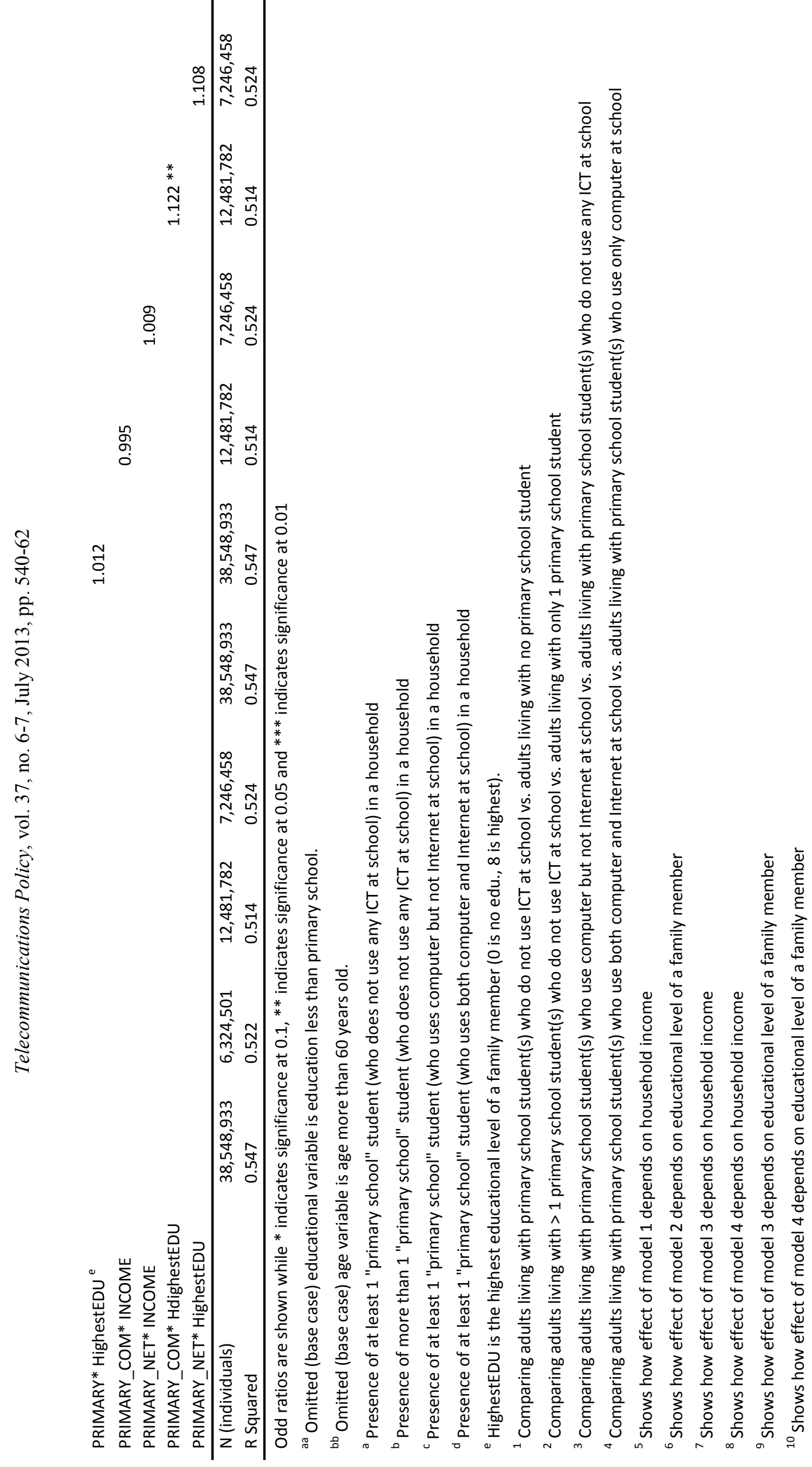


Table 8: Correlation matrix of variables in an analysis of ICT adoption in households.

\begin{tabular}{llllllll} 
Variables & $(1)$ & $(2)$ & $(3)$ & $(4)$ & $(5)$ & $(6)$ & $(7)$ \\
\hline (1) COMPUTER & 1.00 & & & & & & \\
(2) INTERNET & 0.62 & 1.00 & & & & & \\
(3) BB & 0.47 & 0.75 & 1.00 & & & & \\
(4) URBAN & 0.23 & 0.24 & 0.22 & 1.00 & & & \\
(5) INCOME & 0.52 & 0.47 & 0.40 & 0.35 & 1.00 & & \\
(6) HdEDU & 0.41 & 0.37 & 0.31 & 0.30 & 0.51 & 1.00 & \\
(7) HdEMPLOY & 0.00 & -0.01 & -0.01 & -0.04 & 0.06 & 0.14 & 1.00
\end{tabular}

Coefficients of correlation are shown. All coefficients are statistically significant at 0.01

Table 9: Correlation matrix of variables in an analysis of utilization of ICT by adult family members.

\begin{tabular}{llllllllll} 
Variables & $(1)$ & $(2)$ & $(3)$ & $(4)$ & $(5)$ & $(6)$ & $(7)$ & $(8)$ & (9) \\
\hline (1) COM USER & 1.00 & & & & & & & & \\
(2) NET USER & 0.78 & 1.00 & & & & & & \\
(3) URBAN & 0.22 & 0.20 & 1.00 & & & & & \\
(4) INCOME & 0.45 & 0.41 & 0.38 & 1.00 & & & & \\
(5) EMPLOY & 0.11 & 0.08 & -0.05 & 0.03 & 1.00 & & & \\
(6) MALE & 0.00 & 0.00 & -0.02 & -0.01 & 0.19 & 1.00 & & \\
(7) MOBILE USER & 0.31 & 0.26 & 0.19 & 0.31 & 0.21 & 0.07 & 1.00 & \\
(8) EDU & 0.64 & 0.56 & 0.26 & 0.50 & 0.14 & 0.04 & 0.41 & 1.00 & \\
(9) AGE & -0.19 & -0.15 & -0.01 & -0.07 & -0.35 & -0.05 & -0.27 & -0.33 & 1.00
\end{tabular}

Coefficients of correlation are shown. All coefficients are statistically significant at 0.01

Table 10: Descriptive statistics of variables in an analysis of ICT adoption in households based on status of ICT access in school.

\begin{tabular}{lllllll} 
& \multicolumn{2}{l}{ Group A $^{\mathrm{a}}$} & \multicolumn{2}{l}{ Group B $^{\mathrm{b}}$} & \multicolumn{2}{l}{ Group C $^{\mathrm{c}}$} \\
\cline { 2 - 7 } Variables & mean & std.dev. & mean & std.dev. & mean & std.dev. \\
\hline COMPUTER & 0.18 & 0.38 & 0.26 & 0.44 & 0.32 & 0.47 \\
INTERNET & 0.07 & 0.26 & 0.10 & 0.31 & 0.13 & 0.34 \\
BB & 0.04 & 0.20 & 0.06 & 0.23 & 0.07 & 0.25 \\
URBAN & 0.23 & 0.42 & 0.29 & 0.45 & 0.32 & 0.47 \\
INCOME & 2.78 & 2.03 & 3.02 & 2.15 & 3.18 & 2.25 \\
HdEDU & 2.40 & 1.26 & 2.54 & 1.32 & 2.62 & 1.36 \\
HdEMPLOY & 0.83 & 0.38 & 0.83 & 0.38 & 0.82 & 0.39
\end{tabular}




\begin{tabular}{|c|c|c|c|}
\hline N (households) & $3,304,175$ & $6,413,282$ & $2,970,408$ \\
\hline \multicolumn{4}{|c|}{${ }^{\mathrm{a}} \mathrm{HH}$ that have students who do not access ICT in school } \\
\hline \multicolumn{4}{|c|}{${ }^{\mathrm{b}} \mathrm{HH}$ that have students who access only computers and not Internet in school } \\
\hline
\end{tabular}

Table 11: Descriptive statistics of variables in an analysis of utilization of ICT by adult family members based on status of ICT access in school.

\begin{tabular}{lllllll} 
& \multicolumn{2}{l}{ Group A $^{\mathrm{a}}$} & \multicolumn{2}{l}{ Group B $^{\mathrm{b}}$} & \multicolumn{2}{l}{ Group C $^{\mathrm{c}}$} \\
\cline { 2 - 7 } Variables & mean & std.dev. & mean & std.dev. & mean & std.dev. \\
\hline COM USER & 0.10 & 0.29 & 0.12 & 0.32 & 0.14 & 0.34 \\
NET USER & 0.05 & 0.23 & 0.07 & 0.26 & 0.10 & 0.29 \\
URBAN & 0.23 & 0.42 & 0.29 & 0.45 & 0.32 & 0.46 \\
INCOME & 3.02 & 2.13 & 3.28 & 2.24 & 3.50 & 2.37 \\
EMPLOY & 0.83 & 0.37 & 0.83 & 0.37 & 0.84 & 0.37 \\
MALE & 0.48 & 0.50 & 0.47 & 0.50 & 0.47 & 0.50 \\
MOBILE USER & 0.48 & 0.50 & 0.53 & 0.50 & 0.54 & 0.50 \\
EDU: ${ }^{\text {aa }}$ PRIM & 0.62 & 0.49 & 0.61 & 0.49 & 0.60 & 0.49 \\
JUNI & 0.13 & 0.34 & 0.13 & 0.33 & 0.12 & 0.33 \\
HIGH & 0.10 & 0.30 & 0.11 & 0.31 & 0.11 & 0.31 \\
COLL & 0.08 & 0.28 & 0.11 & 0.31 & 0.13 & 0.33 \\
AGE: ${ }^{\text {bb }}$ 15- 19 & 0.03 & 0.18 & 0.03 & 0.17 & 0.03 & 0.16 \\
20- 24 & 0.07 & 0.26 & 0.06 & 0.24 & 0.07 & 0.25 \\
25- 29 & 0.10 & 0.30 & 0.06 & 0.24 & 0.05 & 0.22 \\
30- 34 & 0.15 & 0.36 & 0.10 & 0.31 & 0.07 & 0.26 \\
35- 39 & 0.16 & 0.37 & 0.17 & 0.38 & 0.15 & 0.36 \\
40- 44 & 0.13 & 0.34 & 0.18 & 0.38 & 0.20 & 0.40 \\
45- 49 & 0.09 & 0.29 & 0.13 & 0.33 & 0.15 & 0.36 \\
50- 54 & 0.07 & 0.25 & 0.08 & 0.27 & 0.09 & 0.29 \\
55- 59 & 0.06 & 0.24 & 0.06 & 0.23 & 0.05 & 0.23 \\
\hline N (individuals) & $8,702,444$ & $15,965,795$ & $7,079,218$ \\
\hline
\end{tabular}

${ }^{\text {aa }}$ Omitted (base case) educational variable is education less than primary school.

${ }^{b b}$ Omitted (base case) age variable is age more than 60 years old.

${ }^{a}$ Adults living with students who do not access ICT in school

${ }^{\mathrm{b}}$ Adults living with students who access only computers and not Internet in school

${ }^{c}$ Adults living with students who access both computers and Internet in school

Table 12: Characteristics of adults living in households that are predicted to have computer only because they have students.

\begin{tabular}{lllll}
\hline Adults with computer @ home & $\mathrm{N}$ & $\%$ & Edu. (Iv.) & Age (year) \\
\hline Adults not use computer & $2,506,172$ & 71 & 2.78 & 48.70 \\
Adults use computer & $1,044,762$ & 29 & 4.80 & 36.51 \\
\hline Total adults & $3,550,934$ & 100 & 3.25 & 43.99 \\
\hline
\end{tabular}


Table 13: Likelihood ratio that a household will adopt ICT when the household has one or more students, none of whom use ICT at school, at the given educational level (as shown in

\section{Likelihood of household adoption of ICT: Students do not access ICT at school}

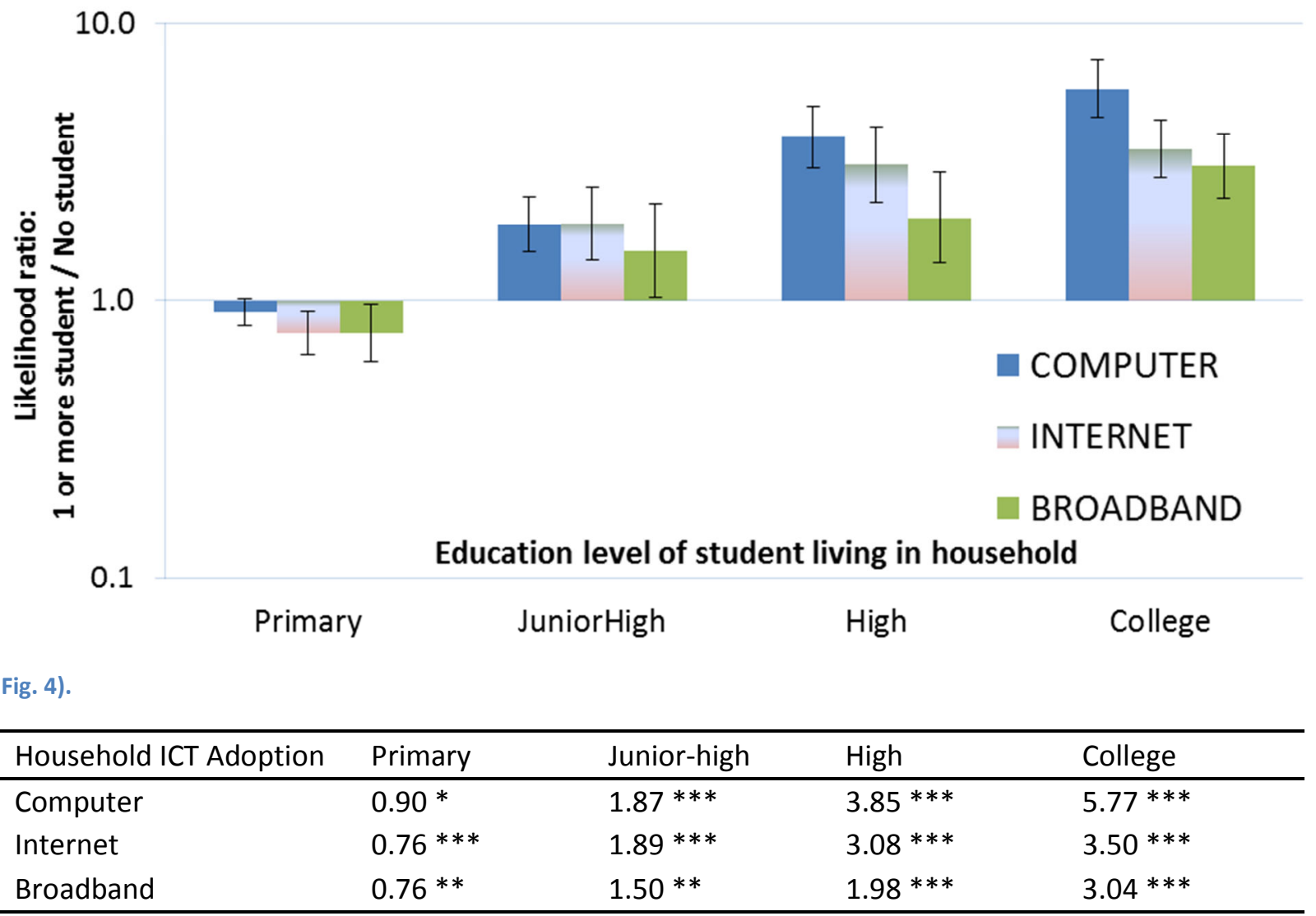

$*$ indicates significance at $0.1, * *$ indicates significance at 0.05 and $* * *$ indicates significance at 0.01 
Table 14: Likelihood ratio that an adult will use ICT when living with one or more students, none of whom use ICT at school, at the given educational level (as shown in

\section{Likelihood of adult's utilization of ICT:} Students do not access ICT at school

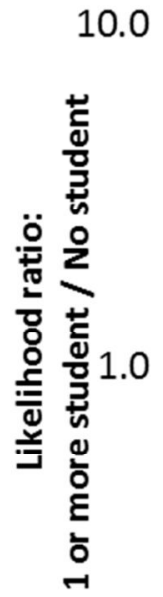

0.1

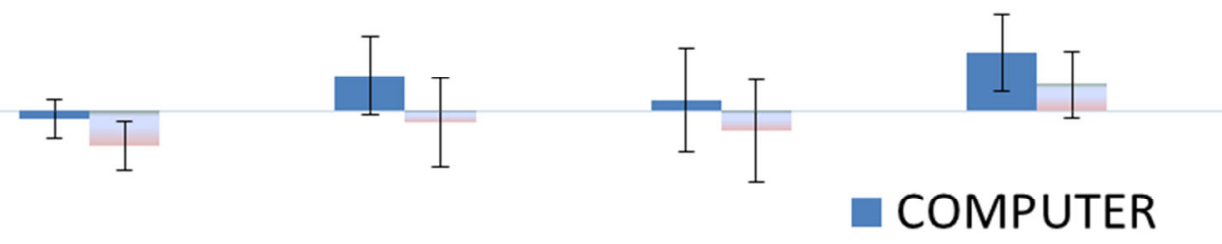

INTERNET

Education of student living in household

High

College

Fig. 5).

\begin{tabular}{lllll}
\hline Utilization of ICT by adults & Primary & Junior-high & High & College \\
\hline Computer & 0.95 & $1.27^{*}$ & 1.07 & $1.48^{* * *}$ \\
Internet & $0.79^{* * *}$ & 0.93 & 0.88 & 1.19 \\
\hline
\end{tabular}

${ }^{*}$ indicates significance at $0.1,{ }^{* *}$ indicates significance at 0.05 and ${ }^{* * *}$ indicates significance at 0.01 
Table 15: Likelihood ratio that a household will adopt ICT when the household has more than 1 student at the given educational level (as shown in

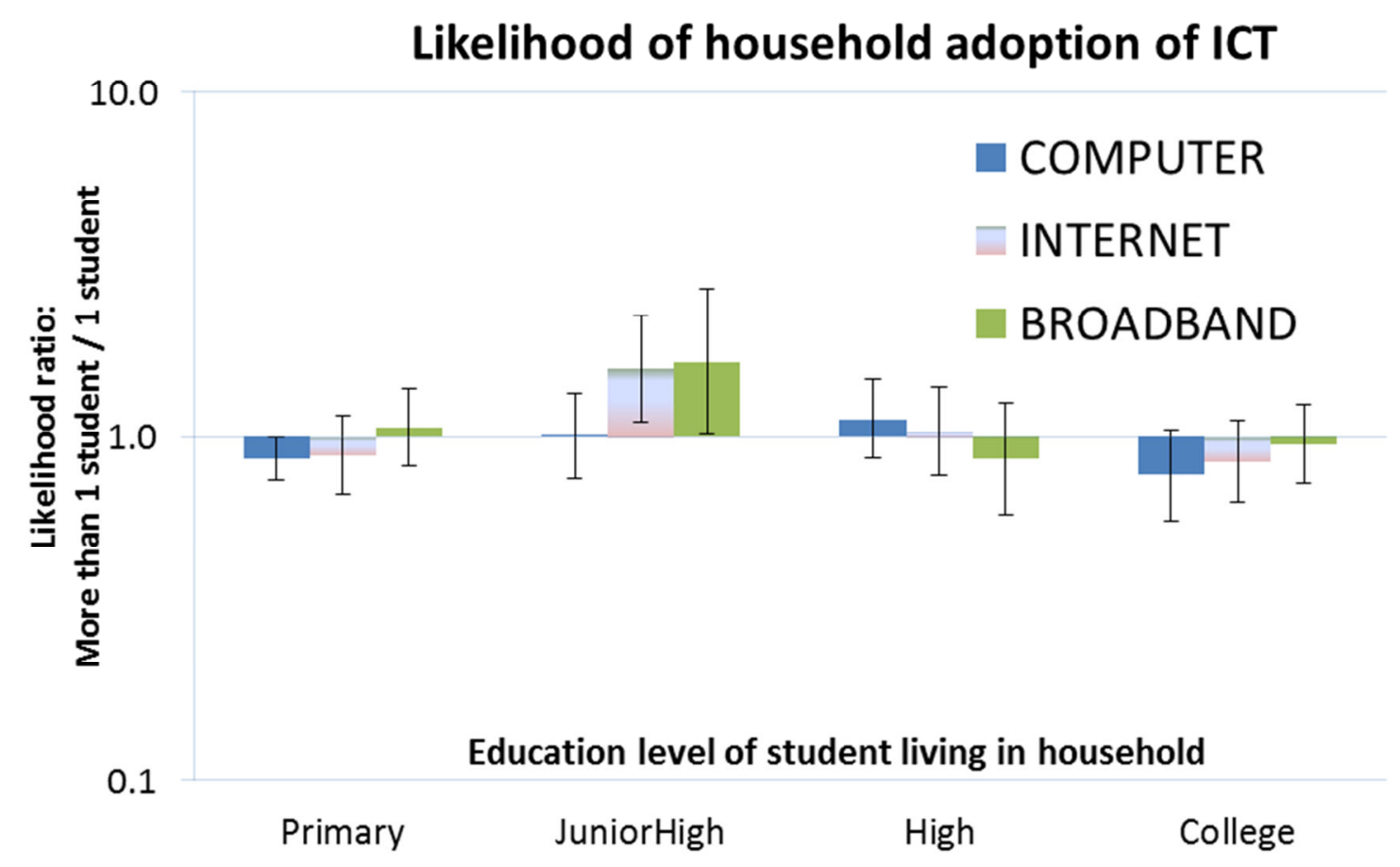

Fig. 6).

\begin{tabular}{lllll}
\hline Household ICT Adoption & Primary & Junior-high & High & College \\
\hline Computer & $0.86^{* *}$ & 1.01 & 1.13 & $0.78^{*}$ \\
Internet & 0.89 & $1.58^{* * *}$ & 1.04 & 0.85 \\
Broadband & 1.07 & $1.65^{* *}$ & 0.87 & 0.95 \\
\hline
\end{tabular}

* indicates significance at $0.1,{ }^{* *}$ indicates significance at 0.05 and $* * *$ indicates significance at 0.01 
Table 16: Likelihood ratios that a household will adopt ICT when there are computers (no Internet) in the kids' school (as

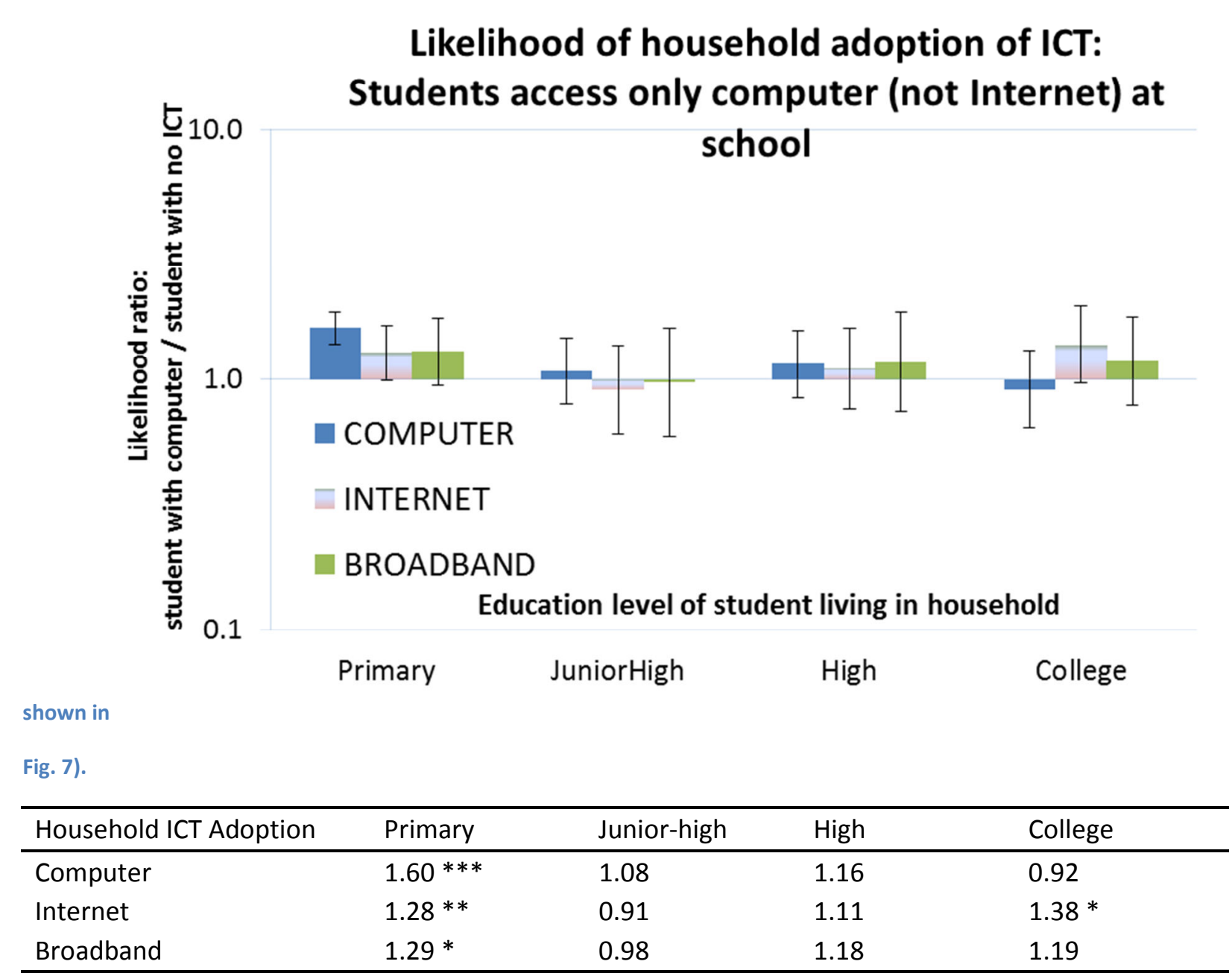

* indicates significance at $0.1, * *$ indicates significance at 0.05 and $* * *$ indicates significance at 0.01 
Table 17: Likelihood ratios that a household will adopt ICT when there are both computers and Internet in the kids' school (as shown in

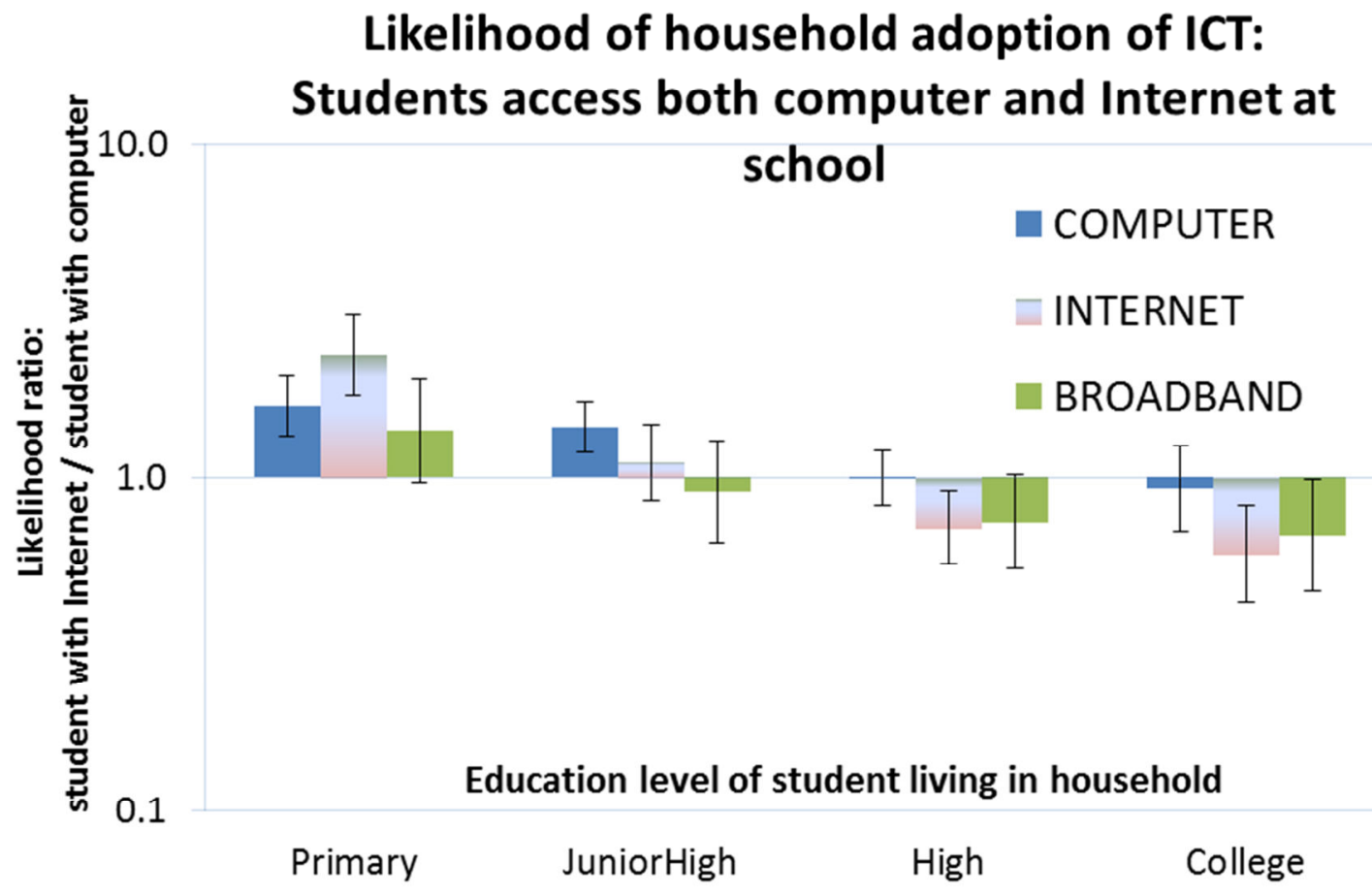

Fig. 8).

\begin{tabular}{lllll}
\hline Household ICT Adoption & Primary & Junior-high & High & College \\
\hline Computer & $1.64^{* * *}$ & $1.42^{* * *}$ & 0.99 & 0.93 \\
Internet & $2.33^{* * *}$ & 1.11 & $0.71^{* * *}$ & $0.59^{* * *}$ \\
Broadband & $1.38^{*}$ & 0.91 & $0.74^{*}$ & $0.67^{* *}$ \\
\hline
\end{tabular}

$*$ indicates significance at $0.1, * *$ indicates significance at 0.05 and $* * *$ indicates significance at 0.01

Table 18: Likelihood ratios that an adult will use ICT when there are computers (no Internet) in the kids' school (as shown in Fig. 9).

\begin{tabular}{lllll}
\hline Utilization of ICT by adults & Primary & Junior-high & High & College \\
\hline Computer & 1.01 & 0.82 & 1.22 & 0.93 \\
Internet & 0.99 & 0.87 & 0.87 & 0.82 \\
\hline
\end{tabular}

$*$ indicates significance at $0.1, * *$ indicates significance at 0.05 and $* * *$ indicates significance at 0.01 
Table 19: Likelihood ratios that an adult will use ICT when there are both computers and Internet in the kids' school (as

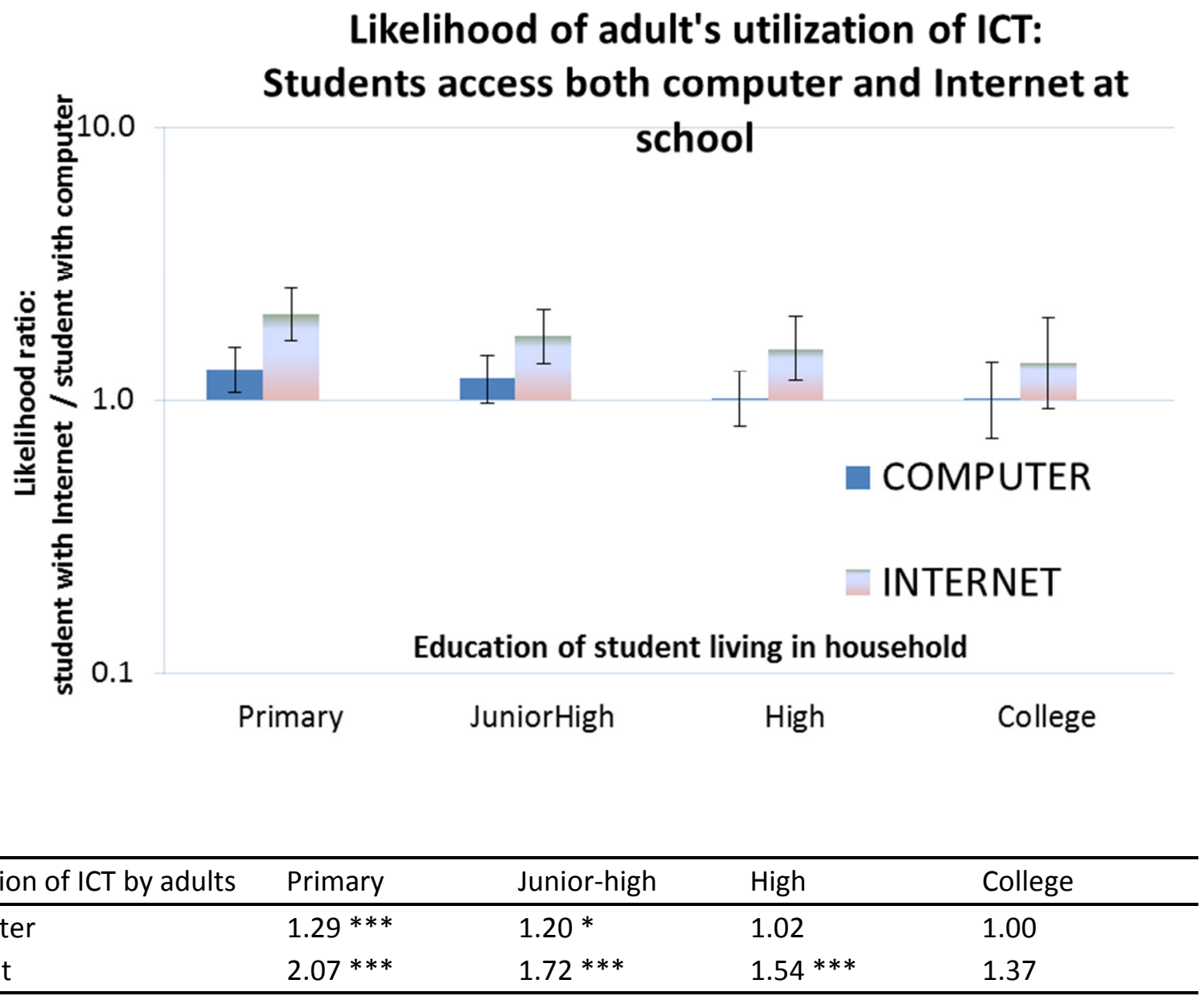

$*$ indicates significance at $0.1, * *$ indicates significance at 0.05 and $* * *$ indicates significance at 0.01 
Table 20: Likelihood ratio that the effect of Internet in schools on household adoption of ICT will change when household income increases (as shown in

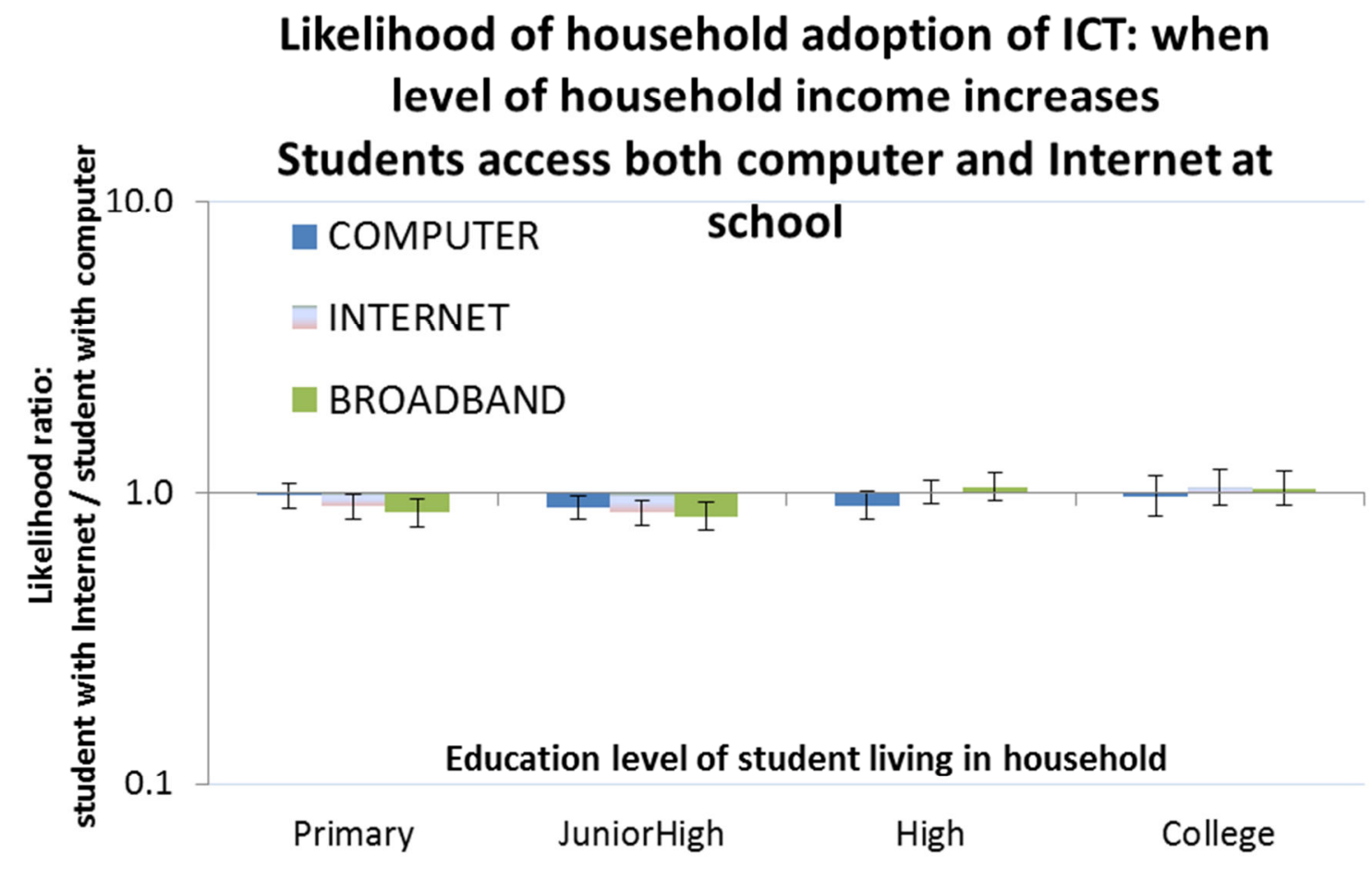

Fig. 11).

\begin{tabular}{lllll}
\hline Household ICT Adoption & Primary & Junior-high & High & College \\
\hline Computer & 0.98 & $0.89^{* *}$ & $0.91^{*}$ & 0.98 \\
Internet & $0.90^{* *}$ & $0.86^{* * *}$ & 1.01 & 1.05 \\
Broadband & $0.86^{* * *}$ & $0.84^{* * *}$ & 1.05 & 1.04 \\
\hline
\end{tabular}

* indicates significance at $0.1,{ }^{* *}$ indicates significance at 0.05 and $* * *$ indicates significance at 0.01 
Table 21: Likelihood ratio that the effect of Internet in schools on utilization of ICT by adult residents will change when the adults have higher education (as shown in

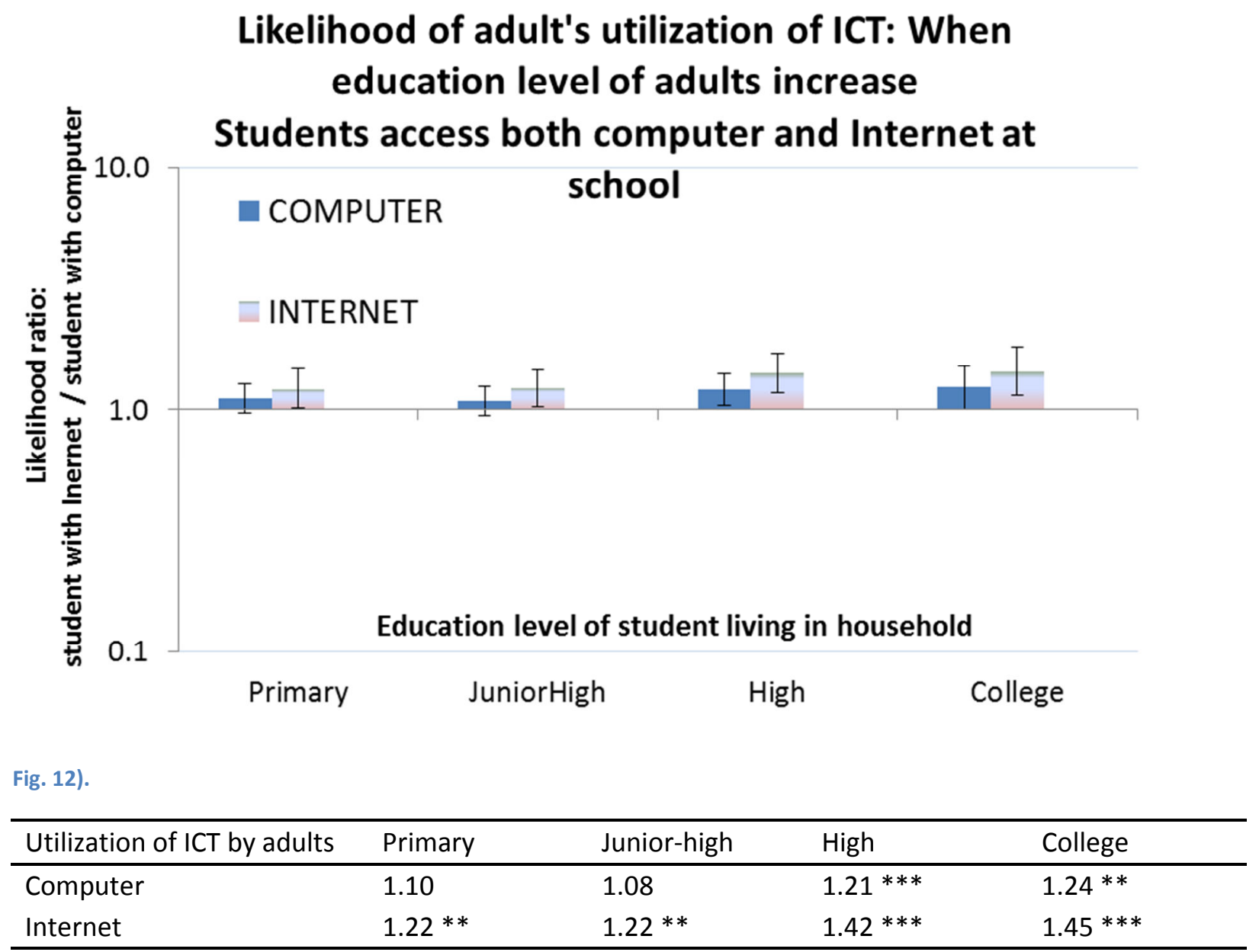

$*$ indicates significance at $0.1,{ }^{* *}$ indicates significance at 0.05 and $* * *$ indicates significance at 0.01 
Table 22: Likelihood ratio that the effect of students' presence (none of whom use ICT at schools) on household adoption of ICT will change when level of household income increases (as shown in

\section{Likelihood of household adoption of ICT: when level of household income increases Students do not access ICT at school}

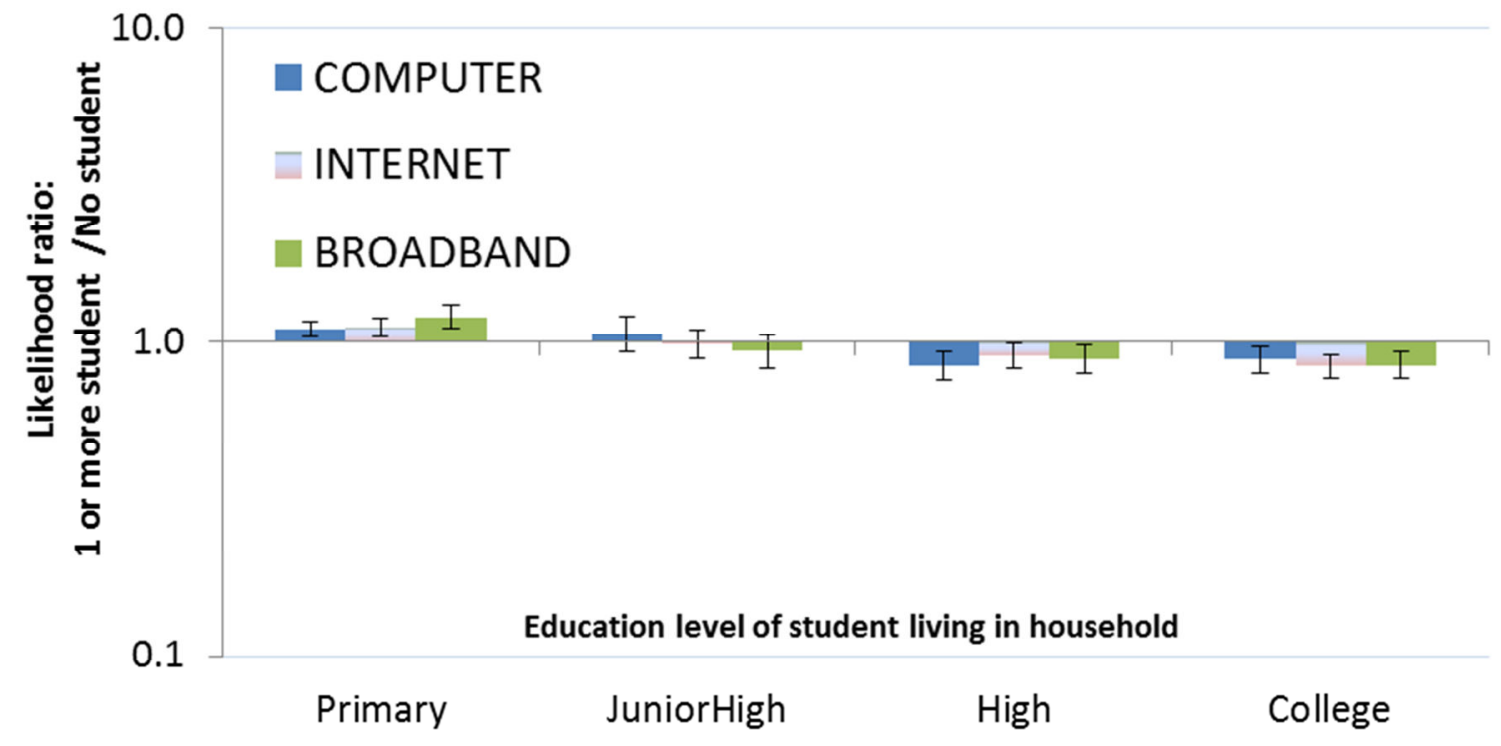

Fig. 13)

\begin{tabular}{lllll}
\hline Household ICT Adoption & Primary & Junior-high & High & College \\
\hline Computer & $1.10^{* * *}$ & 1.07 & $0.84^{* * *}$ & $0.88^{* *}$ \\
Internet & $1.11^{* * *}$ & 0.999 & $0.90^{* *}$ & $0.84^{* * *}$ \\
Broadband & $1.20^{* * *}$ & 0.93 & $0.89^{* *}$ & $0.84^{* * *}$ \\
\hline
\end{tabular}

* indicates significance at $0.1,{ }^{* *}$ indicates significance at 0.05 and $* * *$ indicates significance at 0.01 


\section{References}

Agyapong, P. \& Ferreira, P. (2009). Spillover effects from wiring schools with broadband: Implications for universal service policy. "In:" Proceeding of the $37^{\text {th }}$ Telecommunications Policy Research Conference, Arlington, VA, September 2009. Retrieved from <http://papers.ssrn.com/sol3/Delivery.cfm/SSRN_ID2004029_code1743069.pdf?abstractid=200 4029\&mirid=1>.

Berniell, L., Mata, D., \& Valdes, N. (2010). Spillovers of health education at school on parents' physical activity. Universidad Carlos III De Madrid working papers, 10-31. Retrieved from < http://orff.uc3m.es/bitstream/10016/9706/1/we1031.pdf>.

Black, S. E., Devereux, P. J., \& Salvanes, K. G. (2005). Why the apple doesn't fall far: Understanding intergenerational transmission of human capital. American Economic Review, 95(1), 437-449.

Chen, W. \& Wellman, B. (2004). The global digital divide - Within and between countries. IT \& Society, 1(7), 39-45.

Dehejia, R. H., \& Wahba, S. (2002). Propensity score-matching methods for nonexperimental causal studies. The Review of Economics and Statistics, 84(1), 151-161.

Gardner, M. (2007, May 24). Parents turn to kids for tech support. USA Today. Retrieved from < http://www.usatoday.com/tech/news/2007-05-24-kids-tech-support_N.htm>.

Gelb, E., Maru, A., Brodgen, J., Dodsworth, E., Samii, R., \& Pesce, V. (2008). Adoption of ICT enabled information systems for agricultural development and rural viability. "In:" Proceeding of The Global Forum on Agricultural Research, Atsugi, Japan, August 2008. Retrieved from <http://www.fao.org/docs/eims/upload/258775/Workshop_Summary_final.pdf>.

Gorand, S., \& Selwyn, N. (2005). Towards a learning society? The impact of technology on pattern of participation in lifelong learning. British Journal of Sociology of Education, 26(1), 71-89.

Grazzi, M. \& Vergara, S. (2008). What drives ICT diffusion in developing countries? Evidence from Paraguay. "In:" Proceeding of the Latin American and Caribbean Economic Association, Rio de Janeiro, November 2008. Retrieved from < http://www.webmeets.com/files/papers/LACEALAMES/2008/170/Grazzi_Vergara_27agosto.pdf>.

Haddon, L. (2003). Domestication and mobile telephony. In Katz, J., Machines that become us: The social context of personal communication technology. New Jersey: Transaction, 43-56.

Haddon, L. \& Silverstone, R. (1996). Information and Communication Technologies and the Young Elderly. SPRU/CICT Report Series, 13. Falmer, U.K.: University of Sussex.

Hanson, M. H., Hurwitz, W. N., \& Madow, W. G. (1993). Sample survey methods and theory volume II. New York: John Wiley \& Son.

Henderson, A. T. \& Mapp, K. L. (2002). A new wave of evidence: The impact of school, family, and community connections on student achievement. Texas: National Center for Family \& Community Connections with Schools. Retrieved from $<$ www.sedl.org/connections/resources/evidence.pdf $>$.

Holloway, S. \& Valentine, G. (2003). Cyberkids: Children in the information age. London: Routledge. Horrigan, J. B. (2009). Home Broadband Adoption. Pew Internet \& American Life Project. Retrieved from $<$ http://www.pewinternet.org/ /media//Files/Reports/2009/Home-Broadband-Adoption2009.pdf>. 
Hosmer \& Lemeshow (2000). Applied Logistic Regression. New York: John Wiley \& Sons.

Jang, S., Dai, S., \& Sung, S. (2005). The pattern and externality effect of diffusion of mobile telecommunications: the case of the OECD and Taiwan. Information Economics and Policy, 17(2), 133-148.

Kabamba, J. M. (2008). Globalization a disservice to human development in Africa: the impact of ICT. "In:" Proceeding of the $74^{\text {th }}$ World library and information congress, Canada, August 2008. Retrieved from < http://citeseerx.ist.psu.edu/viewdoc/download?doi=10.1.1.150.9957\&rep=rep1\&type=pdf >.

Kleinbaum, D. G., Kupper, L. L., Nizam, A., \& Muller, K. E. (2007). Applied regression analysis and other multivariable methods. California: Duxbury Press.

Kovacic, Z. J. \& Vukmirovic, D. (2008). ICT adoption and the digital divide in Serbia: Factors and policy implications. "In:" Proceeding of the Informing Science \& IT Education Conference, Bulgaria, June 2008. Retrieved from <http://proceedings.informingscience.org/InSITE2008/InSITE08p363387Kova540.pdf>.

Kraut, R., Mukhopadhyay, T., Szczypula, J., Kiesler, S., \& Scherlis, B. (1999). Information and communication: Alternative uses of the Internet in households. Information Systems Research, 10(4), 287-303.

Kuziemko, I. (2011). Human capital spillovers in families: Do parents learn from or lean on their children? Working paper of National Bureau of Economic Research, Cambridge, MA. $<$ http://www.princeton.edu/ kuziemko/spillovers_26may2011.pdf>.

Lua, Y., Xiao, Y., Sears, A., \& Jacko, A. (2005). A review and a framework of handheld computer adoption in healthcare. International Journal of Medical Informatics, 74(5), 409-422.

Liebowitz, S. J. \& Margolis, S. E. (1994). Network externality: An uncommon tragedy. The Journal of Economic Perspectives, 8(2), 133-150.

Mahajan, V., Muller, E., \& Bass, F. (1990). New product diffusion models in marketing: A review and directions for research, Journal of Marketing, 54(1), 1-26.

MICT (2012). Smart Thailand. "In:" Proceeding of the $1^{\text {st }}$ Asean CIO Forum, Bangkok, Thailand, April 2012. Bangkok: Ministry of Information and Communication Technology. Retrieved from $<$ http://www.aseancioforum.com/LinkClick.aspx?fileticket=VxgzZF6F2KI\%3D\&tabid=210\&mid=6 $55>$.

NBTC (2008). Report of the 2008 Telecommunication services retail price, $1^{\text {st }}$ quarter. Bangkok: Office of the National Broadcasting and Telecommunications Commission. Retrieved from <http://www.nbtc.go.th/wps/wcm/connect/0e7824804b3d32b9b1c7ff19057b96c3/price_2551 _3.pdf?MOD=AJPERES\&CACHEID=0e7824804b3d32b9b1c7ff19057b96c3>.

Newburger, E. C. (2001). Home Computers and Internet Use in the United States: August 2000. Washington, D.C.: U.S. Census Bureau. Retrieved from <https://www.census.gov/prod/2001pubs/p23-207.pdf>.

Norris, P. (2003). Digital divide: Civic engagement, information poverty, and the Internet worldwide.

Cambridge: Cambridge university press.

NSO (2007). Report of the 2007 ICT survey on household, $1^{\text {st }}$ quarter. Bangkok: National Statistical Office. NSO (2008). Report of the 2008 ICT survey on schools. Bangkok: National Statistical Office. 
NTIA (2001). Falling through the net. Washington, DC: Department of Commerce. Retrieved from $<$ http://search.ntia.doc.gov/pdf/fttn00.pdf>.

OECD (2000). Information technology outlook. Paris: OECD. Retrieved from $<$ www.oecd.org/dataoecd/30/56/1939833.pdf>.

Oreopoulos, P., Page, M., \& Stevens, A. (2006). Does human capital transfer from parent to child? The intergeneration effects of compulsory schooling. Journal of Labor Economics, 24(4), 729-760.

Ortiz, R. W. \& Green, T. (2011). Families and home computer use: Exploring parent perceptions of the importance of current technology. Urban Education, 46(2), 202-215.

Pansawat, S. \& Khonklong, Y. (2003). 5000 SchoolNet schools: From NECTEC to the Ministry of Education. NECTEC, 10(52), 6-10. Retrieved from <http://www.nectec.or.th/schoolnet/farewell/shoolnet2.pdf>.

PMO (2001). Thailand government policy. Bangkok: Prime Minister Office. Retrieved from <http://www.thaigov.go.th/webold/general/policy/thaksin/pt-11.htm>.

Rappoport, P. N., Kridel, D. J., Taylor, L.D., Alleman, J. H., \& Duffy-Deno, K. T. (2003) Residential demand for access to the Internet. In Madden, G., Emerging telecommunications networks: The international handbook of telecommunications economics (vol. 2). Cheltenham, U.K.: Edward Elgar, 55-72.

Robertson, A., Soopramanien, D., \& Fields, R. (2004). Understanding residential Internet service adoption patterns in the UK. Telektronikk, 4, 84-94.

Rogers, E. (2003). Diffusion of innovations. New York: Free Press.

Rosenbaum, P. R. \& Rubin, D. B. (1983). The central role of propensity score in observational studies for causal effects. Biometrika, 70, 41-55.

Savage, S. J. \& Waldman, D. (2005). Broadband Internet access, awareness, and use: Analysis of United States household data. Telecommunications Policy, 29(8), 615-633.

Selwyn, N. (2004). Exploring the role of children in adults' adoption and use of computers. Information Technology \& People, 17(1), 53-70.

Tengtrakul, P. \& Peha, J. M. (2011). Access to and penetration of ICT in rural Thailand. Telecommunications Policy, 35(2), 141-155. http://www.ece.cmu.edu/ peha/papers.html

Tengtrakul, P. (2013). Reducing the Digital Divide through ICT adoption and utilization: Factors, barriers, and how ICT in schools can help (Doctoral dissertation). Carnegie Mellon University, Pennsylvania.

Thuvasethakul, C., \& Koanantakool, T. (2002). National ICT policy in Thailand. "In:" Proceeding of the Africa-Asia Workshop: Promoting Co-operation in Information and Communications Technologies Development, Kuala Lumpur and Penang, Malaysia, March 2002. Retrieved from < http://www.nectec.or.th/users/htk/publish/20020302-National-ICT-Policy-v16-word.pdf>.

Tinio, V. L. (2003). ICT in education. E-Primers from United Nations Development Programme to the World Summit on Information Society. Retrieved from < http://www.saigontre.com/FDFiles/ICT_in_Education.pdf>.

U.S. Census (2009). Computer and Internet use in the United States. Retrieved from <http://www.census.gov/hhes/computer/publications/2009.html>.

Umrani, F. \& Ghadially, R. (2003). Empowering women through ICT education: Facilitating computer adoption. Gender, Technology and Development, 7(3), 359-377. 
UNESCO (2007). Initiating and managing SchoolNets: ICT lessons learned series volume III. Bangkok: UNESCO. Retrieved from <http://www2.unescobkk.org/elib/publications/111/Schoolnet_LLVol.3.pdf>.

Van Rompaey, V., Roe, K., \& Struys, K. (2002). Children's influence on Internet access at home. Adoption and use in the family context. Information, Communication and Society, 5(2), 189-206.

Warschauer, M. (2003). Technology and social inclusion: Rethinking the digital divide. Cambridge: MIT Press. 